Illinois State University

ISU ReD: Research and eData

Theses and Dissertations

9-13-2019

\title{
Answering The "more And Cheaper" Push Of The Completion Agenda: What Does It Cost An Illinois Public University To Deliver A Bachelor's Degree?
}

Melissa R. Pitcock

Illinois State University, mepitco@ilstu.edu

Follow this and additional works at: https://ir.library.illinoisstate.edu/etd

Part of the Higher Education Administration Commons, and the Higher Education and Teaching Commons

\section{Recommended Citation}

Pitcock, Melissa R., "Answering The "more And Cheaper" Push Of The Completion Agenda: What Does It Cost An Illinois Public University To Deliver A Bachelor's Degree?" (2019). Theses and Dissertations. 1173. https://ir.library.illinoisstate.edu/etd/1173

This Dissertation is brought to you for free and open access by ISU ReD: Research and eData. It has been accepted for inclusion in Theses and Dissertations by an authorized administrator of ISU ReD: Research and eData. For more information, please contact ISUReD@ilstu.edu. 


\section{ANSWERING THE “MORE AND CHEAPER” PUSH OF THE COMPLETION AGENDA: WHAT DOES IT COST AN ILLINOIS PUBLIC UNIVERSITY \\ TO DELIVER A BACHELOR'S DEGREE?}

\section{MELISSA R. PITCOCK}

\section{Pages}

Using readily available data, this study estimated the costs incurred by an Illinois public university to deliver a bachelor's degree. Building on previous scholarship, the study used the transcript (based on the graduate's path to the degree) and catalog (based on the major's requirements listed in the university catalog) approaches to estimate costs, from three administrative purviews, for native and transfer students graduating from six different academic areas in fiscal 2015. Costs per credit hour were gathered from data prepared annually by the university for the state's board of higher education.

A primary finding of this study was that costs vary across and within degrees. The principal driver of cost variation within degrees was student choice, regardless of whether the students were native or transfer. Based on the findings, as universities develop completion costs in response to concerns that they need to lower costs (to the state and students) and also produce more graduates, how does a campus find the balance between student choice and institutional direction? Ultimately, the ability of whether student choice should be limited is a decision for university administration. The decision of how to limit student choice rests with the department and its success will depend upon the department's culture and its willingness to change. 
KEYWORDS: accountability, bachelor, bachelor's, catalog, completion agenda, cost, degree cost, efficiency, effectiveness, four-year, productivity, public, quality, student choice, transcript 


\title{
ANSWERING THE “MORE AND CHEAPER” PUSH OF THE COMPLETION AGENDA: WHAT DOES IT COST AN ILLINOIS PUBLIC UNIVERSITY TO DELIVER A BACHELOR'S DEGREE?
}

\author{
MELISSA R. PITCOCK
}

\author{
A Dissertation Submitted in Partial \\ Fulfillment of the Requirements \\ for the Degree of \\ DOCTOR OF PHILOSOPHY \\ Department of Educational Administration and Foundations \\ ILLINOIS STATE UNIVERSITY
}


Copyright 2019 Melissa R. Pitcock 


\title{
ANSWERING THE “MORE AND CHEAPER” PUSH OF THE COMPLETION AGENDA: WHAT DOES IT COST AN ILLINOIS PUBLIC UNIVERSITY TO DELIVER A BACHELOR'S DEGREE?
}

\author{
MELISSA R. PITCOCK
}

COMMITTEE MEMBERS:

James C. Palmer, Chair

Patricia H. Klass

Zeng Lin

Richard M. Romano

Lenford C. Sutton 


\section{ACKNOWLEDGMENTS}

This work is the culmination of a long journey and, without the support of my husband Corbitt and our youngest daughter Rachel, it would not have been possible. You have taken over household chores, encouraged me when I received edits (again), listened unceasingly to me talk about degree costs, and jumped right in to help me work through the implications of a finding. This manuscript is dedicated to the two of you.

The biggest supporter, next to my family, has been my advisor and chair Dr. Jim Palmer. You have been amazing. Your knowledge and resources have been invaluable. Thank you for editing, clarifying, challenging, and motivating.

Next, Dr. Richard Romano, it was your work at SUNY Broome that inspired me to choose this topic. Thank you so much for your insights and discussions as the work proceeded.

Thank you also to my other committee members (Dr. Patricia Klass, Dr. Zeng Lin, \& Dr. Lenford Sutton) who were such a big help, especially with the quantitative and qualitative sections. A special thank you to Dr. Klass, who as a former chair, first counseled me to enter the program and is particularly knowledgeable in regard to the cost data and university operations.

Finally, a big thank you to my colleague and friend Julie O’Brien Brines who kept checking in, asking about my progress, and buoying my spirits when I was ready to quit. You have most certainly been the glue for our cohort.

M.R.P. 


\section{CONTENTS}

Page

ACKNOWLEDGMENTS

TABLES $\quad$ V

FIGURES vii

CHAPTER I: THE FUTURE OF ACCOUNTABILITY IN HIGHER EDUCATION 1

Introduction to the Research Problem

Evolution of the Research Regarding Completion Costs 3

Methods $\quad 8$

Research Questions 11

$\begin{array}{ll}\text { Stage One } & 11\end{array}$

Stage Two 12

Conceptual Framework 13

The Illinois Context $\quad 16$

$\begin{array}{ll}\text { Study Limitations } & 18\end{array}$

CHAPTER II: REVIEW OF THE LITERATURE 22

The Phenomenon Under Study: Completion 22

Conceptual Framework: Productivity 25

Defining Productivity $\quad 27$

The Alternative to Productivity Indices: The Cost to Deliver a Degree 29

Review of Prior Research 33

Growing Interest at the National Level $\quad 34$

A State Level Study of Degree Cost 37

Leading the Way: Community Colleges 39

Current State of Completion Cost Research $\quad 46$

$\begin{array}{ll}\text { CHAPTER III: METHODOLOGY } & 48\end{array}$

$\begin{array}{ll}\text { Introduction } & 48\end{array}$

Methods and Procedures: Stage One $\quad 49$

Degree and Participant Selection Parameters $\quad 50$

Readily Available Cost Data $\quad 53$

Coursework and Transcript Data $\quad 57$ 
$\begin{array}{ll}\text { Work Prior to Quantitative Calculations } & 60\end{array}$

Estimating Completion Costs: Catalog Method 64

Costs of Major Coursework $\quad 64$

Costs of General Education Coursework 66

Costs of University Electives

Estimating Completion Costs: Transcript Method $\quad 74$

Data Limitations $\quad 77$

Stage Two: Inviting Administrator Perceptions $\quad 78$

Interview Participants $\quad 79$

$\begin{array}{ll}\text { Procedures } & 79\end{array}$

$\begin{array}{lr}\text { Study Limitations } & 80\end{array}$

$\begin{array}{ll}\text { CHAPTER IV: FINDINGS } & 84\end{array}$

Quantitative Stage: Cost Findings $\quad 85$

Art Degree Costs

Business Administration Degree Costs $\quad 89$

Criminal Justice Degree Costs $\quad 92$

Middle Level Teacher Education Degree Costs 94

Nursing Degree Costs $\quad 97$

Psychology Degree Costs 99

Qualitative Stage: Administrator Perceptions 101

$\begin{array}{ll}\text { Summary of Findings } & 106\end{array}$

CHAPTER V: IMPLICATIONS, RECOMMENDATIONS, AND FUTURE RESEARCH 107

$\begin{array}{ll}\text { Causes and Implications } & 108\end{array}$

Cost Variations Between and Within Degree Areas 109

Differences Between Native and Transfer Student Cost Variation 119

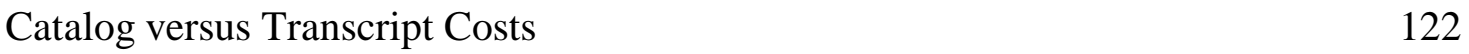

Upper-Division Costs 123

Dollar Amounts Do Not Tell the Whole Story 126

Recommendations to Improve Results 129

Recommendations to Mitigate Data Limitations $\quad 129$

Recommendations to Improve Reporting of Degree Costs 133

$\begin{array}{ll}\text { Remaining Considerations } & 134\end{array}$

Recommendations for Future Research 136 
$\begin{array}{ll}\text { Closing } & 138\end{array}$

$\begin{array}{ll}\text { REFERENCES } & 140\end{array}$

APPENDIX A: QUANTITATIVE STAGE COST FINDINGS 150

APPENDIX B: IBHE COST CATEGORIES AND DESCRIPTIONS 156 


\section{TABLES}

Table

Page

1. Approaches to Estimating Cost 45

2. Bachelor’s Degrees Conferred in Fiscal Year 2015

3. Selected Degree Programs: 2015 Native and Transfer Graduates 53

4. ADUCS Categories of Per-Credit-Hour Costs in Art, 2014 Nominal and Inflation-

$\begin{array}{ll}\text { Adjusted Costs } & 55\end{array}$

5. Student Data Provided by PRPA $\quad 59$

6. ISU Courses Provided by PRPA 59

7. Transfer Courses Provided by PRPA $\quad 59$

8. Statistics Describing the Cost to Deliver General Education Courses to Native $\begin{array}{ll}\text { Students Graduating with a Degree in Art } & 68\end{array}$

9. Core Structure of General Education Regardless of Major $\quad 70$

10. Comparing Three Approaches to General Education Catalog Cost for Native Students

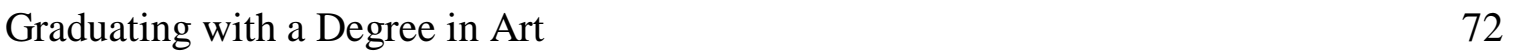

11. Costs per Credit Hour for University Elective Coursework 74

12. Process One: Associating Costs to a Completed Course 75

13. Process Two: Summing the Total Course Costs for an Individual Degree 76

14. Descriptive Statistics: Estimated Cost to Deliver an Art Degree (Controllable Level) 76

15. Student Descriptors: Summary of the Credit Hours Across the Six Degrees 86

16. Cost to Deliver Degrees by Administrative Purview and Student Group Aggregated Across the Six Degrees $\quad 86$

17. Cost Results: Controllable Purview Across Majors 106 
18. Native Students: Percent of Required Major Hours and Related Costs and Cost Variation

19. Transfer Students: Percent of Required Major Hours and Related Costs and Cost Variation

20. Comparison of Costs: Transfer Students vs Upper-Division Native Students

21. Comparison of Costs Across Degree Areas: Transfer Students with 50 or Fewer Hours to Degree

22. ISU Hours Completed 


\section{FIGURES}

Figure

1. 2015 Native Art Graduates’ Transcript and Catalog Costs 88

2. 2015 Transfer Art Graduates’ Transcript Costs 89

3. 2015 Native Business Administration Graduates’ Transcript and Catalog Costs $\quad 91$

4. $\quad 2015$ Transfer Business Administration Graduates’ Transcript Costs 91

5. 2015 Native Criminal Justice Graduates’ Transcript and Catalog Costs 93

6. 2015 Transfer Criminal Justice Graduates’ Transcript Costs 94

7. 2015 Native Middle Level Education Graduates’ Transcript and Catalog Costs 96

8. 2015 Transfer Middle Level Education Graduates’ Transcript Costs 96

9. 2015 Native Nursing Graduates’ Transcript and Catalog Costs 98

10. 2015 Transfer Nursing Graduates’ Transcript Costs 99

11. 2015 Native Psychology Graduates’ Transcript and Catalog Costs 100

12. 2015 Transfer Psychology Graduates’ Transcript Costs 101

13. NBER Analysis: Baseline Cross-Field Log Cost Differences, Relative to English 110

14. ADUCS Analysis: Cross-Field Percentage Cost Differences, Relative to English 111 


\section{CHAPTER I: THE FUTURE OF ACCOUNTABILITY IN HIGHER EDUCATION}

\section{Introduction to the Research Problem}

The environment of higher education is swiftly changing. “As few as twenty years ago, colleges and universities were rarely mentioned in the extensive public discussion of education reform” (Bailey, Smith Jaggars, \& Jenkins, 2015, p. 3). However, at the turn of the century, a number of issues quickly developed that started to change public and policy-maker perceptions of higher education. Today, external pressure on higher education is pushing for a focus on what has been called the completion agenda (Humphreys, 2012).

The foundation of the completion agenda was formed with the passage of the Student Right-to-Know and Campus Security Act of 1990 (SRTK) which mandated, for the first time, that higher education institutions publish metrics that would allow students and parents to compare colleges and universities (Bailey et al., 2015). When the first metrics were published a little over 10 years later, the average six-year graduation rate at four-year public universities was revealed to be only 51.7\% (U.S. Department of Education, 2018). At the same time, consensus was emerging that at least some college education was necessary to earn a living wage, and more students were setting their sights on a degree (Bailey et al., 2015). Concerned that low graduation rates hindered the students’ ability to meet their goals, policy makers began pushing for answers. In an attempt to address this issue, President Obama, in 2009, announced a challenge that the nation increase its proportion of college graduates to the highest in the world by 2020 (Humphreys, 2012). In response, several initiatives were launched to reach the goal.

In the same year, for example, Complete College America launched an initiative that pushed for shorter completion times and encouraged participating states to commit to comprehensive reforms (Humphreys, 2012). A second initiative was funded by the Lumina 
Foundation with the goal of increasing completions to $60 \%$ of the nation's adult population by the year 2025 (Bailey et al., 2015). A third initiative, Complete to Compete, was announced by the National Governor's Association in 2010 and focused on “better data collection to track student progress through state higher education systems” (Humphreys, 2012, p. 10).

Well-funded and backed politically, the three initiatives slowly began to force higher education to move away from its traditional focus on access to one of performance (Bailey et al., 2015). Of course, the access agenda had been largely successful. The "total fall enrollment increased nearly tenfold from 1947 to 2011, from 2.3 million to 21.0 million” (Bailey et al., 2015, p. 4). The proportion of students enrolling in public institutions accounted for the largest growth during this time period, increasing from "1.2 million to 15.1 million” (p 4). But, completion agenda proponents believed increased access was not enough. "Not only must colleges give students a chance to enroll, but students should also graduate or complete a degree” (Bailey et al., 2015, p. 73). Humphreys (2012) believed that changing the focus of higher education was not that simple. She explained that while the national priority should be to find approaches that help students remain in and complete college, the reforms were announced at a particularly bad time, "in the midst of a severe economic downturn and after years of demographic shifts and educational shortfalls at both the K-12 and higher education levels" (Humphreys, 2012, p. 8).

Beginning near the end of the year 2007, the great recessions shrunk state revenues and, as a result, allocations to higher education were reduced as competition for limited resources increased. Though the economic turndown lasted just over one and a half years, it was particularly severe. The deep overall cuts to higher education had still not been restored several years later and funding was still below pre-recession levels in many states (State Higher 
Education Executive Officers, 2014). By 2014, some scholars were calling this the "new normal” and strongly suggesting that higher education would have to contend with attenuated state funding far into the future (State Higher Education Executive Officers, 2014). The consequence of lower state funding was a sharp increase in tuition, a phenomenon that shifts costs from the states to the students (Mitchell, Palacios, \& Leachman, 2014). This, in turn, increased attention to affordability. As a result, Humphreys suggested that the "completion agenda has morphed into a more-completion-at-less-cost agenda” (p. 10). Instead of “'more and better,' policy leaders are trying to deliver 'more and cheaper”' (Humphreys, 2012, p. 10).

Combined, these changes have had a profound effect on how higher education manages its resources. To meet the goal of more and cheaper, higher education must find a way to increase productivity; the ratio of expenditures to completions must decrease. This means that costing procedures must become more innovative. Instead of focusing on the traditional base units of Carnegie credit hours to evaluate student progress, instructional costs, and tuition charges, institutions must begin to focus on the total cost of a completion: the cost of delivering a credential or degree.

\section{Evolution of the Research Regarding Completion Costs}

As a field of research, determining the cost of a completion is very new, and policies regarding it have been slow to develop. Some of the earliest groundwork was laid in 2000 when the Institute for Higher Education Policy convened a seminar to "explore the public policy aspects of higher education cost measurement” (Ambrosio \& Merisotis, 2000, p. 5). Though 10 years had passed since the SRTK mandate, seminar participants perceived that policy development and research was being held back by "the tension between public accountability demands and the reality that costs are complicated" (Wellman \& O'Brien, 2000, p. 7). 
McKeown-Moak (2000) further explained that the "issue [of productivity] is relatively thorny because there is little good information on the relationship between dollars of input and quality of output in higher education” (p. 21).

In truth, the issue may be complicated and thorny because much of the work performed by higher education researchers in the area of cost has focused on traditional Carnegie credit hours. For example, the Delaware Cost Study (Higher Education Consortia, 2019) has been analyzing instructional costs per credit hour, by discipline, at four-year colleges since 1992 and has contributed considerable insight into research methodologies that examine costs. The Kansas Study (Seybert \& Rossol, 2010) began a similar analysis for two-year colleges in 1997. However, neither study includes the significant cost of institutional overhead expenditures that support the academic core. In addition, neither study has attempted to extend costs per credit hour into estimates of the total cost of a completion.

The direction of this research field finally turned toward completion costs in 2009. Believing that robust research into the costs of delivering a degree was being held back by the lack of defining methodologies, Nate Johnson (2009) used data prepared by the Florida Board of Governors to explain five possible approaches.

Two of the approaches were the full-cost attribution model and the regression analysis model. Full cost models attribute expenditures only to students who graduate, assuming that the cost of "attrition, failed courses, and excess hours are seen as a kind of 'overhead' that cannot be avoided” (p. 15). In 2004, The Florida Board of Governors had applied this model using three years of costs, course-taking patterns by students with declared majors, and degrees awarded (p. 16). The result was a degree cost estimate that worked relatively well at the institutional level and for larger programs. However, the model did not work as well when applied to programs 
with high attrition rates, new or smaller programs, and programs with a high number of transfers from another major. Johnson suggested that an alternative approach to this model was to track students from their date of entry rather than retrospectively from their date of graduation. For example, at the end of six years, Johnson suggested that a cohort could be divided into those who had graduated and those who had not. The costs to deliver coursework could then be distributed between those two groups, effectively showing the cost of attribution in comparison to the cost of a completion.

The second approach, a regression analysis model, worked by comparing “award-level data and instructional cost data” (p. 22) from the Integrated Postsecondary Education Data System (IPEDS) in an attempt to estimate the cost to deliver a degree and to identify factors that might contribute to or create a barrier to completion. "Stepwise multiple regression was used to identify the degree award levels that were significantly associated with direct and attributed instructional costs" (p. 23) and Johnson found that in using this model, "the number of degrees and other credentials that institutions award explains $88 \%$ of the variation in direct and indirect instructional costs” (p. 23). Although the regression analysis model helped to quantify the cost of increasing the number of awarded degrees, it did not estimate costs by academic area. In fact, neither of the first two approaches could be easily applied to the program level.

However, Johnson described a third approach that did apply at the program level: a summation of the price paid by students. Of course, the price charged to students and a university's cost to deliver a degree are two different concepts; one cannot estimate cost using tuition figures. However, this approach did provide an interesting companion metric that might allow a comparison of changes in tuition prices against changes in the cost to deliver a degree.

The last two approaches described by Johnson were applicable at the program level and 
utilized university budgeted expenditures: the catalog and transcript methods. Both methods began with the annual report of expenditures per credit hour, by student level and academic discipline prepared by the Board of Governors. The catalog method assumed students never vary from the catalog's prescribed path for completing a specific degree. To calculate the catalog cost, the Board's cost per credit hour for the appropriate discipline was multiplied against each of the required courses for a specific degree. The result was an "estimate of what it costs to provide the published course requirements for a degree from the institution's perspective” (p. 9). The transcript method recognized that students rarely follow the catalog to the letter. This approach also utilized the Board's annual costs per credit hour, but substituted courses listed on student transcripts for those in the catalog. The resulting transcript cost was a single, average cost to deliver a degree and "include[d] failed or withdrawn courses as well as courses in excess of degree requirements, and it [was] net of any accelerated AP or dual enrollment credits brought in to reduce the number of hours required" (p. 14).

In his description of the catalog and transcript methods, Johnson also addressed the primary piece missing from the Delaware and Kansas studies. Rather than examining only the costs of direct instruction, the annual reports of per-credit-hour costs prepared by the Florida Board of Governors included two different approaches to also allocate expenditures for indirect instruction. Costs related to academic support (e.g., student services, advising, and financial aid) were allocated by each program's Classification of Instructional Programs (CIP) based on the proportion of student credit hours generated in each program. University level costs (e.g., central administration and plant operations) were allocated to the programs based on the proportion of full-time equivalent employees directly involved in each academic area. By including these additional costs, Johnson's catalog and transcript approaches effectively moved the estimation of 
completion costs to the next level.

Although calls for studies on cost measurement in higher education go back to 2000, when the Institute for Higher Education Policy convened a seminar described in the document by O’Brien and Wellman (2000), only Johnson's Florida study examines completion costs in the four-year sector. However, progress has been made in the two-year sector. Inspired by Johnson's work, Romano, Losinger, and Millard (2011) developed a process that used the catalog and transcript methods to calculate degree costs at Broome Community College in New York. Like Johnson, the authors used readily available data to determine the completion costs. However, rather than use state prepared per-credit-hour data, Romano et al. used actual departmental expenditures and divided those costs by the number of credit hours generated in each department. Similar to Seybert and Rossol (2010), who worked with the Kansas Study of costs for community colleges, Romano et al. found that variations in cost at their SUNY Community College were driven primarily by instructional expenditures and that overhead costs did not vary significantly between academic departments. As a result, the authors added overhead costs using a standard 'mark-up' of “48.4\%” (p. 219) to each degree area to arrive at the full cost of a completion.

Since the SUNY study, more community college studies have been completed and, in addition to determining completion costs, they help researchers to understand the types of methodology decisions that must be made in this murky new field. For example, Belfield, Crosta, and Jenkins (2014) used community college budget data as their cost source, positing that absent large reserves or loans, budgets should be substantially equal to expenditures. However, as state funding becomes less predictable, using budget data in states that allow fund reserves will become less helpful in cost analyses. In the SUNY study, Romano et al. elected to use actual 
expenditures because large reserves had been created in anticipation of impending state budget cuts. In 2015, Bailey, Smith Jaggars, and Jenkins calculated the cost of completion by tracking a cohort of students from the point of original entry: the "pathway" approach. Their methodology attempted to account for the costs of any and all student progress, regardless of full- or part-time status, and examined a wide variety of completion definitions including certificates and degrees.

The common denominator in all of these manuscripts reveal that the process of examining higher education costs is indeed complicated and thorny. However, those barriers have not slowed the determination of policy-makers who are set on a "more-completion-at-lesscost agenda” (Humphreys, 2012, p. 10) as evidenced by the rise of performance based funding, which ties a portion of state allocations to institutional performance and is now practiced in the majority of states (National Conference of State Legislatures, 2019). In the same way, lack of progress and difficult methodology decisions cannot become deterrents to researchers. Johnson helped to pave the way by offering descriptions of five approaches to completion costs and by providing insight into which methods might work best. The work of Romano et al. proved that completion costs, based on Johnson's approaches, could be estimated at the community college level. This study extends that research to the four-year sector. Positioned as an exploratory work, this manuscript describes the researcher's approach to estimating and understanding the costs incurred by an Illinois university to deliver a bachelor’s degree.

\section{Methods}

Using quantitative techniques, the study applied the catalog and transcript approaches (Johnson, 2009; Romano et al., 2011) to estimate the cost of delivering a bachelor’s degree awarded by one program in each of the six colleges on the campus of Illinois State University (ISU) during fiscal year 2015. The six programs award bachelor’s degrees in Art (general 
sequence), Business Administration, Criminal Justice, Middle School Education, Nursing, and Psychology. Each program entails a single, identifiable course sequence, thereby simplifying the process of calculating completion costs. Inclusion criteria for selected programs required the area to have awarded degrees to at least 50 students during fiscal year 2015, including at least 10 transfer students from community colleges and 10 native students who began their postsecondary study at ISU. Native graduates were those who completed no more than 10 credit hours of work outside of Illinois State University. Transfer graduates were those who completed an associate's degree at a community college prior to beginning the final years of study at the university. Only those who completed their degrees within $150 \%$ of normal time were included in the analysis. This means that native students must have initially enrolled no earlier than six years prior to graduation. Transfer graduates must have completed coursework at the university in three years or less. Following these parameters, completion costs were calculated for 703 graduates who earned degrees in these six areas during fiscal year 2015.

To estimate catalog costs, courses listed for each of the six majors were supplemented with information from the departmental plans of study. The plans of study, typically prepared by departmental advisors, provide more detail than the catalog and can be used as guides to course selection. For example, a specific program’s prerequisite courses might also fulfill general education requirements, a detail not included in the catalogs. Further, although the university stresses student choice when it comes to registering for specific classes, a plan of study represents what is assumed to be the more efficient path to a degree, should that be what a student desires.

The transcript method represents the opposite end of the spectrum, reflecting the student's actual pathway, rather than the prescribed route of the university catalog. Students must 
fulfill the requirements of their selected major, but they may also take courses that interest them or compliment their major coursework. As a result, the transcript method is assumed to more closely match the actual expenditures necessary for the university to deliver a degree. To estimate the transcript costs, the study began by requesting a list of courses completed by the fiscal 2015 graduates who majored in the six selected degrees. The credit hours listed for each course completed by an individual graduate were multiplied against an appropriate cost percredit-hour. The total cost for each graduate is the sum of all course costs, adjusted for inflation. The costs were obtained from data prepared by the university's research office in support of the Academic Discipline Unit Cost Study (ADUCS), an annual report prepared by the Illinois Board of Higher Education (IBHE). The IBHE requires that each Illinois public university submit its annual costs per credit hour by student level (lower division or upper division) and by subject area according to the Classification of Instructional Programs (CIP) code. The per-credit-hour cost data used in this study covers six fiscal years (FY2009 - FY 2015) and includes instructional expenditures as well as cumulative administrative and overhead expenses. Chapter Three provides a complete description of the data used in the analysis.

In addition to calculating completion costs, the study planned to employ interviews with the top administrator in each of the six degree areas. Two of the administrators accepted the invitation to share their perceptions of the extent to which the cost data were useful to them, their thoughts about the data that underlie the final results and how it might be made more useful, and how they thought the final results might be used. An important goal of this exploratory study beyond using available data at ISU to calculate completion costs - was to shed light on how data routinely reported by the university might need to be changed if the institution decides to move in this direction. 


\section{Research Questions}

The analysis was carried out in two stages. The first stage developed and applied an approach to estimate the cost of delivering a bachelor's degree to native and transfer students. The second stage was qualitative and elicited administrator perceptions about the usefulness of the cost data calculated in the analysis and the steps that might be taken by the university to increase its capacity to obtain more accurate cost estimates.

\section{Stage One}

The first stage focused on estimating the cost of each of the six degrees for both native and transfer students. It is important to note that cost, as defined by this study, represents expenditures incurred by the university. Cost is not the same as tuition, the price charged to students. As noted above, a native student is defined as a graduate who completed no more than 10 credit hours outside of Illinois State University and completed degree requirements in six or fewer years. In addition to the native student's total completion cost, an estimate was also prepared for the portion of total costs associated with their upper division study (courses subsequent to the first 59 hours of ISU coursework), thereby allowing a rough comparison to transfer student costs. A transfer graduate is a student who completed an associate's degree from a community college prior to transferring to the university to complete a bachelor's degree. Their university study must have been completed in three years or less.

This stage of the study was guided by the following research questions:

1. What is the estimated catalog cost of delivering each of the six degrees included in the analysis?

2. Using the transcript methodology to calculate the cost of delivering each of the six degrees to native students, what is the range across students of costs incurred by the 
institution, what is the mean and median cost incurred, and what is the standard deviation and the coefficient of variation for each degree?

3. Using the transcript methodology to calculate the cost of delivering final coursework for each of the six degrees to transfer students, what is the range across students of costs incurred by the institution, what is the mean and median cost incurred, and what is the standard deviation and coefficient of variation for each degree?

4. Using the transcript methodology to calculate the cost of delivering upper-division coursework in each of the six degrees to native students, what is the range across students of costs incurred by the institution, what is the mean and median cost incurred, and what is the standard deviation and coefficient of variation for each degree?

\section{Stage Two}

The study’s second stage involved interviews with key stakeholders (top administrators of each academic area) who were familiar with the program requirements and varying pathways taken by students to complete each of the six degrees. The study's quantitative results were shared in order to elicit their perceptions of the data, what steps might be taken to increase its accuracy, and how the results might be used. The following research questions were answered in this stage.

1. As fiscal and academic managers, what are your thoughts about the estimated transcript and catalog costs, and do the results help you to better understand the cost to your department of delivering a degree?

2. What are your thoughts regarding the data that underlie the final results in regard to department contribution, accuracy of the reports, or other data that might supplement 
the results?

3. How do you think these estimates might be used by yourself and others?

\section{Conceptual Framework}

The conceptual framework for this study is productivity, an element of institutional accountability. For many years, accountability in higher education meant producing financial statements evidencing good stewardship of state tax dollars and student tuition. Today, accountability is more conceptual, the balancing act of higher education in response to "state priorities, academic concerns, and market forces” (Burke, 2005, p. x). Among the many concepts of what accountability might mean, productivity, as viewed by those outside of the university, is an increasingly important deliverable of accountability. A primary example of this is the "more and cheaper" (Humphreys, 2012, p. 10) push of the completion agenda. Proponents of the completion agenda believe that universities should increase graduation rates while holding costs steady (which reflects an increase to productivity). By costs the proponents mean tuition, the price charged to students. However, holding tuition steady also means managing the costs incurred by a university to deliver degrees to their graduates and, as Kirshstein and Wellman (2012) pointed out, universities are focused more on revenue than expenditures.

Searching for a tool to help manage costs, the National Research Council (NRC) charged a panel of experts to "identify an analytically well-defined concept of productivity for higher education and to recommend practical guidelines for its measurement” (National Research Council, 2012, p. 1). Over a two and a half year period, the panel endeavored to produce a measure similar to the Bureau of Labor Statistics (BLS) productivity index. Using data from IPEDS, the panel's proposed productivity formula compared the change in the ratio of credit hours to the change in cost from one period to the next, while attempting to adjust for quality and 
the multi-factor productivity characteristics of higher education. In addition to the productivity measure, the panel offered a detailed examination of the factors that contribute to cost and learning in higher education and followed with a critical and ideological evaluation of the factors' complexity. In an interesting tie back to Burke’s suggestion that market forces are being allowed to define accountability (2005), the panel defined accountability as "a managerial or political term addressing the need for responsibility and transparency to stakeholders, constituents, or to the public generally” (National Research Council, 2012, p. 19). Recognizing that the "higher education productivity issue will not go away" (Massy, Sullivan, \& Mackie, 2013, p. 17) and the "inevitable presence of difficult-to-quantify elements... should not be an excuse to ignore those elements" (p. 16), the panel suggested that the "best approach is to begin working with currently available data" (p. 17) supported by a "thoroughly vetted and agreedupon set of metrics" (p. 16). In addition, the panel emphatically urged that "quality should always be central to the productivity conversations, even if it cannot be fully captured by the metrics” (p. 16).

The panel provided excellent advice, but the final productivity metric itself presents a complication due to its use of IPEDS data. It was calculated at the institutional level, making it difficult to apply at the department or degree level. Productivity metrics must provide the ability to examine the link "between productivity, cost, and quality, recognizing that the unit cost of educating students will go down only if productivity goes up and quality is not compromised" (Romano \& Palmer, 2015, p. 49). This examination must occur at the level of action: department or program levels. The link between productivity, cost and quality also means, for example, that singular measures of productivity such as an institution's graduation or persistence rate, will not suffice. Instead, those measures should be components of a holistic approach to productivity that 
would also include analyses of the costs incurred by an institution in delivering a completion, the ability to track changes in that cost over time, and the will to act upon the results. This is most likely what Carey (2007) meant when he wrote that "real accountability systems push institutions to act on that information in a manner that is designed to change what they do in order to make them more successful than they would otherwise be” (p. 24).

To measure productivity in terms of completion costs, higher education's traditional accountability systems and their focus on institutional revenues must be re-tooled. As Kirshstein and Wellman posited in 2012, the traditional cost models focus too much on revenue and not enough on what institutions do with that revenue. They urged institutions to shift their financial focus to "costs and cost structures... as well as on learning outcomes” (p. 14). However, changing focus to costs, rather than revenue, will not be easy because scholars have little evidence of the "costs and effects of higher education practices" and institutions lack the “incentive to use cost-effectiveness as a way to guide decision-making” (Harris \& Goldrick-Rab, 2010, p. 1). Further, it may be the case that educational leadership is reluctant to be measured for good reason: the 1990 mandate to publish graduation rates uncovered data and results that riled policy-makers and certainly contributed to today's tense environment. However, fear that transparency will bring additional negative consequences should not impede institutions from action. Higher education must see ongoing efforts to measure productivity as "a challenge, not a choice" (Burke, 2005, p. 297), because "higher education has become too important to the success of society and its citizens to leave the academy unaccountable for its responses and results” (p. xvii). In truth, as the NRC panel suggested, if the academy does not develop a measure of productivity for itself, then someone else will create the measure and it may not work in higher education’s favor (National Research Council, 2012, p. 11). 


\section{The Illinois Context}

The completion agenda’s push for productivity, its focus on more completions for cheaper cost at the same or higher level of quality, is especially salient in Illinois. The great recession (December 2007 to June 2009) “was particularly bad for Illinois, as the state’s economy suffered a worse downturn than the rest of the nation” (Divounguy \& Hill, 2018, para. 10) and "has also experienced a much slower expansion in the time since then” (para. 11). Still struggling to recover from the recession, the state also went without a budget for more than two years (July 2015 - August 2017) while its universities cut personnel, delayed maintenance, and struggled with decreasing enrollments (Bauman, 2018). Unfortunately, fiscal challenges are not new to Illinois. The state has accumulated deep structural deficits that stem primarily from the increasing costs of Medicaid and chronically underfunded state pension systems (Merriman, 2014; State Higher Education Executive Officers, 2015). Structural deficits mean that the state does not have enough money to pay all of its debt even when its economy is operating at full potential. Even though legislators and the new governor passed a fiscal year 2020 budget that included more generous allocations for higher education, the state and its higher education institutions continue to face large and growing challenges to their fiscal stability.

As a result of the state's fiscal condition, competition for state funding is very high and, regrettably, an annual appropriation for higher education operations is not a mandatory expenditure. Recognizing that higher education is also one of the very few state agencies with an alternative source of revenue (tuition), it is difficult for legislators to allocate increasing, or even flat, funding year after year when other agencies are suffering through financial cutbacks (Zumeta, 2012). In fact, the Illinois legislature did over the years what many states do in difficult financial times: siphoned off higher education money and redirected it to other priorities until the 
economy recovered from periodic recessionary periods. This back and forth of higher education funding is known as the balance wheel, a concept first posited by Hovey (1999) and later confirmed in a longitudinal study by Delaney and Doyle (2011). However, in Illinois full funding was not always restored to higher education after each recession.

For example, the State Higher Education Executive Officer’s State Higher Education Finance (SHEF) report for fiscal year 2014 showed that funding for Illinois higher education had increased substantially from the previous year, but the increase stemmed almost entirely from mandated pension system payments rather than funds for operations (State Higher Education Executive Officers [SHEEO], 2015). In the SHEF report for fiscal year 2017, the SHEEO (2018) noted that almost $40 \%$ of the Illinois appropriation was still allocated to pension system payments (p. 31) and what initially appeared to be a substantial increase in appropriations per FTE "between 2016 and 2017 was primarily due to institutions receiving 30 percent of their annual state appropriations (compared to levels in adjacent years)” (p. 31). To put these examples into perspective, the most recent fiscal year 2020 budget allocations for Illinois higher education still remain below 2002 funding levels when adjusted for inflation (Robinson, 2019).

The financial facts alone bring dire news, but the truth is that financial issues are not the biggest challenge for Illinois higher education. Deep concerns over the current fiscal situation are masking another issue that must be dealt with strategically over the long term: substantial drops in enrollment. A 2012 report showed that the number of Illinois high school graduates would drop by almost three percentage points by 2025 as compared to 2015 (Prescott \& Bransberger, 2012). However, the 2012 predictions appear to have been conservative. The SHEF report for fiscal year 2017 showed that Illinois’ FTE enrollment dropped more than 14\% between 2012 and 2017, almost double the national average (State Higher Education Executive Officers, 2018). 
Given the impending enrollment declines overall, college leaders will need to base their appeals for additional funding less on enrollment and more on productivity. A holistic approach to productivity, as discussed earlier, might be one tool that could help Illinois universities develop stronger connections "between the way [they] deliver academic work and the way [they] pay for it." (Louis Soares, as quoted by Toner, 2015, p. 17). As components of the tool, singular measures such as graduation and persistence rates are already mandated. As another component of the tool, data is readily available to estimate completion costs and, though the process is still in the exploratory stage, valuable information can be gained from the results. If this information were combined with quality measurements, Illinois universities might finally have an approach that works in their favor by providing actionable information that could, over time, strengthen their financial condition.

\section{Study Limitations}

The study of university completion costs is a very new field of research and scholars tell us that higher education's current accounting systems and the data submitted to IPEDS are not adequate to determine the cost of a degree. Fortunately, Illinois is one of a few states that have substantial, long-term cost study data (Conger, Bell, \& Stanley, 2008). The state requires each of its universities to annually calculate and submit the per-credit-hour cost of their academic disciplines. The summarized data from each university is published by the Illinois Board of Higher Education in the Academic Discipline Unit Cost Study (ADUCS). The ADUCS has been compiled for more than a decade using consistent data definitions and requirements for gathering and preparing the data. The ADUCS report and the university-submitted supporting data are the source of cost data for this study. The other pieces required for completion of cost estimates, such as records of coursework completed by students and requirements listed in university 
catalogs, is also available to approved university researchers. However, the decision to use readily available data, provided to this study by Illinois State University, posed four potential limitations. The first two limitations related to coursework data and the remaining two limitations related to the cost data.

First, the transcript data provided by the university’s research office was gathered shortly after the records had been migrated to a new student record system. PRPA had not yet completed a full data validation and communicated that, as expected with a new system, the data might still hold some inconsistencies. Secondly, neither the transcript data nor the university catalog provided any indicators to identify potential changes to degree requirements between the selected students’ point of entry and their subsequent graduation. If changes were made and if some students began to follow new requirements, the event would not be not be identified.

The third limitation, related to the cost data, was that the Faculty Activity Analysis (FAA) may have been prepared inconsistently across campus by academic units. This report is prepared at the end of each term by the academic units and is used to allocate faculty salaries across credit hours generated by each reporting unit. PRPA provides instructions and assistance to the academic units, but the interpretation of the instructions may vary from one department to the next. The final limitation of the data was that the ADUCS' primary basis of allocation for non-instruction cost categories (i.e. college overhead, administrative support) was based on the accumulated expenditures of the academic units. This approach increasingly skewed successive (and cumulative) allocations the further the expenditures were incurred from the academic core. For example, the department receiving the largest portion of its college's expenditures (due to the department's larger total annual costs in relation to other departments) would also receive a higher allocation of university administration costs and, in the next allocation, would also be 
allocated a larger portion of plant and maintenance costs. The costs allocated for university administration and plant are not due to the department receiving more assistance or attention, but simply because it spent more money that year than the other departments within the same college.

Aside from the limitations posed by readily available data at ISU, the researcher identified two limitations and four delimitations of the larger study. The first limitation of the study at large was that the estimates of cost are only one measure of productivity. As the NRC (2012) panel stated, "a single high-stakes measure is a flawed approach in that it makes gaming the system simpler; a range of measures will almost always be preferable for weighing overall performance” ( $p$.2). The second limitation is that the IBHE data does not require or make use of available quality indicators. Discussions of quality should always be included in a holistic analysis to help guard against changes that might lower cost at the expense of quality.

The four delimitations of the study restrict how its results should be used. First, the study does not produce a productivity index, which examines the change in the ratio of inputs to outputs over time. Estimates of the cost to deliver a degree can be compared over time, but dollar amounts alone make it difficult to discern the relationship between inputs and outputs. Second, the cost estimates are not be comparable across campus. Each degree's cost estimate is unique due to the cost of faculty employed by the department, the ratio of adjunct to tenure-line faculty, the mix of courses required to obtain the degree, and the typical pathway taken by the student. The study's third delimitation is that the study does not produce absolute costs to deliver the examined degrees. The results are estimates of cost, which vary around the mean. The final delimitation is that the estimates cannot be used to make judgments regarding the relative effectiveness or efficiency of the awarding department. These are the pecuniary measurements of 
business and industry outcomes. In higher education, how quickly a student completes the degree requirements and whether the student took the shortest path (at presumably less cost) is only one educational outcome; it does not reflect the overall efforts or actions of faculty and staff. 


\section{CHAPTER II: REVIEW OF THE LITERATURE}

\section{The Phenomenon Under Study: Completion}

Higher education has long focused on access and the endeavor has been largely successful. For example, Bailey et al. (2015) tells us that "total fall enrollment increased nearly tenfold from 1947 to 2011, from 2.3 million to 21.0 million. During that time, fall enrollment in public higher education institutions grew from 1.2 million to 15.1 million” (p. 4). In addition, overall participation rates, the proportion of high school graduates who immediately enroll in college, reached 69\% by 2008 and, although equity gaps still exist, participation rates for Black and Hispanic students that year reached 59\% and 62\%, respectively. (Kelly \& Schneider, 2012).

However, though access and participation rates were on the rise, not all students were completing their degree. Seeking information about just how many did, the Student Right-toKnow and Campus Security Act (SRTK) was passed in 1990 and mandated that higher education institutions publish their graduation rates. The first figures were published in 1996 and it was an eye-opening event, exposing four-year public university averages of only 51.7\% (U.S. Department of Education, 2018). Since then, graduation rates have increased, but "more than half of the students who start postsecondary education fail to finish a bachelor's degree in six years, and this rate has been relatively stable over time.” (Kelly \& Schneider, 2012, p. 3). In fact, by 2011 the United States had dropped to fourth place in the world for overall degree attainment and placed twelfth for college attainment in the 25 to 34 year-old age group (Kelly \& Schneider, 2012). The increased attention on graduation rates and worldwide ranking figures put pressure on higher education to change its focus from access to what has been called the completion agenda (Humphreys, 2012). The completion agenda is a movement that provides incentives for institutions to not only enroll students, but to make sure that those students walk across the stage. 
The movement gained support in 2009 when President Obama issued a challenge for the nation to regain the highest proportion of college graduates in the world (Humphreys, 2012). Several organizations launched initiatives in response to the challenge. Complete College America launched in 2009, pushing for shorter completion times and requiring participating states to commit to comprehensive reforms (Humphreys, 2012). The Goal 2025 program, launched in the same year, was funded by the Lumina Foundation (Bailey et al., 2015) and supported approaches designed to increase attainment to $60 \%$ by the year 2025. The National Governor's Association announced its Complete to Compete program in 2010 and focused on "better data collection to track student progress through state higher education systems” (Humphreys, 2012, p. 10).

It is difficult to argue against increased college completion rates. "It should be a national priority to pursue productive approaches that help different groups of students stay in college and graduate on time, and we absolutely should make policy changes and devote more resources to support them” (Humphreys, 2012, p. 11). Unfortunately, another factor was working against increased completion: cost-shifting.

Cost-shifting is a term used to describe the transfer of the higher education cost burden from the states to students through increases in tuition. Two well-known proposals contributed to an environment supportive of the cost shifting phenomena. First, Gary Becker (1964) published a paper that drew on theories of human capital to suggest that private benefits reaped by students upon graduation required their financial contribution. Nine years later, the Carnegie Commission on Higher Education (1973) proposed that students should carry one third of the cost burden, and many institutions began to implement the suggestion literally (Zumeta, 2004; Zumeta, Breneman, Callan, \& Finney, 2012). Student loans, first proposed in the Higher Education Act of 1965, helped to accelerate cost-shifting and by the 1990s, tuition was beginning to rise 
significantly (Johnstone \& Marcucci, 2010). The student share had surged to 47.7\% by 2013 (State Higher Education Executive Officers, 2018).

One of the greatest challenges for higher education in responding to the completion agenda is that the phenomenon began just as the nation was entering the great recession in late 2007. As state revenues fell, legislatures resorted to redirecting higher education funds into other priorities, noting the lack of a legal mandate to appropriate funding and the availability of tuition as a second revenue source. This is a common state response during recessions, and the assumed intention is that lower funding levels remain until the economy starts to recover. In fact, Hovey (1999) posited that economic cycles are the primary reason for sizable changes in state appropriation levels for higher education. To test the theory, Delaney and Doyle (2011) analyzed changes in state appropriation levels from 1985 to 2004 and found the states' "balance wheel" approach to higher education funding, as Hovey (1999, p. 19) phrased it, to be a consistently applied response to economic recession and recovery. Today, state funding for higher education has increased somewhat since the end of the recession, but inflation-adjusted per student funding is still below pre-recession levels and continues to decrease over time as a proportion of total revenues (State Higher Education Executive Officers, 2018). Some scholars are calling this the "new normal" and strongly suggesting that higher education will have to contend with attenuated state funding far into the future (State Higher Education Executive Officers, 2014).

As states struggled to stabilize funding after the recession, policy-makers increasingly perceived higher education to be an investment of state funds and student tuition. Investments almost always carry some degree of risk, but policy-makers were starting to believe their investment in higher education might be too high, given the low completion rates, and that tuition had risen too much for many students to make the attempt regardless of whether they 
were ultimately successful. The shifting perceptions led Humphreys to suggest that the “completion agenda has morphed into a more-completion-at-less-cost agenda” (2012, p. 10). Policy leaders are not trying to deliver "more and better"; they want "more and cheaper" (Humphreys, 2012, p. 10). This means higher graduation rates without increases to state and student investment. It also means that higher education will have to change its focus on how much revenue can be raised and begin thinking about how that revenue is spent and "a far more intimate connection between the way you deliver academic work and the way you pay for it" (Louis Soares, as quoted by Toner, 2015, p. 17).

This new operating environment, the 'new normal' of attenuated funding in the face of a more-completion-at-less-cost agenda cannot be ignored. A university must understand how it can become more productive without reducing the quality of its degrees. This dilemma leads directly to the conceptual framework for this study - productivity and what it means for higher education.

\section{Conceptual Framework: Productivity}

Productivity is rooted in the idea of accountability as posited by Burke (2005), who conceptualized six demands of organizational accountability for higher education. Two of the six demands relate to reporting on performance and the sources and uses of funds. These demands form the basis of productivity, the primary framework of this study. Accountability in higher education is not a new concept, but the definition has changed over time. From the colonial days through the Second World War, very little accountability was expected from higher education, which had catered to the elite members of society. In 1940, "only 6 percent of males and 4 percent of females had completed 4 years of college” (Snyder, 1993, p. 7). But those percentages skyrocketed in 1944, when the federal government passed the Servicemen's Readjustment Act. As enrollment grew, the states and higher education formed a "social compact" (Burke, 2005, p. 
5) that "obligated state taxpayers to provide adequate operating funding for public colleges and universities, which in turn would keep tuition reasonably low" (Burke, 2005, p.5). The compact persisted for the next 30 years and, during this time, institutions evidenced accountability by producing financial reports that reflected good stewardship of state tax dollars and student tuition and fees.

However, fissures began to open in the social compact during the 1970s. The states began to form coordinating boards to monitor higher education, which often received the largest percentage of the states' annual budget, and "regulation became the lever of accountability" (Burke, 2005, p. 7). By the 1980s, in an attempt to combine public accountability with professional autonomy, the states called upon external accountability organizations to monitor intuitional performance. States also wanted to increase the quality of student learning outcomes and a number of assessment programs were implemented by the external organizations as well (Burke, 2005). The most dramatic shift in accountability came in the 1990s. Emboldened by the passage of the Student Right-to-Know and Campus Security Act (SRTK), states decentralized their control of higher education, but changed the "concept of accountability from complying with rules to producing results” (Burke, 2005, p. 216). As the decade faded into the new century, another shift occurred as "competition for tax support increased and economic recession reduced public revenue” (Burke, 2005, p. 297). To weather the recession, states reduced funding for higher education. The reduction, combined with the states' reduced control, allowed market forces to become a "surrogate for state priorities" (Burke, 2005, p. 297). The market, always focused on increasing productivity, eventually pushed higher education to take on a consumer focus that concentrated on the ends, rather than the means (Burke, 2005).

Today, higher education stands at the crossroads of performance demands and market 
forces, and is at a loss to form a response that is acceptable to the completion agenda's push to produce more graduates for less cost. Although access and quality are still, and will always be vitally important, the states' support of the completion agenda has led to a new and different operating environment for higher education. Working within the boundaries of this environment and inspired by Burton Clark (1983), Burke envisioned the new definition of accountability to be a triangulation of "state priorities, academic concerns, and market forces" (Burke, 2005, p. 2122) presenting “a challenge, not a choice, for higher education" (p. 297). "Accountability is here to stay" (p. xvii) because "higher education has become too important to the success of society and its citizens to leave the academy unaccountable for its responses and results” (p. xvii). This new operating environment has challenged scholars to consider what productivity really is and how it might be measured and documented in higher education.

\section{Defining Productivity}

The general definition of productivity, a complex and multi-faceted measure, is defined by the U.S. Bureau of Labor Statistics (BLS) as the output per hour of labor (U.S. Department of Labor, 2014). Productivity indices are considered key measures because economic growth "has the potential to lead to improved living standards for the participants of an economy” (Sprague, 2014). Published quarterly, the BLS productivity index is expressed as the quality adjusted percentage change from the previous period (U.S. Department of Labor, 2014). The Bureau also annually publishes a value-added, multi-factor analysis which analyzes the "joint effects of many factors including research and development (R\&D), new technologies, economies of scale, managerial skill, and changes in the organization of production” (U.S. Department of Labor, 2008, para. 8). The indices have been published since 1947 (U.S. Department of Labor, 2014) and cover the manufacturing and service sectors. However, the measures do not include higher 
education as a specific sector. One scholar called this out, cautioning that "if higher education's endless fight against such accountability continues, it may have thrust upon it a version that is real but harmful” (Carey, 2007, p. 29).

To that end, the National Research Council charged a panel of scholars and economists "to identify an analytically well-defined concept of productivity for higher education and to recommend practical guidelines for its measurement" in order to "better track the performance of colleges and universities in the hope that their costs can be contained while not compromising quality or accessibility” (National Research Council, 2012, p.1). The panel deliberated for two and a half years before producing its report which could well be considered the gold standard of productivity in higher education.

The panel's report began by defining productivity and the related concepts of efficiency and accountability. First, productivity is defined "as the quantity of outputs delivered per unit of input utilized" (p. 19). The next definition is set out for efficiency, which "connotes maximizing outputs for a given set of fixed resources” (p. 19). Finally, the panel defined accountability as: “a managerial or political term addressing the need for responsibility and transparency to stakeholders, constituents, or to the public generally" (p. 19). The panel's last definition is the most relevant to the current study and implies that accountability is being insisted upon by political forces rather than provided by academia. It is also similar to Burke’s (2005) suggestion that accountability is a triangulation of state priorities, academic concerns, and market forces. Those political and market forces are represented in the goals of the completion agenda: more completions for lower cost.

Overall, the NRC panel's report is a complex review of the factors that can be used to measure productivity in higher education as well as those that the panel determined to be not 
useful. The report's productivity measure, the ratio of quality adjusted outputs (credit hours earned and degrees awarded) to inputs (labor and operating expenses), is very similar to the index produced by the BLS. Although the panel did not foresee the measure to be of great use at the institutional level, it hoped that the ability to "measure higher education productivity in the aggregate will produce a better policy environment, which may in turn lead to indirect productivity improvements over time” (p. 60). As that environment slowly develops, the panel urged institutions to use the currently available data to begin analysis of "productivity at the level of degree and subject, just as manufacturers should analyze productivity at the level of individual production processes” (p. 42), and emphasized “proper support of additional quality measures” (p. 15) to avoid exploitation of the results.

\section{The Alternative to Productivity Indices: The Cost to Deliver a Degree}

Beginning a cost analysis with readily available data, however, it not so easy. Higher education’s current accounting systems were designed to comply with the traditional good stewardship model of accountability and are focused on compliance with accounting rules and production of financial reports. These systems cannot produce the metrics needed to calculate the NRC panel's productivity measure. Making the analysis even more difficult, higher education has been unable to agree upon an acceptable measure of quality (Romano \& Palmer, 2015). Lacking more suitable data and definitions, institutions typically rely upon alternative measures of productivity (Romano \& Palmer, 2015) such as annual persistence and graduation rates, which are celebrated by ranking reports as evidence of accountability.

While proponents of the completion agenda must certainly be happy with rising persistence and graduation numbers, these measures alone are not enough. They also insist upon lower costs, regardless of how many courses are completed. If higher education is to meet this 
challenge, it must carefully consider how performance is reported and how much increased performance will cost. "The cost of educating students will go down only if productivity goes up and quality is not compromised” (Romano \& Palmer, 2015, p. 49).

One way to examine the link between productivity, costs, and quality is through a cost study. Although the NRC panel argued that cost studies do not measure productivity, it did acknowledge that, when properly done, a cost study can be a proxy for productivity. A handful of scholars called for more scholarship in this area, and their preliminary work suggested that more than one approach could be taken. In doing so, the primary objective, regardless of the approach, should be to produce data that can drive conclusions and identify areas for action (Carey, 2007).

Two of the scholars who called for cost studies were Jane Wellman and Rita Kirshstein. Their 2012 piece “Technology and the Broken Higher Education Cost Model” drew upon data produced by the Delta Cost Project and defined productivity as becoming more efficient (restraining costs) and more effective (producing more degrees). Recognizing that today's political and social climate is driving the call for productivity, Kirshstein and Wellman (2012) posited that the old cost models that focus on revenue are broken. "The focus on revenues ... means that relatively little attention has been paid to what institutions do with the revenue” (p. 14). The authors argued that higher education must address the "long overlooked" (p. 14) spending side of education. Today, an institution must have an understanding of "costs and cost structures... as well as on learning outcomes” (p. 14).

Kirshstein and Wellman, like the NRC panel, point out that data produced for the Integrated Postsecondary Education Data System (IPEDS) is not sufficient for individual institutions to understand their spending by discipline, level of instruction, or enrollment status. 
Yet, data at these levels are critical to decision-makers who are tasked with implementing systematic improvements without falling victim to the "sticky functions” that Massy (2008) believed result from higher education's eagerness to add programs without evaluating the continued usefulness of those already in play. Kirshstein and Wellman wrote that institutions must develop the ability to scrutinize cost on a "per-student and per-degree basis, since that is the only way to determine whether alternative investments are cost-effective” (p. 14). Spending in relation to outcomes must be benchmarked, the authors asserted, to allow analysis of spending patterns over time and in comparison to peer institutions. It is this type of analysis that will allow leaders to "make better decisions about spending and ultimately to connect spending to performance, including quality” (p. 18).

Douglas Harris and Sara Goldrick-Rab (2010), wrote of their concerns with decisionmaking in regard to productivity in The (Un)Productivity of American Higher Education: From “Cost Disease” to Cost-Effectiveness. They pointed out that higher education expenditures have increased by $25 \%$ since 1992, but the number of degrees conferred declined by $4.6 \%$ over the same time period (p. 2). The reason, the authors proposed, is that many programs are not cost effective. The lack of evidence regarding cost and effects in higher education practice, coupled with low incentive to use "cost-effectiveness as a way to guide decision-making” (p. 1), leads to the "perception among college leaders and scholars that college productivity is impossible to control” (p. 5). Breaking from traditional dollar values, the authors include "opportunity costs" in their calculations: imputed values for items such as volunteer time, textbooks, and the student's own time. The calculation is difficult, but answers the NRC panel's admonition that "the inevitable presence of difficult-to-quantify elements in a measure should not be used as an excuse to ignore those elements” (National Research Council, 2012, p. 2). 
Another group of scholars, Bailey, et al. (2015), examining costs in the community college sector, believed that colleges have too long focused on containing costs "per student in a given course or semester” (p. 172) rather than on the “cost per high-quality completion” (p. 172). They cautioned, as did the NRC panel, that the focus on reducing the cost of immediate outcomes (per course or semester) can result in higher completion costs for a credential. For example, "research suggests that two primary ways community colleges have reduced costs relying on part-time instructors and increasing student-to-faculty ratios - have hurt completion rates and may also have reduced the quality of the education provided” (p. 174). Despite these findings, “community colleges have traditionally calculated costs on a per-credit-hour (or perstudent enrolled) basis rather than on a per-credential-completed basis” (p. 175) and funding continues to be based primarily on "enrollment levels rather than students' eventual outcomes” (p. 175).

In regard to the four-year sector, four states (Florida, Illinois, New York-SUNY, and Ohio) have been collecting cost study data for several years. In 2008, the State Higher Education Executive Officers conducted a "meta-analysis" of data from those four states to explore fundamental cost issues (Conger, Bell, \& Stanley, 2010). The study focused on per-credit-hour costs and the total cost of instruction by academic area. It also provided examples of how the data could be used. However, it did not produce costs per completed degree.

The research and conclusions presented by these scholars suggest that cost studies can indeed be proxies of productivity that can serve as a basis to begin the conversation about how productivity might be measured and ultimately improved. Their work also highlights several important considerations for scholars who take up this challenge. First, the authors seem to agree that institutionally reported IPEDS data is insufficient to develop a useful cost study and that 
institutions, systems, and states must develop new databases. Second, the data used in a cost study must be rigorously obtained and evaluated, regardless of the difficulty in its initial identification. Next, analysts must develop repeatable methods to measure and facilitate analysis of changes over time. Fourth, the authors suggested that educational leadership is reluctant to be measured and indeed, some valid reasons do exist, but they should not overrule the usefulness of a holistic evaluation of productivity and its effect upon student learning. Finally, the authors all suggest that properly conceived and utilized metrics will contribute to a better policy environment that benefits states, institutions, and students.

\section{Review of Prior Research}

The call for increased research into the cost to deliver a completion has grown significantly louder since President Obama's challenge in 2009. However, increased scrutiny of higher education began decades earlier. In the 1970s, the states formed coordinating boards to monitor institutions and their budgets (Burke, 2005). External assessment programs were implemented in the 1980s to monitor the quality of student learning outcomes (Burke, 2005). By the time that the SRTK act was passed in 1990, it was becoming clear that higher education could no longer rely on a simple social compact that required only good stewardship as evidence of accountability. Seeking better tools to evidence accountability, three studies were launched to provide a closer examination of higher education expenditures. The first was completed by the Office of Educational Research and Improvement in 1987 using the Higher Education General Information Survey (HEGIS) (To, 1987), a national data set of comprehensive information on postsecondary education and predecessor to IPEDS. The Delaware Study (Middaugh et al., 2003) was launched five years later to estimate institutional costs per-credit-hour by examining expenditure data provided by participating universities and, in 1997, the Kansas Study (Seybert 
\& Rossol, 2010) began similar work for community colleges.

In the year 2000, the Institute for Higher Education Policy convened a seminar on the policy aspects and practices of cost management. The seminar discussion and papers were compiled by O'Brien and Wellman (2000) in an attempt to jump-start research on the topics of costs and productivity. The tenor of the discussion was succinctly described by McKeown-Moak (2000), who noted that "this issue [of productivity] is relatively thorny because there is little good information on the relationship between dollars of input and quality of output in higher education” (p. 21). Perhaps because the issue is so thorny, research in the area continued to lag until 2009 when the first state-wide study of costs per degree at the university level was conducted in Florida (Johnson, 2009). Johnson's piece set out definitions and examples of five possible approaches and served as the launching point for subsequent research. Since then, scholars of community colleges have been leading the way as their sector comes under increased scrutiny to increase outcomes without increasing cost (Belfield et al., 2014).

\section{Growing Interest at the National Level}

Kilgore and Elliot (1987) succinctly described the fiscal environment of higher education in the 1980s; educational expenditures were rising, policy makers were questioning effective use of funding, and the quality of learning was under review. In response, Duc-Le To (1987), analyst for the Office of Educational Research and Improvement, attempted one of the earliest studies to determine the cost of a bachelor's degree using data from HEGIS. Due of the nature of the HEGIS data, Dr. To had to make several "assumptions about direct cost measures, allocation of indirect cost, and the grouping of institutions" (p. iv). In addition, the data allowed estimates of degree cost only at the university level (public or private baccalaureate, comprehensive, doctoral, and research) and could not be applied to individual departments or programs. Despite the 
aggregate nature of the HEGIS data, To's analysis helped to move research forward because it proved that the cost of a degree could be calculated. The piece also elaborated upon the difficulty of determining which costs to include, suggested options for allocating overhead, and made clear the significant differences that exist between institutions by classification. What the study did not do, is help individual universities examine spending patterns or better understand what actions might increase their awarded number of degrees without significant increases in cost.

The Delaware study of universities. The Delaware study helped to fill that gap. In 1992, Delaware University developed what was to become an annual report of institutional expenditures from a new perspective. Not only was it the first of its kind at this level of aggregation, it exemplified the recommendations made by the NRC panel (2012) that universities start with the data they have rather than waiting until someone else has paved (or mandated) the way. The National Study of Instructional Costs and Productivity grew from an initial group of 77 institutions in 1992. Since then, more than 700 universities have voluntarily contributed data and shared in the results. With each annual iteration, the research group implemented improvements. By 1995, the study had "developed a reporting convention consistent with the best practices” (Middaugh, 2000, p. 30) that continues to inform cost studies today.

The focus of the Delaware Study was and continues to be on instructional expenditures per credit hour. It is predicated on analysis at the discipline level as defined by the Classification of Instructional Programs (CIP) taxonomic scheme developed by the NCES in 1980. Delaware's data collection begins with an analysis of faculty workload by discipline which accumulates the number of student credit hours delivered in any organized class section and then allocates the hours by faculty rank (an indicator of quality used by the NRC panel) and level of instruction 
(lower and upper undergraduate and graduate) based on traditional course numbering. For example, 100- and 200- level courses are considered lower division undergraduate and 300- level courses are upper division. The next step collects total academic expenditures, which include faculty and staff compensation, benefits, and other departmental expenses (including equipment) incurred in support of the functional areas of instruction, service, and research. The costs are separated into NACUBO regulated categories of direct instruction, research, and public service. Total expenditures for service and research are separately benchmarked. The remaining expenses (of direct instruction) are allocated to each discipline and divided by the credit hour data (obtained earlier) to produce costs per credit hour for each discipline.

The Delaware study does not determine the cost to deliver a degree. "By definition, the Delaware study is not a full cost model” (Middaugh, 2000, p. 31) and is intended only for internal planning and budgeting purposes by participating institutions. Stopping at the per-credithour costs of direct instruction, the research group was wary of pitfalls associated with varying bases of allocation for non-instructional expenses and felt that the differing rules promulgated by the Financial Accounting Standards Board (FASB) for private institutions and the Governmental Accounting Standards Board (GASB) for public institutions would make comparisons between institutions problematic.

The Kansas study of community colleges. The Delaware study of costs does not include community colleges because their mission and costs are significantly different from universities. However, the U.S. Congress felt that cost containment was important for all institutions and, in 1997, created the National Commission on the Cost of Higher Education and charged the Commission to address cost concerns (Seybert \& Rossol, 2010). In response, The Kansas Study of Community College Instructional Costs and Productivity was created in 2004 to provide 
community colleges with a "valid, reliable tool to facilitate strategic and operational planning and management decision making” (p. 40).

Now referred to as the National Community College Cost \& Productivity Project, the study is supported by The National Higher Education Benchmarking Institute and has benefited from the participation of more than 450 community colleges since its inception. The project's methodology follows a path very similar to the Delaware study, focusing on costs directly attributable to instruction, excluding expenditures for non-instruction activities, and disaggregating the costs per credit hour by CIP classification.

\section{A State Level Study of Degree Cost}

Until 2009, Delaware and Kansas were the only published studies of per-credit-hour costs and, although both furthered research in the field, neither database could be used to calculate the full cost of a degree. Johnson (2009) believed that lack of defined methods might be holding back research in this area. His work developed definitions that he hoped would start a dialogue for and between institutions that wished to conduct such a study. Only 10 years old, the piece was one of the earliest projects in regard to completion costs and serves as the basis for subsequent research by scholars seeking to estimate and understand the cost to deliver a degree.

Johnson's work differed from the Delaware and Kansas studies in two major ways. First,

the Johnson study used a proxy for actual expenditures: the Florida system’s budget data for state appropriations and student tuition. Second, despite the complications of choosing an appropriate method to allocate overhead, Johnson included costs for direct instruction (like the Delaware and Kansas studies) and also for the indirect costs of providing that instruction. Johnson offered five approaches: catalog, transcript, full-cost attribution, regression-based estimates, and student cost. For each approach, he also provided illustrative examples, using data from the Florida Board of 
Governors (FBOG), of how the approach might be developed.

Catalog, transcript, and full-cost. The catalog method assumed students never swerve from the prescribed coursework. In this approach, Johnson estimated the average cost of a degree for an institution by very simply multiplying the cost per-credit-hour found in the FBOG data by the number of credit hours required in the university catalog for a degree. Johnson suggested that the same approach could be applied at the program level using internally prepared data and recommended that per-credit-hour calculations at this level be further refined to examine the cost of lower and upper division undergraduate expenditures by broad discipline area.

Johnson's transcript method followed the sometimes meandering path of a student by summing the "cost of the courses on a student’s actual transcript" (p. 13). To determine the transcript cost, Johnson examined data from the 2003-04 graduate transcripts by discipline. The "cost per degree was estimated by summing the credit hours in each CIP code taken by graduates in each degree program, multiplying by the [FBOG] expenditure analysis' cost per credit for 2003-04 ... and dividing by the number of graduates.” (p. 13). The result was a single, average cost that could be compared to the catalog cost for each discipline.

The full cost attribution approach added another layer of analysis by accounting for any course attempted, regardless of completion or eventual non-graduation. To calculate this cost, Johnson suggested two approaches. In the first approach, the total of all credits taken within a specific discipline over three years was multiplied by the discipline's ratio of its three-year average costs per credit hour to the total number of degrees awarded over the three year period. The approach was comprehensive and assumed that course taking patterns would be smoothed out over the three-year period, but the cost results tended to skew (higher) for majors that experience a high attrition rate. The second approach analyzed the cost of attrition separately 
from the cost of degree completion. In this approach, students were tracked from initial entry and separated into cohorts of those who graduate and those who do not. Instructional costs were then calculated for each group. The second approach resulted in two cohort costs per discipline. However, the costs across cohorts were not comparable; the cost to educate non-completers is naturally lower because the courses completed by this cohort were primarily lower division courses that reflected lower costs in the Florida data.

Regression-based estimates and student cost. Johnson's regression-based and student cost approaches were very different from catalog, transfer, and full-attribution methods. The regression estimates used data submitted to IPEDS or internally collected data points to determine the cost of a degree. The goal of this approach was to resolve the issue of multiple products (undergraduate and graduate degrees) and to examine economies of scale and scope. Unfortunately, the regression estimates were completed at the credential level (i.e. bachelor's degrees, master's degrees, etc.) and did not provide information for disciplinary departments to make decisions.

The student cost approach calculated the price of a degree as paid by students. It is an interesting approach and might serve as a metric for comparison to the cost to deliver the degree. However, given the tenuous link between price and cost as pointed out by McKeown-Moak (2000), this single ratio did not provide significant value to the advancement of research focused on examining higher education expenditures.

\section{Leading the Way: Community Colleges}

More recent research conducted at the community colleges has advanced a small but growing scholarship on costing out completions. Community colleges have long been considered a low cost alternative for the first two years of a bachelor's degree (Bailey et al., 2015). However 
determining the cost of a "completion" delivered by a community college is complicated by the multiple missions of these open-access institutions, which include transferable degrees, vocational certificates, adult and corporate education, and casual instruction. Despite their complicated nature, these colleges especially are facing mounting pressure to increase completions without raising costs (Belfield et al., 2014). As a result, they are leading the way in regard to research that determines the cost to deliver a degree.

The SUNY Broome study. The work of Romano, Losinger, and Millard (2011) was the first study to calculate the cost of a degree at the community college level. It analyzed expenditures using three of the five basic methods defined by Johnson: catalog, transcript, and a version of full cost attribution.

For both the catalog and transcript methods, the authors applied the costs of direct instruction by department rather than by CIP discipline. To obtain the per-credit-hour cost of each department, direct instructional expenditures were divided by the number of full-time equivalent students enrolled. This approach allowed the authors to account for failed, withdrawn, and completed courses in addition to accounting for students who did not complete. The percredit-hour cost for each department was multiplied by either the number of credits required in the catalog or as listed on graduate transcripts to determine final degree costs.

The catalog and transcript methods, as applied in the SUNY study, produce the instructional costs involved in delivering a degree. The authors' full cost approach adds the overhead portion. In this study, the full cost is estimated by "marking up” the previously determined catalog and transcript costs by a percentage of the total college overhead, $48.4 \%$ in the case of SUNY Broome. Because overhead is allocated to departments on a relatively even basis in community colleges, the mark-up method is a safe approach that avoids the limitations 
called out in the Delaware and Kansas studies regarding overhead allocation methods.

Economic models of efficiency. Echoing McKeown-Moak’s (2000) concern that few studies explained the link between completion rates and resources, Belfield, Crosta and Jenkins (2014) used data from a community college in North Carolina to develop an economic model of efficiency: "the production of a given output at the lowest possible cost” (p. 329). This study did not attempt to determine the cost of a discipline's degree. Instead, the goal was to determine the total cost to deliver degrees or certificates to a specific group of students in a cohort of interest to the college. Some examples of a cohort included full-time or part-time students, majors in various disciplines, students on academic or vocational pathways, or students who required developmental coursework. Tracking cohorts in this fashion utilizes a methodology based on the entry dates of students and was developed by the Community College Research Center (CCRC), which is accomplished through a longitudinal study of transcript data listing courses attempted by students in a particular cohort (Bailey, et al., 2015).

Belfield et al. defined output as the number of degrees and certificates awarded to a cohort at the end of five years, "weighted by the number of credits required to attain them” (2014, p. 331). In weighting the awards, the study assigned a weight of one to an associate's degree and adjusted the weight of a certificate by comparing its required number of credits to an associate’s degree. For example, if the certificate requires 35 credits and the average degree requires 70 , the certificate is counted as 0.5 outputs. The weight assigned to the award listed on each student's transcript was summed to determine the total output for the cohort.

The study’s input is “pathway spending” which includes all costs of instruction, administration, overhead, and student services incurred as a result of a particular student’s course-taking pattern. Rather than using actual expenditures, the authors simplified the cost piece 
by assuming that "absent significant borrowing or holdings in reserve, aggregate cost and budgets should be in balance” (p. 332). They “derive[d] revenue per pathway” (p. 332) by summing the revenue received from the state funding formula and from student tuition for each credit hour. The final result, the "pathway cost” was calculated by dividing the cohort's total "pathway spending” by the number of weighted outputs.

In an almost concurrent study, Manning and Crosta (2014), who are also affiliated with the CCRC, set out to find relative efficiency measures using program and pathway cost approaches to help colleges "understand the factors that affect costs, where changes can be made to increase efficiency, and where recruitment and retention efforts should be focused” (p. 42). The program cost approach "emphasizes instructional costs and assumes program completion" (p. 41) and "exclude[s] the costs associated with administration, student support services, college operations, and facilities (p. 47). It was calculated by dividing a program's budget by FTE credit hours generated within the program.

Searching for measures of efficiency, Manning and Crosta (2014) extended their study's cost results by comparing the costs to state reimbursement levels (standard appropriations received and based on the number of FTE students or enrolled credit hours). The results indicated that some programs are "cash cows" (p. 42) generating significant levels of positive income while other programs are more expensive to deliver. However, the authors also pointed out that it is the unique academic mix of courses required by a program that determine the program's total cost. They authors posited that this information can be used by budget managers to manage course enrollment, consolidate programs, grow program enrollment, evaluate the relevance of a program's curriculum, or identify funding opportunities within their community. Examining their colleagues' pathway approach, Manning and Crosta adjusted the 
formula's output to provide "a way to compare program costs on a scale that corrects for student success in each program” (p. 47). For example, they noted that the total pathway cost for a college-ready cohort is more expensive than the pathway cost of students who require developmental coursework. However, after adjusting for output for credit hours (vs completion of a degree or certificate) they found that the adjusted pathway cost for students who require remedial courses, in comparison to a college-ready cohort, was 2.5 times higher "when considering both costs and outcomes” (p. 48). The authors suggested that adjusted pathway approach could be used in several ways, such as in a comparison of the before and after costs of intervention programs, to determine if the innovations are effectively reducing costs.

The support of the CCRC contributed to a final piece of cost-related scholarship by Bailey, Smith Jaggars, and Jenkins (2015) who called for a complete redesign as to how instruction is delivered, who delivers it, and how the colleges are funded. Bailey et al. used the pathway method to examine costs in community colleges and suggested that concentrating on enrollment to increase funding rather than reforms to increase completions will ultimately raise overall costs to a college. To measure the results of reforms, the authors recommend calculating pathway costs at various milestones throughout a cohort's progress rather than measuring only at graduation. Mirroring milestone measures adopted in the second generation of performance based funding models (McKeown-Moak, 2013), the authors suggested examining pathway costs after a specific number of credits are completed, as students persist into a second year, or the point at which students transfer to a university.

As a body of research, the work of CCRC scholars built upon the work completed by Johnson (2009) and Romano et al. (2011). Together, the studies provide evidence that higher education has several approaches, as shown in Table 1, to determine the cost of a completion. 
Any one or a combination of two or more approaches can be used as a tool that helps evaluate an institution's level of productivity: the output gained for a given level of input. Given enough data and time to react, these data, along with other measures, can help us move along on the quest to calculate productivity in higher education and answer the completion agenda's calls to provide more and cheaper completions without sacrificing the quality of learning that is delivered. 
Table 1

Approaches to Estimating Cost

\begin{tabular}{|c|c|c|}
\hline Approach & Descriptive Summary & Results \\
\hline Catalog Cost & $\begin{array}{l}\text { Sums the instructional cost, per credit hour, of } \\
\text { all courses listed in the institution's catalog, } \\
\text { which are required to obtain a specific degree. }\end{array}$ & $\begin{array}{l}\text { Instructional cost of a } \\
\text { specific degree. }\end{array}$ \\
\hline Transcript Cost & $\begin{array}{l}\text { Sums the instructional cost, per credit hour, of } \\
\text { all courses listed on a student transcript, which } \\
\text { were completed to obtain a specific degree. }\end{array}$ & $\begin{array}{l}\text { Instructional cost of a } \\
\text { specific degree. }\end{array}$ \\
\hline Full Cost & $\begin{array}{l}\text { Similar to catalog and transcript methods, but } \\
\text { includes expenditures for college and university } \\
\text { overhead in the cost per credit hour. }\end{array}$ & $\begin{array}{l}\text { Full cost of a specific } \\
\text { degree. }\end{array}$ \\
\hline $\begin{array}{l}\text { Regression of } \\
\text { Expenditure Data }\end{array}$ & $\begin{array}{l}\text { Utilizes university level expenditure data, } \\
\text { which may also be reported to IPEDS, to } \\
\text { determine the factors that increase or decrease } \\
\text { the cost to deliver a degree. }\end{array}$ & $\begin{array}{l}\text { Instructional or full } \\
\text { cost of a generic } \\
\text { degree and factors that } \\
\text { impact the cost. }\end{array}$ \\
\hline Student Cost & $\begin{array}{l}\text { Sums the per-credit-hour price of tuition } \\
\text { charged to a student to complete the } \\
\text { coursework required to obtain a degree. }\end{array}$ & $\begin{array}{l}\text { Price of a specific or } \\
\text { generic degree. }\end{array}$ \\
\hline Graduate Cohort & $\begin{array}{l}\text { Examines the cost to deliver a degree to a group } \\
\text { of students, each of whom graduated from the } \\
\text { institution at the same time. }\end{array}$ & $\begin{array}{l}\text { Cost of a degree, } \\
\text { program, or specific } \\
\text { student group. }\end{array}$ \\
\hline Entry Cohort & $\begin{array}{l}\text { Examines the cost to deliver a degree to a group } \\
\text { of students, each of whom entered the } \\
\text { institution at the same time. }\end{array}$ & $\begin{array}{l}\text { Cost of a degree, } \\
\text { program, or specific } \\
\text { student group. }\end{array}$ \\
\hline Budget data & $\begin{array}{l}\text { Utilizes budgeted dollars to determine the cost } \\
\text { to deliver a credit hour or degree. }\end{array}$ & $\begin{array}{l}\text { Anticipated cost to } \\
\text { deliver instruction. }\end{array}$ \\
\hline Expenditure data & $\begin{array}{l}\text { Utilizes actual expenditures to determine the } \\
\text { cost to deliver a credit hour or degree. }\end{array}$ & $\begin{array}{l}\text { Actual cost to deliver } \\
\text { instruction. }\end{array}$ \\
\hline Pathway Spending & $\begin{array}{l}\text { Sums the total budgeted dollars or actual } \\
\text { expenditures required to deliver instruction to a } \\
\text { specific cohort of students of interest to the } \\
\text { institution. }\end{array}$ & $\begin{array}{l}\text { Total cost to deliver } \\
\text { degrees to the cohort. }\end{array}$ \\
\hline Pathway Cost & $\begin{array}{l}\text { Divides pathway spending by the number of } \\
\text { students in the cohort to determine the per } \\
\text { student cost. }\end{array}$ & $\begin{array}{l}\text { Per student cost of } \\
\text { delivering a degree to } \\
\text { a cohort. }\end{array}$ \\
\hline
\end{tabular}




\section{Current State of Completion Cost Research}

Like many newer topics, approaches to determine the cost of a degree have been refined over time, maturing from studies that work with nation-wide data sets that calculate costs per credit hour to projects that transform existing college- and university-level data into a full examination of degree costs. At a very high level, several states and nationwide consortiums are using cost studies for budgetary and planning purposes. For example, the Delaware and Kansas cost studies calculate the instructional cost of a Carnegie credit hour by academic discipline for participating universities and community colleges. The Florida Board of Governors did the same thing using budget data for its institutions (Johnson, 2009). Illinois also calculates costs per credit hour, but the numbers are based upon expenditures submitted by the universities and include the cost of instruction in addition to the cost of supporting and administrative overheads (State of Illinois Board of Higher Education, 2014). Building upon the work of these two states, Johnson (2009) used Florida's centrally generated data to provide five methods that could potentially be used by institutions to convert the costs per-credit-hour into the cost of various disciplines offered within the state.

However, as noted above, it is the community colleges that are leading the way in developing studies from their own data and implementing innovations as a result. The SUNY Broome study was the first to calculate the cost of a degree (Romano et al., 2011) at the community college level using the catalog and transcript methods defined by Johnson (2009). Taking a slightly different perspective, CCRC scholars Manning and Crosta (2014) and Belfield, Crosta, and Jenkins (2014) calculated costs borne by a college for student pathway spending. Further, they explained how these costs can be used by institutions to measure efficiency and in support of decision making. Finally, Bailey, Smith Jaggars, and Jenkins (2015) found that 
concentrating on the cost of an immediate outcome, the cost of delivering a course, rather than focusing on the goal of reducing completions can actually raise the overall cost to a campus. Missing from the literature is any evidence of a study performed for or by a four-year university with its own data at the degree level, (rather than discipline level). Although some states calculate costs per credit hour or by discipline, the primary objective of their process is to allocate revenue rather than examine what institutions do with the revenue. Garnering the ability to respond to the completion agenda's push to increase productivity (lower costs and/or increased degrees) without reducing quality means that further work must be done to determine how revenue dollars are actually spent within a university.

The NRC panel (2012) recommends that institutions that desire a better understanding of their own productivity begin with available data to determine what gaps exist in it and what improvements can be made in gathering and examining the data. The panel further suggests that researchers not wait until the data is perfect or until the field has developed standardized measures. This study was positioned to follow that advice. Building on Johnson's work, this study employs a modified transcript and catalog method and uses readily available expenditure data produced by Illinois State University to estimate specific bachelor degree costs, endeavor to understand the costs to deliver those degrees, and develop recommendations to improve the calculation and use of the resulting data. 


\section{CHAPTER III: METHODOLOGY}

\section{Introduction}

Public higher education institutions have long been under the government microscope in regard to accountability for public funds. Now, however, the colleges are being held accountable for outcomes as well. For example, in 1996, the published graduation rates for four-year universities revealed that only half (51.7\%) of students who attended four-year public universities graduated within six years (U.S. Department of Education, 2018). Over the next decade, completion rates improved by only 5.5\%. Believing that progress in increasing graduation rates was insufficient, President Obama challenged the nation to increase its proportion of college graduates to the highest in the world by 2020 (The White House, Office of the Press Secretary, 2009).

Unfortunately, the challenge was issued in the midst of the Great Recession. State revenues were falling and appropriations for higher education were being cut so that competing priorities could be funded. Desperate to fill the revenue gap, public universities increased tuition (Desrochers \& Hurlburt, 2016), a move that caused a public outcry about college affordability and drew even more negative attention. Today, higher education faces the dual charge to produce more graduates and to deliver degrees for less cost; to increase their productivity. This dual charge is commonly referred to as the completion agenda.

The completion agenda took flight quickly, and it has proven to be a challenge for higher education. University accounting systems are designed to track revenues and expenditures by department rather than by student. Graduation rates continue to be reported and celebrated when they increase, but there is no systematic tie between operating expenditures and student progress. Without data to examine, universities have no way to determine their productivity or to 
understand their cost to deliver a bachelor's degree. In an effort to add to the body of scholarship in this relatively new research field, the purpose of this study was to use readily-available data produced by a four-year, public university to estimate the costs it incurs to deliver bachelor's degrees. The study utilized modified catalog and transcript methods (Johnson, 2009; Romano et al., 2011) and limited the examination to one degree from each of Illinois State University's six colleges. To describe the process very simply, the catalog approach estimated the cost of completing the official course requirements as listed in the catalog for each of the six degrees. The transcript approach traced the student pathway to a degree by examining a list of courses completed by the 2015 graduates of the six degrees. In each approach, the credit hours (by CIP) were multiplied by the appropriate per-credit-hour cost that the University annually prepares for the Illinois Board of Higher Education’s Academic Discipline Unit Cost Study (ADUCS). The sum of the course costs provided the estimated cost to deliver the degree.

The study proceeded in two stages. First, a quantitative analysis estimated the catalog and transcript costs to deliver the six degrees to both native and transfer students. This stage also produced descriptive statistics for further analysis of the results. During the qualitative second stage, top administrators of the six degree programs were invited to share their perceptions of the data, what steps might be taken to increase its accuracy, and how the results might be used. Finally, the results were examined for implications and used to recommend steps that might be taken by the university to increase its capacity to calculate completion costs.

\section{Methods and Procedures: Stage One}

The literature outlines a handful of approaches (explained in Chapters One and Two) to determine the cost of a completion. The primary approaches are the catalog and transcript methods, full cost attribution, regression analyses of IPEDS expenditure data, and student 
(tuition) cost. In calculating completion costs, this study employed the catalog and transcript method originally suggested by Johnson (2009) and further tested by Romano et al. (2011). The catalog approach was slightly modified to include plans of study, developed by the departments, to determine the timing of course completion and any specific coursework recommendations for general education classes, university electives, or senior college coursework. The transcript method was also slightly modified as student transcripts are protected by FERPA. Rather than transcripts themselves, this study drew on spreadsheet data (provided by the University's Office of Planning, Research, and Policy Analysis [PRPA]) that listed the courses and completion dates of each graduate, but were stripped of personally identifying data.

\section{Degree and Participant Selection Parameters}

Before cost estimates could be calculated, it was necessary to identify the degrees and graduates for analysis. Planned as an exploratory study, the analysis limited its examination to one degree from each of the university's six colleges. The graduation year under study was fiscal year (FY) 2015, which included students who completed degree requirements in the summer or fall of 2014 or in the spring of 2015. The six degrees selected for the study were the Bachelor of Science or Arts in Art (general sequence), Business Administration, Criminal Justice, Middle Level Teacher Education, Nursing, and Psychology. The total number of degrees awarded in these programs are shown in Table 2. 
Table 2

Bachelor's Degrees Conferred in Fiscal Year 2015

\begin{tabular}{lclc}
\hline College & Degrees & Examined Major & Degrees $^{\text {a }}$ \\
\hline Fine Arts & 215 & Art (General Sequence) & 73 \\
Business & 806 & Business Administration & 96 \\
Applied Science \& Technology & 1,096 & Criminal Justice Sciences & 149 \\
Education & 519 & Middle Level Teacher Education & 54 \\
Nursing & 187 & Nursing (BSN) & 187 \\
Arts and Sciences & 1,349 & Psychology & 144 \\
Other & 150 & & \\
Total & 4,322 & Total & 703 \\
\hline
\end{tabular}

Note. Source: Office of Planning, Research, and Policy Analysis (2015). The data here refer to total degrees awarded in fiscal year 2015.

${ }^{\mathrm{a}}$ The data here reflect the total number of degrees awarded in each of the six degree programs listed. The analysis undertaken in this study includes only native graduates who earned their degrees within six years of entering the University and transfer graduates who completed their degrees within three years of transferring to the university after earning an associate’s degree at a community college.

The six degrees analyzed in this study were selected in a two-round process based on the figures reported in the University’s FY 2015 graduation report, which lists the number of graduates by major and sequence. The first round of selection required that the major offer a single sequence and award at least 75 degrees during the fiscal year. The first round identified six degrees that met these criteria, but not all colleges were represented. Therefore, a second selection round was applied to reduce the threshold to 50 graduates. To obtain a sufficient number of participants for the study, the second round also required the major to have at least 10 native graduates (i.e., graduates who started their postsecondary study at Illinois State University and who transferred in no more than 10 credit hours from another institution) and 10 transfer graduates (i.e., students who transferred to Illinois State University after earning an associate’s degree at a community college). The probable number of native and transfer graduates was obtained from the university’s 2010 and 2012 fall census data. The fall census reports the 
number of new native (2010) and transfer (2012) students admitted to each degree program. To account for student attrition, the census numbers were multiplied by the graduation rates reported in 2010 and 2012. In total, the degree selection process identified eight degrees that met the criteria. Three degrees were identified in the College of Arts and Sciences, and the study retained the degree with the highest number of graduates.

Of the 703 conferred degrees shown in Table 2, only graduates who completed a degree within $150 \%$ of normal time were included in the analysis. This is the time period used by the Integrated Postsecondary Education Data System (IPEDS) to calculate graduation rates. Native graduates, students who completed no more than ten credit hours outside of the University, must have entered the university in or after the fall of 2009 and completed degree requirements in six years or less. Transfer graduates who completed an associate’s degree before transferring, must have finished their final coursework at the university in three years or less and must have transferred to the university in or after the summer of 2012. Table 3, below, details the number of transfer and native graduates included in this analysis for each of the six degree program areas. 
Table 3

Selected Degree Programs: 2015 Native and Transfer Graduates

\begin{tabular}{lccc} 
Examined Major & Degrees $^{\text {a }}$ & Native $^{\text {b }}$ & Transfer $^{{ }^{b}}$ \\
\hline Art (General Sequence) & 73 & 14 & 18 \\
Business Administration & 96 & 37 & 25 \\
Criminal Justice Sciences & 149 & 52 & 33 \\
Middle Level Teacher Education & 54 & 29 & 7 \\
Nursing (BSN) & 187 & 89 & 16 \\
Psychology & $\underline{144}$ & $\underline{77}$ & $\underline{21}$ \\
Total & 703 & 298 & 120 \\
\hline
\end{tabular}

Note. Source: Office of Planning, Research, and Policy Analysis (2015). The data here refer to total degrees awarded in fiscal year 2015.

${ }^{\mathrm{a}}$ The data here reflect the total number of degrees awarded in each of the six degree programs listed.

$\mathrm{b}$ The analysis undertaken in this study includes only native graduates who earned their degrees within six years of entering the University and transfer graduates who completed their degrees within three years of transferring to the university after earning an associate's degree at a community college.

\section{Readily Available Cost Data}

With degrees and possible participants selected, the second step of this stage was to obtain cost data representing the expenses incurred by the University to deliver a degree. Each year, universities in the state of Illinois must prepare and submit their costs per credit hour for several Classification of Instructional Programs (CIP) codes to the Illinois Board of Higher Education (IBHE). The costs reflect appropriated and tuition dollars expended during the university's fiscal year and the CIP codes are developed and maintained by the National Center for Education Statistics (U.S. Department of Education, 2015). The CIP codes classify disciplines at the two-, four-, and six-digit levels, each level providing a finer delineation. For example, CIP 50 classifies visual and performing arts. CIP 50.04 is design and applied arts. At the six-digit level, 50.0409 is graphic design. In its annually published Academic Discipline Unit Cost Study (ADUCS), the IBHE presents the costs of academic disciplines in groupings similar 
to the two-digit CIP level, applying its own title or label to each discipline group. However, universities are required to submit cost data at the four-digit CIP level. For this study, the university’s Office of Planning, Research, and Policy Analysis (PRPA) provided the four-digit CIP data in PDF format for fiscal years 2009 through 2015. This data was exported to Excel and then uploaded into an Access database. Finally, the 2015 Higher Education Cost Adjustment (HECA) developed by State Higher Education Executive Officers (2019) was applied to index the costs for inflation, using 2015 as the base year. An example of the IBHE cost data (published in the ADUCS) is presented in Table 4 for the fiscal 2014 costs of the arts discipline. The IBHE label for the costs in this table is "Visual Arts", which is an accumulation of three 4-digit CIP codes: 50.04 Designed and Applied Arts, 50.06 Film/Video and Photographic Arts, and 50.07 Fine and Studio Arts. In this table, fiscal 2014 is presented to show the nominal (original fiscal 2014 costs) next to the indexed cost (adjusted for inflation using 2015 as the base year) for the same year. 
Table 4

ADUCS Categories of Per-Credit-Hour Costs in Art, 2014 Nominal and Inflation-Adjusted Costs

\begin{tabular}{|c|c|c|c|c|}
\hline \multirow{3}{*}{ Categories of Cost } & \multicolumn{2}{|c|}{ Lower division $^{\mathrm{a}}$} & \multicolumn{2}{|c|}{ Upper division $^{\mathrm{b}}$} \\
\hline & & Cost in & & Cost in \\
\hline & $\begin{array}{l}\text { Nominal } \\
2014 \text { cost }\end{array}$ & $\begin{array}{c}2015 \\
\text { dollars }\end{array}$ & $\begin{array}{l}\text { Nominal } \\
2014 \text { cost }\end{array}$ & $\begin{array}{c}2015 \\
\text { dollars }\end{array}$ \\
\hline \multicolumn{5}{|l|}{ Controllable purview } \\
\hline Direct salary costs [of faculty] & $\$ 104.37$ & $\$ 108.30$ & $\$ 189.45$ & $\$ 196.59$ \\
\hline Indirect salary costs & $\$ 39.97$ & $\$ 41.48$ & $\$ 24.54$ & $\$ 25.46$ \\
\hline Departmental research & $\$ 57.77$ & $\$ 59.95$ & $\$ 57.72$ & $\$ 59.89$ \\
\hline Departmental overheads & $\$ 52.12$ & $\$ 54.08$ & $\$ 70.08$ & $\$ 72.72$ \\
\hline College or school overheads & $\$ 31.66$ & $\$ 32.85$ & $\$ 46.29$ & $\$ 48.03$ \\
\hline Subtotal departmental and college costs & $\$ 285.89$ & $\$ 296.66$ & $\$ 388.08$ & $\$ 402.69$ \\
\hline \multicolumn{5}{|l|}{ Manageable purview } \\
\hline Overhead support unique to a function & $\$ 16.16$ & $\$ 16.77$ & $\$ 21.94$ & $\$ 22.77$ \\
\hline Academic support & $\$ 46.06$ & $\$ \quad 47.79$ & $\$ 62.52$ & $\$ 64.87$ \\
\hline Subtotal (manageable plus controllable costs) & $\$ 348.11$ & $\$ 361.22$ & $\$ 472.53$ & $\$ 490.33$ \\
\hline \multicolumn{5}{|l|}{ Additional costs } \\
\hline Student services & 10.83 & 11.24 & $\$ 10.83$ & $\$ 11.24$ \\
\hline Institutional support & $\$ 88.51$ & $\$ 91.84$ & $\$ 119.19$ & $\$ 123.68$ \\
\hline O\&M physical plant & $\$ 96.27$ & $\$ 99.90$ & $\$ 129.64$ & $\$ 134.52$ \\
\hline Fully allocated purview (all costs) & $\$ 543.71$ & $\$ 564.20$ & $\$ 732.19$ & $\$ 759.77$ \\
\hline \multicolumn{5}{|c|}{$\begin{array}{l}{ }^{a} \text { Lower-division indicates hours completed by a student who has completed fewer than } 60 \text { total } \\
\text { credit hours. Indexed costs are adjusted for inflation using the HECA index and } 2015 \\
\text { as the base year. }\end{array}$} \\
\hline
\end{tabular}

Looking at this table, it becomes clear that cost can mean many things. The question for this study was at which level costs should be examined. Further analysis of the complete cost database showed that approximately half of the cost per credit hour is expended at the department/college level for all degrees. These controllable costs were posited to be the figures that chairs and college deans would be most interested in because the costs are the figures over which they have a measure of control. The cumulative costs per hour at this level begin with 
faculty and staff salaries and operating expenses of the department (or CIP). Each college's administrative cost is then allocated to its reporting units in proportion to the total expenses incurred by each unit. However, controllable cost is only half of the total.

The categories of cost for overhead unique to a function and academic support, when added to the controllable cost, are classified as manageable because those costs are within the academic purview. The costs of overhead support unique to a function are those that are not allocated to the university at large. For example, the registrar's office is unique to instruction and its costs are allocated to each academic discipline, while the expenses of a research office are unique to organized research and are not allocated to academic units at all (the IBHE removes research and community service from the costs of instruction). Academic support is the expense allocated for libraries, galleries, museums, etc. Although a department or college does not have direct oversight of the costs incurred in the two categories, (overhead support unique to a specific function and academic support) the units do have some influence when voicing perspectives in the faculty senate and in discussions with the provost. The two cost categories contribute approximately $12 \%$ of the total cost per credit hour. The total annual costs incurred by each of the two cost categories are allocated to each discipline (i.e. visual arts) based upon the discipline's proportional level of accumulated expenditures at the department/college level; the higher the expenses, the higher the allocation of unique and academic support dollars.

The remaining cost categories (additional costs in Table 4) contribute the final 38\% of per-credit-hour costs. The student services category allocates a fixed dollar amount to each CIP. The inflation indexed amount for FY 2014 was \$11.24 (in FY2015 dollars). Institutional support (university administration, fleet, financial services, etc.) and O\&M physical plant costs per hour are applied as a percentage of their cost to the university as a whole: institution support was just 
over $16 \%$ and O\&M was almost $18 \%$ in 2014 . At this level, university administration exerts the most influence over expenditures. As a result, the accumulated costs of controllable and manageable purviews plus the additional costs represent the fully allocated cost per credit hour.

Any of the three administrative purviews, controllable, manageable, or fully allocated, could be considered interesting depending upon the perspective of the person examining the numbers. For example, faculty might be interested to see that delivery of instruction is about half of the cost to deliver a degree (controllable as a proportion of fully allocated). Chairs and deans might want to track changes over time or after major program revisions using the controllable level results. Executive administration might use the manageable level results to understand how individual programs might contribute to raising or lowering the cost of delivering other degrees (cross-subsidizing), while development officers could use the fully allocated data to illustrate the need for financial gifts and donations or scholarships. In consideration of the varying perspectives, transcript and catalog costs were estimated at each of the three cost levels.

\section{Coursework and Transcript Data}

The third step of stage one was to gather coursework and awarded credit hours (by CIP). The study's two approaches to estimating completion costs, catalog and transcript, required different sources. The catalog approach to estimating degree costs utilized the 2010-2012 undergraduate catalog because it included the most probable years of entry for the 2015 graduates. The requirements for each degree, as listed in the catalog, were supplemented by the department plans of study for each of the six degree programs that detailed the sequence in which courses should be completed and also helped to fill in recommended course selections, if appropriate, when students were allowed to choose from more than one course to fulfill a requirement. 
The transcript approach theoretically examines the records of the graduates selected for the study However, the university's PRPA office was unable to provide actual transcripts because those educational records are protected by FERPA. In their place, the office supplied three spreadsheets that provided the data without identifying individual students: a list of the 2015 graduates in each of the six areas (names replaced by sequential ID), a list of ISU courses completed by each student, and a list of transfer courses submitted and accepted for each student. Imported easily into an Access cost database, the data was converted into relational tables that allowed data to be parsed or combined as necessary. In addition, the tables allowed the researcher to determine which students were native (as identified by PRPA), which students had transferred, and whether or not those students met the parameters of the study. The parameters called for including native students who completed 10 or fewer credit hours outside of ISU and who completed within six years, $150 \%$ of normal time to complete a bachelor's degree. Transfer students selected for the study must have completed an associate's degree prior to transfer and must have completed ISU coursework within three years. The layout of each spreadsheet and the information provided by PRPA is presented in Tables 5, 6, and 7.

One issue of note was encountered in the Nursing program. Twelve transfer students were identified as having graduated from the College of Nursing's Pathways Program and their data was removed from the study's estimates of the cost to complete a degree in nursing. The Pathways Program is offered online and is available to community college students who are enrolled in a program leading to an Associate’s Degree in Nursing. Only transfer students who completed a non-nursing associate degree and followed the traditional pre-licensure BSN sequence were examined in this study. 
Table 5

Student Data Provided by PRPA

\begin{tabular}{ll}
\hline Field & Description $^{\text {a }}$ \\
\hline Unique ID & Anonymous student identifier \\
Degree & BS, BA, MS, etc. \\
Original Term & Year and semester of first course, YYYYT \\
Admit Type & Native or Transfer \\
Grad Term & Year and semester of graduation, YYYYT \\
Accepted Transfer Hours & Accepted from other institution, 999 \\
Associate Degree & Text, if applicable \\
Associate Degree Institution & Text, if applicable \\
\hline
\end{tabular}

a: YYYY=4 digit year, T=term (1=spring, 2=summer, 4=fall), 9=digits 1-9 as

appropriate

Table 6

ISU Courses Provided by PRPA

\begin{tabular}{|c|c|}
\hline Field & Description $^{a}$ \\
\hline Unique ID & Anonymous student identifier \\
\hline Course Dep Number & Three digit identifier, 999 \\
\hline Course Department & Department name \\
\hline Term Course Taken & YYYYT \\
\hline Course Number & 999 \\
\hline Course Hours & 9 \\
\hline
\end{tabular}

a: YYYY=4 digit year, T=term (1=spring, 2=summer, 4=fall), 9=digits 1-9 as appropriate

Table 7

Transfer Courses Provided by PRPA

\begin{tabular}{ll}
\hline Field & Description $^{\text {a }}$ \\
\hline Unique ID & Anonymous student identifier \\
Credit Type Description & Transfer, Advanced Placement, Military, Proficiency Credit ${ }^{\text {b }}$ \\
School Name & Text, as stated \\
Term Course Taken & YYYYT \\
Transfer Department & Text, as stated \\
Course Number & 999 \\
Credit-No-Credit & Credit, No-Credit \\
ISU Equivalent Hours & 9 \\
\hline${ }^{a}:$ YYYY=4 digit year, T=term (1=spring, 2=summer, 4=fall), 9=digits 1-9 as appropriate \\
${ }^{\text {b }}$ Awarded credit through (CLEP), general or departmental proficiency examinations
\end{tabular}




\section{Work Prior to Quantitative Calculations}

The fourth step of the quantitative stage was to perform a thorough analysis of the data itself. The analysis revealed five inconsistencies that required resolution. As mentioned earlier, the university had recently completed a system conversion moving student data from an older mainframe system to a new relational database application. System conversions often result in purposeful or inadvertent inconsistencies in the data, which can include changes in characters, new fields, combined data, etc. Often, inconsistencies exist in the legacy system as well and are carried over to the new system. In addition to system issues, inconsistencies were also found in relation to department or program names, reporting levels, and the nature of academic disciplines. Regardless of the reason for inconsistencies, each was managed in a way that made logical sense after examining the data. The following examples were found in the data for departments or programs that did not award one of this study’s six selected degrees. However, the graduates of those degrees did complete credit hours awarded by those departments and adjustments had to be made in order to associate those credit hours with the correct cost.

First, some departments changed names, structures, or reporting between 2009 and 2015. For example, the Department of Curriculum and Instruction became the School of Teaching and Learning, but the area did not introduce new programs. Simple department or program name changes such as this were managed by creating a department crosswalk table in the study's database. However, structural changes were managed on a case-by-case basis. For example, prior to 2012, the School of Kinesiology did not offer lower-division coursework and had no associated lower-division costs. However, the transcript data provided by the research office labeled all recreation courses as provided by Kinesiology, regardless of the term completion date. To accommodate this, lower-division courses in this area were matched to Leisure and 
Recreation, which did report lower-division costs and is a similar area within the School.

Second, some departments submit the Faculty Activity Analysis (FAA), a secondary report leading to costs per credit hour, in a manner different from the way coursework is identified in the transcript data. Although instructions are provided, the university may have multiple uses for the reported data, as do the reporting departments, and interpretation of the instructions can vary according to the preparer's perceptions and goals. For example, the Department of Geography, Geology, and the Environment submits separate reports of faculty activity for geology and geography, which results in two different costs per credit hour. However, all courses are offered with the identifier of "GEO," and the transcript data identified the coursework as "Geology - Geography.” A similar situation existed in the School of Theatre and Dance. The coursework is labeled with the prefixes "THE" (theatre) or "DAN" (dance) and faculty activity is reported separately for the two areas, but the transcript data identified the courses as offered by the School of Theatre and Dance. This inconsistency in Geology/Geography and Theatre/Dance required individual evaluation of each course to determine the proper program and associated cost. Another inconsistency found in the data is a change (during the years under study) in how departments report their programs. Agriculture, for example, submitted one FAA for agri-business and another for all other agriculture during fiscal 2009. However, the programs were combined in 2010 and afterward, leading to a single cost per credit hour for any agriculture course.

A third, but much more complex, inconsistency between per-credit-hour costs and coursework was found in the Department of Languages, Literatures, and Cultures. The department offers five different language programs, in addition to general courses, and utilizes unique course prefixes for each area (i.e., SPA for Spanish, LAN for general). However, the 
department annually submitted only four faculty activity reports which provided per-credit-hour costs for general courses, Japanese / Italian, German, and French / Spanish. Further complicating the analysis, the courses listed in the students' transcript data were associated generically to the department rather than a specific language. As a result, the coursework data could not be matched to the cost of specific language or general course. Resolving this issue required a more complex analysis of the cost data and utilized the university's fall census report for the years 2009 through 2015 that provided enrolled headcount for each of the languages. The four separate per-credit-hour costs were weighted by the census reports' headcount to produce a single language cost for each year. Of course, headcount does not properly reflect FTE or enrolled credit hours, but lacking better data, the risk (of inaccurate language per-credit-hour costs) was deemed acceptable due to the low number of language credit hours as a proportion of the total hours completed by most graduates included in the study. The final per-credit-hour costs skewed toward Spanish, as the majority of students were enrolled in this area. As a result, the per-credithour cost for other language courses may be overstated. The results were not considered to be limitations of the study, due to the low proportions of language credits, but other avenues for resolving this problem should be considered by future researchers.

The fourth issue to be resolved was a proper accounting for credit hours not awarded by ISU. The transcript data included two categories of non-ISU credit: transferred and awarded. Transferred credit represented courses completed at another institution. If the coursework was accepted by ISU, the student received credit. Unaccepted courses were listed in the transcript data but were reported as zero credit hours. Awarded credit was generally given for proficiency in a subject or for completion of advanced placement courses. Regardless of how the transfer and awarded credit was acquired, the accepted work counted as part of the 120 hours required to 
complete a bachelor's degree. As the results will show in Chapter Four, the number of accepted non-ISU credit hours affected how many hours a student must complete at ISU and contributed to variations across students completing the same degree. Another complication posed by nonISU credit was the discovery of hours awarded for U.S. military experience or coursework. The transcript data included military credit hours in the transferred category and, as a result, overstated total transfer hours and inappropriately eliminated some native graduates from the study because their total transferred hours were more than ten. To correct for this, queries were written to move the military credit to the awarded credit category.

The final issue complicating the data was the exclusion of military science instruction from the faculty activity reports. The purpose of the Department of Military Science is to offer the required academics for Army ROTC, but no degree is awarded. This coursework can be associated with a CIP code, but because the coursework does not lead to a degree, the department does not prepare a faculty activity report and it is not associated with costs per credit hour. With the exception of one nursing graduate, all other military science courses were completed by criminal justice students. Seeking a basis to determine credit hour costs for this area, the study determined that the best course of action was to substitute costs from a similar subject area. Assuming that the popularity of military science with the criminal justice students might indicate this similarity, all military science credit hours were associated with the per-credit-hour costs of criminal justice coursework. Although this resolution was not considered a limitation of the current study, like the resolution of languages, future researchers are urged to evaluate other avenues to estimate the costs of military science coursework.

The fifth and last step in stage one was to estimate the cost of a completion for each degree. The catalog cost was estimated by applying a cost per credit hour to each course required 
in completion of the six degrees. Similarly, the transcript approach applied costs to actual courses completed. Each is described in the following two sections of this chapter.

\section{Estimating Completion Costs: Catalog Method}

Surprisingly, estimating catalog costs for each degree presented more of a challenge than estimating the actual costs using the transcript approach. This was because the catalog lists only the required major courses for each degree and does not specify when those courses should be completed. In addition to the major coursework, each 2015 graduate must complete 42 hours of general education, prerequisites for major coursework, and enough university electives to bring the completed total of credit hours to a minimum of 120 . There is no limit to the number of courses a student is allowed to complete. The catalog also emphasizes student choice in selecting coursework. As a result, it was possible that as many as half of the courses completed by one graduate may be different from those completed by another graduate of the same degree area even though both graduates followed the catalog requirements.

The student choice concept, a traditional component of a university education, made it very difficult to determine catalog costs. Fortunately, advisors in each department work with faculty to map out the recommended path in a plan of study. This document, retrieved from university websites, was used to help estimate the catalog cost. The plans do not provide the only path, but the assumption was that the published plans represent what the department considered to be the best path.

\section{Costs of Major Coursework}

The following discussion provides an example of the catalog approach by following the steps required to estimate the cost of major coursework required for art degree. Each of the five remaining degrees followed the same process. 
The School of Art offers a Bachelor of Arts or Sciences. Students are allowed to choose from more than one sequence, but Graphic Design and Studio Arts were the most popular. The catalog cost for an art degree is based upon the undergraduate catalog requirements and the plans of study for those two sequences. The first step compared the plans of study to the requirements listed in the 2010-2012 undergraduate catalog, which would most likely be followed by a 2015 native graduate who completed a degree within six or fewer years. The assumption that most students followed the 2010-2012 catalog was based on a single fact. Of the 298 native graduates included in this study, only 10 students (3\%) took longer than five years to complete and, based on their entry years, would have been following an earlier catalog. As a result, this researcher made the determination that the added complexity of including a second catalog cost for three percent of the students would unnecessarily complicate the study results.

In the second step, using the 2010-2012 undergraduate catalog, the courses required for an art degree were assigned to the year and semester suggested by the plans of study. Finally, the costs for lower- and upper-division courses (based on the sequence suggested in the plan of study) were calculated by multiplying the per-credit-hour costs for the appropriate discipline (adjusted for inflation with the HECA index using 2015 as the base year) against the credit hours awarded for the course. In art, an analysis of the courses completed by the study's 14 qualifying native students showed that $42 \%$ followed the graphic design sequence and just over half followed the studio arts sequence. The two remaining graduates also pursued an education endorsement. A comparison of the plans of study for the two sequences determined that the required coursework, in regard to the number of credit hours and discipline, was exactly the same. Therefore, either sequence resulted in the same catalog cost for major coursework. 


\section{Costs of General Education Coursework}

General education coursework is required of all native graduates. (Transfer students who completed an associate's degree have fulfilled the University’s general education requirement.) The catalog cost associated with the native graduate's general education coursework was calculated in the same manner for each degree. As a result, this section is not unique to art, but the art results are used to provide examples. The primary challenge of calculating the cost was that students need only choose 14 of an available 131 courses. Secondly, each degree allows an exemption for one of the courses, depending upon the major. In addition, the student may complete the general education requirements at any time prior to graduation. This means that even though all students are required to complete English 101, the cost per credit hour ranged from $\$ 128$ to $\$ 202$, depending upon when the course was completed (i.e., taking the course before the student had completed 60 credit hours or taking the course after the student had completed a total of 60 hours). Of course, some of the general education course options serve as prerequisites to classes that a student may be required to complete for a chosen major. Keeping this in mind, some plans of study recommend specific general education courses to be completed in specific semesters, but students are not required to follow those recommendations.

Although it was not possible to calculate the cost of every possible combination, the researcher developed four primary approaches to estimating general education course costs: plan of study, anything goes, core structure, and controlled chaos. Each approach was applied to the six degree areas and evaluated for results. As the following discussion will describe, none of the four approaches was identified as perfect. Forced to choose from the least of four evils, the controlled chaos approach was ultimately used to apply costs whenever specific general education courses were not recommended in the degree's plan of study. 
Plan of study approach. The first approach, based on the actual departmental plans of study, was an attempt to follow the spirit of the catalog method to estimating completion costs. This option began with the assumption that plans of study would suggest specific general education courses, similar to the major requirements listed in the catalog. But an examination of several plans (in addition to the those posted for the six degrees in this study) revealed that while some provided specific course recommendations, others were less specific and only recommended that the student choose courses from the inner-, middle- or outer-core categories that, according to the catalog, comprise general education requirements. In addition, some plans fully embraced the concept of student choice and generically listed the recommendation to complete any general education course within the given year and semester.

Faced with the wide variety of recommendations, the researcher hypothesized that students might be given verbal recommendations, a de facto plan of study. To test this theory, the researcher examined the transcript data, looking for common course-taking patterns among the students completing each of the six degrees. The data provided by PRPA provided enough information to identify any course that fulfilled a general education requirement and to create an estimate of the cost to deliver those courses. But as the descriptive statistics in Table 8 reveal, a de facto plan of study among native art majors for fulfilling the University's general education requirement did not emerge. Though only 42 credit hours are required for general education, and in consideration of the fact that one course (three credit hours) might be waived, the mean of 48.71 general education credit hours is far too high. In addition, if there were a de facto plan of study indicating that students tended to take the same general education courses in the same sequence, the cost variations would be much smaller than those shown in Table 8. 
Table 8

Statistics Describing the Cost to Deliver General Education Courses to Native Students Graduating with a Degree in Art

\begin{tabular}{lcc}
\hline Statistic & Credit Hours & Cost \\
\hline Range & $34-64$ & $\$ 4,252-\$ 8,920$ \\
Mean & 48.71 & $\$ 6,507$ \\
Standard Deviation & 8.54 & $\$ 1,373$ \\
Coefficient of Variation & $17.5 \%$ & $21.1 \%$ \\
\hline
\end{tabular}

Further examination of general education course-taking patterns among the art majors revealed a wide range in hours and costs (per student) that could have been due to a variety of factors including the variety of course options, the range of costs from differing departments, the ability of a student to select the course for reasons other than fulfilling general education requirements, and the acceptance of transferred credit which also satisfies the general education requirements. The same wide-ranging results were reflected in the other five degrees. As a result, the plan of study approach was discarded as an option to estimate the catalog cost of general education coursework.

Anything goes approach. Approach two acknowledged that a student could complete any number of general education courses at any time: an anything goes scenario. The first step of this approach determined the mean lower- and upper-division cost (for each fiscal year 2011 2015) of a general education credit hour based on the fiscal year's per-credit-hour costs of all 131 general education courses. This step resulted in a mean cost per credit hour ranging from \$121 for each credit hour completed in the first year to \$195 for credits awarded in the fourth year. Next, based upon an examination of several plans of study (in addition to the six included in this study), it was determined that the majority recommend students complete 15 general education hours in the first year of attendance, 12 hours in the next, nine in the third, and the final six in the last year. Multiplying the appropriate year's per-credit-hour cost by the 
recommended number of credit hours each year produced a general education cost of $\$ 6,259$ for each native student graduating with a degree in art.

Core structure and controlled chaos approaches. Approaches three and four were attempts to bring some degree of order to the anything goes approach. Both approaches utilize the core structure of general education and assume that students will complete the inner core requirements first (5 courses), followed by the middle ( 5 courses) and finally the outer (4 courses). The 2010-2012 catalog states that the purpose of the structure is to ensure that "developmental objectives are achieved through the coherent and sequential interrelationship of courses. Inner Core courses provide basic knowledge and skills upon which Middle Core courses build, and those courses in turn prepare students for courses in the Outer Core" (Illinois State University, 2010, p. 64). For each of the three cores, the catalog lists acceptable coursework, which is further divided into categories of instruction that provide "an essential grounding for work in the student's major” (p. 64). Table 9 illustrates the structure. 
Table 9

Core Structure of General Education Regardless of Major

\begin{tabular}{|c|c|}
\hline Core and Categories & Courses Required \\
\hline Inner Core & 5 \\
\hline Composition (English 101) & 1 \\
\hline Communication (Communication 110) & 1 \\
\hline Mathematics & 1 \\
\hline Natural Sciences & 2 \\
\hline Middle Core & 5 \\
\hline Quantitative Reasoning ${ }^{\text {a }}$ & 1 \\
\hline Language in the Humanities & 1 \\
\hline United States Traditions & 1 \\
\hline Individuals and Civic Life & 1 \\
\hline Individuals and Societies & 1 \\
\hline Outer Core & 4 \\
\hline Science, Mathematics, and Technology & 1 \\
\hline Social Sciences & 1 \\
\hline Fine Arts & 1 \\
\hline Humanities & 1 \\
\hline
\end{tabular}

${ }^{\mathrm{a}}$ If the student completes a BA rather than BS, this requirement is replaced by a language course.

Approach three, titled core structure, calculated separate mean costs for each of the three cores and was based on two assumptions. First, the core structure approach assumed general education courses were completed in order (5 inner-core, 5 middle-core, and then 4 outer-core courses). Second, it assumed students would complete a specific number of hours each year (15, 12, 9, and 6 as described in the anything goes scenario). Following the two assumptions, a student completing courses under this approach would complete the inner core during the first year of study, four middle core courses in the second year, the last middle core class and two of the outer core classes in the third year, and the two final outer core courses would be completed in the fourth year of study. The first step of the core structure approach calculated the mean per- 
credit-hour cost of all courses listed in the catalog for each of the core's requirements, by fiscal year. For example, the mean cost per credit hour of inner core courses completed in fiscal 2012 was $\$ 124$, based on lower division costs. In the final year, the mean per-credit-hour cost of outer core courses (upper division) was \$217. The final cost using this approach was \$6,326 for native students majoring in art, which was $\$ 67$ higher than the anything goes approach.

The controlled chaos method was developed as the fourth approach and further refined the core structure approach by category. Under this approach, rather than complete any inner core course, students chose one course per category. This accounted for the fact that only one course was required in each core category, with the exception of two natural sciences in the inner core. Students would not, for example, complete two math courses unless the second course was for a purpose other than fulfillment of general education requirements. The basic formula of the controlled chaos approach was to calculate a mean cost per credit hour from any course fulfilling a core category requirement. The mean costs of each category were averaged together, resulting in a mean of all mean cost per credit hour for each core. For example, the middle core mandated students to select one course in fulfillment of the Quantitative Reasoning (QR) requirement. That course may be selected from 12 classes offered by nine different departments. There was an equal chance that any of the 12 courses fulfilling the QR requirement might be chosen and the resulting (arithmetic) mean cost per credit hour of the QR courses was $\$ 120$ if completed in the second year of study at lower-division cost. A mean per-credit-hour cost was also calculated for the remaining categories of the middle core (Language in the Humanities, United States Traditions, Individuals and Civic Life, and Individuals and Societies). The mean costs of all six categories were averaged together, resulting in a mean of all the mean costs of $\$ 116$ for the middle core credit hours completed during a student's second year of study. The process was 
repeated for the inner and outer cores. Finally, mean-of-the-mean costs were multiplied against the number of credit hours completed in each year, by core. The total cost of general education using the controlled chaos approach was $\$ 6,188$. This approach could be tweaked further, in recognition that English 101 and Communication 110 were the only non-negotiable general education requirements and were typically completed in a student's first year. Holding those courses separately from the other inner course options lowered the total cost by $\$ 5$, hardly enough to make a difference. A summary of results for the final three approaches are shown in Table 10.

Table 10

Comparing Three Approaches to General Education Catalog Cost for Native Students Graduating with a Degree in Art

\begin{tabular}{lccccc}
\hline & \multicolumn{2}{c}{ Lower Division } & \multicolumn{2}{c}{ Upper Division } & \\
Credit Hours and Approaches to Cost & FY12 & FY13 & FY14 & FY15 & Total \\
\hline Hours per Year based on Plans of Study & 15 & 12 & 9 & 6 & 42 \\
& & & & & \\
$\begin{array}{l}\text { Anything Goes Approach } \\
\quad \text { Mean Cost per Credit Hour All Courses }\end{array}$ & $\$ 121$ & $\$ 130$ & $\$ 191$ & $\$ 195$ & \\
$\quad$ Total Cost & $\$ 1,810$ & $\$ 1,556$ & $\$ 1,722$ & $\$ 1,170$ & $\$ 6,259$ \\
& & & & & \\
$\begin{array}{l}\text { Core Structure Approach } \\
\text { Mean Cost per Credit Hour Inner Core }\end{array}$ & $\$ 124$ & & & & \\
$\quad \begin{array}{l}\text { Mean Cost per Credit Hour Middle Core } \\
\text { Mean Cost per Credit Hour Outer Core }\end{array}$ & & $\$ 119$ & $\$ 170$ & & \\
$\quad \begin{array}{l}\text { Total Cost } \\
\text { Controlled Chaos Approach }\end{array}$ & $\$ 1,857$ & $\$ 1,425$ & $\$ 1,741$ & $\$ 1,303$ & $\$ 6,326$ \\
$\quad \begin{array}{l}\text { Mean of Mean Costs per Credit Hour } \\
\text { Total Cost }\end{array}$ & $\$ 120$ & $\$ 127$ & $\$ 190$ & $\$ 192$ & \\
\hline
\end{tabular}
Note: All costs are adjusted for inflation (in FY2015 dollars).

The reality, after examining the results of the four approaches to estimating the catalog cost of general education coursework, was that none of the approaches might be exactly correct. What the approaches did provide was evidence that the final three resulted in approximately the 
same cost. Absent a plan of study specifying course and semester selection, it was posited that controlled chaos was the best option because it places limits on credit hours per year, follows the core path, and accounts for the differences in cost to deliver each category. Therefore, the study used this approach to estimate the cost of delivering general education to students awarded any degree that does not utilize a plan of study addressing the specifics of general education coursework. Whenever specific courses were suggested, the cost of general education was adjusted appropriately.

\section{Costs of University Electives}

Costs for elective courses completed by students were based simply on the university’s average cost per credit hour (for fiscal years 2010 through 2015) as provided by PRPA. The average costs were converted to 2015 dollars according to the HECA inflation index and assigned to each course based on the fiscal year of completion and division (lower division or upper division) based on the student's total completed credit hours at the time.

Similar to general education coursework, university electives vary widely in cost because any course can be taken at any time. However, the required number of (university elective) credit hours vary by degree and the choices are not restricted to only 131 courses, as they are in the University’s general education curriculum. A university elective can be any course chosen by the student from any department on campus if the student has completed the prerequisite coursework and if the course is not blocked to non-majors. In the case of an art student, 21 hours of university electives are required and all are recommended for completion in the final two years. Therefore, an upper division cost is applied to the coursework. As shown in Table 11, the total cost per credit hour to complete electives during upper division study is much higher than the costs would be if the courses were completed during lower division study. 
Table 11

Costs per Credit Hour for University Elective Coursework

\begin{tabular}{lcccc}
\hline & 2012 & 2013 & 2014 & 2015 \\
& $\begin{array}{c}\text { Lower }^{\mathrm{a}} \\
\text { Division }\end{array}$ & $\begin{array}{c}\text { Lower } \\
\text { Division }\end{array}$ & $\begin{array}{c}\text { Upper }^{\mathrm{b}} \\
\text { Division }\end{array}$ & $\begin{array}{c}\text { Upper } \\
\text { Division }\end{array}$ \\
\hline Controllable & $\$ 121.16$ & $\$ 126.37$ & $\$ 214.92$ & $\$ 212.38$ \\
Fully Allocated & $\$ 247.48$ & $\$ 257.83$ & $\$ 413.44$ & $\$ 413.93$ \\
Manageable & $\$ 149.26$ & $\$ 155.22$ & $\$ 261.70$ & $\$ 260.05$ \\
\hline
\end{tabular}

${ }^{\mathrm{a}}$ Lower division represents the cost to deliver credit hours to students who have completed less than 60 total credit hours.

${ }^{\mathrm{b}}$ Upper division represents the cost to deliver credit hours to students who have completed more than 59 total credit hours.

\section{Estimating Completion Costs: Transcript Method}

The transcript cost of a degree was calculated as the sum of the cost for each credit hour completed by a graduate. Of course, each graduate completes coursework that spans several CIP codes over several years. The challenge was to write queries (for the cost database) that matched the correct cost to each credit hour completed. To begin, crosswalk tables were created to match department names in the ADUCS cost tables to the awarding department for completed coursework listed in the transcript data. A second crosswalk was created to align the year and semester of course completion to the fiscal year of a cost. Finally, cost tables were produced from the PRPA data to associate each CIP with an inflation adjusted cost per credit hour for all fiscal years 2009 through 2015 at the appropriate purview (controllable, manageable, and fully allocated).

To reduce computing time and memory usage, further steps for each degree were handled separately. However, each degree exactly replicated the same two major processes to produce a record reflecting the correct cost for each completed course and degree. The first step in process one was to write a query to combine the PRPA provided student and course data (shown earlier 
in this chapter in Tables 5 and 6) into a table listing every ISU course completed, by degree, for every native and transfer graduate selected for inclusion in the study. A second query matched each student's coursework, by CIP code, to a fiscal year and returned, from the cost tables, the inflation-adjusted, per-credit-hour cost. For native students, the query returned lower-division costs for courses completed before students had accumulated 59 credit hours and upper-division costs for courses completed after students had completed 60 or more hours. If the graduate was identified as a transfer student, only upper-division costs were returned. Finally, the returned cost per credit hour was multiplied by the number of credits, which produced the course cost. This process also allowed selection of the level of cost to utilize: controllable, manageable, or fully allocated. Table 12 shows the first four courses completed by art student "A1" and the cost per course using inflation indexed, controllable purview costs per course.

Table 12

Process One: Associating Costs to a Completed Course

\section{Term}

Field Unique YrsTo Admit Course

Name ID Grad a Type Taken ${ }^{\mathrm{b}}$ Fiscal

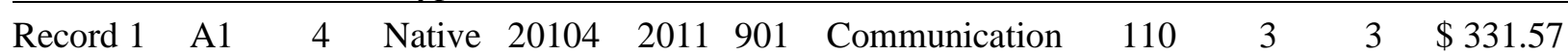

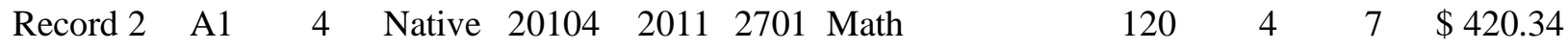

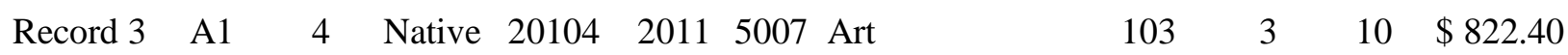

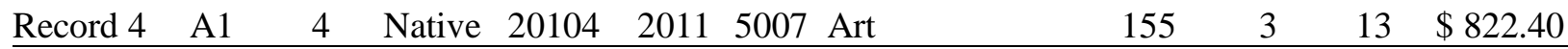

${ }^{a}$ Represents the number of years the student was enrolled at ISU.

${ }^{\mathrm{b}}$ The digit after the year refers to the term. 1 = spring, 2 = summer, $4=$ fall

The second major process summed the total estimated course costs for each student and allowed selection of graduates that fit the study parameters including the number of years to graduation, hours transferred from another institution, and whether or not a transfer student completed an associate degree. Table 13 shows the estimated cost, at the controllable purview, of two native art students who completed the required coursework in six or fewer years. 
Table 13

Process Two: Summing the Total Course Costs for an Individual Degree

\begin{tabular}{|c|c|c|c|c|c|c|}
\hline $\begin{array}{l}\text { Field } \\
\text { Name }\end{array}$ & $\begin{array}{l}\text { Unique } \\
\text { ID }\end{array}$ & $\begin{array}{l}\text { Admit } \\
\text { Type }\end{array}$ & $\begin{array}{c}\text { Sum Of } \\
\text { Cost }\end{array}$ & $\begin{array}{c}\text { ISU } \\
\text { Hours }\end{array}$ & $\begin{array}{c}\text { Associate } \\
\text { Degree }\end{array}$ & $\begin{array}{c}\text { YrsTo } \\
\text { Grad }\end{array}$ \\
\hline Record 1 & A1 & Native & $\$ 31,044$ & 118 & & 4 \\
\hline Record 2 & A10 & Native & $\$ 26,949$ & 117 & & 3 \\
\hline
\end{tabular}

Unfortunately, the cost data in Tables 12 and 13 tell us relatively little because few students follow the same path. They change majors, pick classes that are interesting but not required, and obtain credit by other means such as advanced placement or military, etc. To give the transcript cost estimates more depth, descriptive statistics were calculated for each degree and student category (native, upper-division native, and transfer) to present the range, mean, standard deviation, and the coefficient of variation of credit hours and costs. Table 14 provides an example of descriptive statistics for the art degree.

Table 14

Descriptive Statistics: Estimated Cost to Deliver an Art Degree (Controllable Level)

\begin{tabular}{lccc}
\hline Statistic & Native Graduate & $\begin{array}{c}\text { Native Graduate } \\
\text { Upper Division }\end{array}$ & $\begin{array}{c}\text { Transfer Graduate } \\
\text { (Upper Division) }\end{array}$ \\
\hline Range & $\$ 25,541-37,048$ & $\$ 15,461-30,633$ & $\$ 15,829-29,859$ \\
Mean & $\$ 29,919$ & $\$ 19,979$ & $\$ 21,322$ \\
Median & $\$ 29,500$ & $\$ 18,364$ & $\$ 20,905$ \\
Standard Deviation & $\$ 2,902$ & $\$ 4,078$ & $\$ 2,967$ \\
Coefficient of Variation & $9.7 \%$ & $20.4 \%$ & $13.9 \%$ \\
\hline
\end{tabular}

The descriptive statistics facilitated a comparison between students awarded the same degree. For example, the figures for upper-division native and transfer graduates presumably reflect essentially the same coursework in the final years of study. One would also expect the upper-division cost to be more than half of the total costs incurred for each native graduate because upper-division coursework is more expensive to deliver and because students often take 
more than the required 120 credit hours.

\section{Data Limitations}

The study's use of data prepared by the university followed the NRC panel’s 2012 recommendation to begin with whatever data is currently available. Indeed, researchers in the relatively new field of completion-cost analysis have to start somewhere and improve as they move along, identifying limitations of available data that might need to be addressed in future studies. As the researcher worked with available data at Illinois State university, four limitations became apparent and should be noted.

The first limitation arose due to the timing of the study itself. Illinois State University recently migrated student record data from a legacy mainframe to a new student record system. In any system conversion, inconsistencies inevitably occur. For example, data definitions or record names may have changed. At the time of the request, PRPA had not completed data validation and could not guarantee that the data gathered for this study was absolutely correct.

The second limitation of the study was that major degree requirements might have changed between the time of the student's entry and graduation. The study utilized degree requirements listed in the 2010-2012 undergraduate catalog, which would be the most likely entry years for the graduates selected for the study. However, if changes were made to degree requirements and a student was given the choice to follow the new requirements, the data contained no indicators of the event. Such an occurrence would create an unidentified variance in completion costs across students completing the same degree.

The third limitation was a possible lack of consistency in multi-unit reporting. The IBHE, in addition to providing requirements for cost data, also requires a secondary report, the Faculty Activity Analysis (FAA). The FAA is prepared by academic units at the end of each term and is 
used by the university to accumulate and allocate faculty salaries based on credit hours generated by each reporting unit. Although PRPA presumably reviews the FAA information, informal discussion in the study's planning stages indicated that instructions for FAA preparation may not be consistently followed across reporting departments. Concerns in regard to this speculative inconsistency were also discussed by administrators in the study's qualitative stage, though it needs to be emphasized that this study did not examine department practices in providing FAA data.

A fourth limitation of the data may lie in the IBHE's chosen methods of allocation which, as noted by Romano et al. (2011), can be a point of contention. In the data prepared for the IBHE, credit hours are used to allocate faculty costs, the first step in determining costs per credit hour. However, many of the successive IBHE cost categories are allocated by the proportion of the academic unit's accumulated costs, a method that increasingly skews the distribution across departments to the extent that expenditures are driven by obligations beyond those incurred in the academic work itself. For example, the high and increasing cost of health insurance is charged to the university based upon its number of full-time equivalent employees and their associated marital status and number of dependents. However, healthcare cost allocations (by IBHE method) to each department are based on the department's accumulated expenditures. The two bases (of actual charges versus accumulated expenditures) are not comparable and may result in per-credit-hour cost allocations that have no relation at all to the actual expenditures.

\section{Stage Two: Inviting Administrator Perceptions}

In stage one, the study produced descriptive statistics to quantify estimates of the cost to deliver a degree to native and transfer students. The second stage was a qualitative assessment that attempted to obtain a deeper understanding of results and underlying data. This stage 
engaged key stakeholders, the top administrators of the academic unit, who are familiar with the unique characteristics of the six degrees selected for examination.

\section{Interview Participants}

The administrators were asked to participate in a focus group discussion, a step that this researcher agreed is crucial to developing a "thoroughly vetted and agreed-upon set of metrics" (National Research Council, 2012, p. 16). Due to conflicting schedules, only two administrators were able to participate. In addition, telephone interviews with each of the two administrators were substituted for the focus group discussion. The administrators were asked to evaluate the data and its ability to help them understand the cost to deliver their degrees. They were also asked to provide their thoughts about the data underlying the reports upon which the cost data were based (i.e., the faculty activity analyses and the cost reports prepared by PRPA for the IBHE). Finally, they were also asked to consider what other data might help in the interpretation of the results and how the cost-of-completion data might be used and by whom.

\section{Procedures}

Prior to the interviews, the researcher contacted each participant to explain that they would be asked to sign a form giving their consent to participate. Those who agreed to participate were given a summary of results for all six degrees, detailed in Appendix A, which

illustrate the descriptive cost statistics and other metrics such as the number of graduates in each degree area and the number of completed hours (ISU and non-ISU). A summary of the costs per credit hour, as presented in the ADUCS report, was also provided as shown in Appendix B. The guiding questions for the session were as follows.

1. As fiscal and academic managers, what are your thoughts about the estimated transcript and catalog costs and do the results help you to better understand the cost to 
your department of delivering a degree?

2. What are your thoughts regarding the data that underlie the final results in regard to department contribution, accuracy of the reports, or other data that might supplement the results?

3. How do you think these estimates might be used by yourself and others?

The sessions were recorded and each session was transcribed. Using an inductive approach, the transcripts were color coded to group emerging themes in response to the research questions. Finally, the themes were organized into a narrative, as presented in Chapter Four. The recordings and transcripts were destroyed upon acceptance of the manuscript by the graduate school.

\section{Study Limitations}

As a field of research, the examination of completion costs in higher education is in the embryonic stage. Policies, methodologies, and measures are still under development. Community college scholars have completed valuable work for their sector (Bailey et al., 2015, Belfield et al., 2014, Manning \& Crosta, 2014, Romano et al., 2011), but only Johnson’s (2009) work has been completed at the university level and develops approaches to estimate the cost to deliver individual degrees. Johnson's research utilized statewide data prepared by the Florida Board of Governors to estimate degree costs in the state's two major university systems. However, this study proposed that Johnson's work be taken one step further by estimating and completing an examination of degree costs using a university's readily-available data. Proposing a plan to estimate the cost of six degrees awarded by Illinois State University, this study moved away from traditional credit-hour costing processes and toward an analysis of costs incurred in delivering a degree. By thinking in the longer term, universities will have better information for 
decision making, as well as a greater capacity to make better use of increasingly limited resources and the ability to respond to proponents of the completion agenda.

Nonetheless, study limitations should be acknowledged. The first of the two larger limitations is that estimates of completion costs are only one measure. As the NRC (2012) panel states, "a single high-stakes measure is a flawed approach in that it makes gaming the system simpler; a range of measures will almost always be preferable for weighing overall performance” (p .2). A more holistic analysis of productivity would include other measures, such as persistence and graduation rates, which are already produced by universities. The second limitation is that the IBHE does not require or make use of available measurements of quality. For example, the NRC panel (2012) refers to the literature in suggesting that higher-ranking faculty members deliver a higher quality of instruction and learning. Class size is also perceived to be a component of instructional quality, as evidenced by the measure's use in ranking reports. The lack of quality measures might hinder a reader's interpretation of the study results in a holistic evaluation of completion costs (i.e., lower costs may not indicate lower quality just as higher costs do not necessarily indicate higher quality).

In addition to the limitations of the study's analysis, four delimiters were identified. Delimiters are results that the study did not or could not provide. The first, and perhaps obvious, delimiter was that the study's estimates of degree completion costs are not actual productivity indices in that the results do not estimate the ratio of the changes in output (degrees) to the changes in input (costs). Although the cost of a specific degree can be compared over time, cost estimates do "not necessarily reflect [the] underlying relationship between inputs and outputs because similar inputs may be priced differently” (National Research Council, 2012, p. 142).

The concept of the relationship between inputs and outputs led to the second delimiter, 
which was that a comparison of degree costs within the institution cannot be conclusive and is not appropriate as a result. For example, if the salaries of department A's faculty are substantially higher than salaries in department B, the cost to produce a credit hour of instruction and the resulting degree cost will also be higher, all other things being equal. The higher cost to for department A to deliver the degree does not indicate that the degree of higher quality or that the department is inefficient relative to department B.

A third delimiter arose from the limitations inherent in the university's readily available data, as discussed above. The results therefore do not represent the absolute cost to deliver each degree. The costs developed in the study are only estimations that tend to vary around a mean or follow an inputted path to a degree. As estimates, there will always be a margin of error.

The fourth delimiter of the study was that the cost estimations cannot be used to make judgments about the relative efficiency or effectiveness of a department in awarding its degrees. To begin, the awarding of degrees is only one of many important outputs produced by higher education. For example, department faculty must deliver instruction, be productive in research, and participate in community service. The multiple outputs of a department make it difficult to determine its effectiveness or efficiency in awarding degrees as a standalone measure. In addition, efficiency and effectiveness cannot be measured without including an analysis of quality. For example, if a department increased the number of its awarded degrees (increasing effectiveness) the increase might come at the cost of hiring more faculty, which would reduce the department's efficiency. However, if the same department tried to control personnel costs by hiring less qualified faculty, the quality of its degrees might suffer. Awarded degrees and salary costs are simple numbers, but quality is an elusive measure for which higher education has no standard and this study, due to its use of readily available data, was not able to include factors 
that might indicate quality. Finally, awarding degrees, though important, is secondary to another output: learning, for which higher education also has no established standard. Learning cannot be measured by completed degrees alone because learning does not only occur in the classroom. Completing a course does not necessarily mean the student has learned the material, just as failure to complete a degree does not mean that a student did not learn. In fact, students contribute to their own learning becoming, in effect, both input and output in a sought after formula for efficiency and effectiveness in which the cost to deliver degrees is only one factor. Regardless of the limitations and delimiters of the study, the resulting estimations of cost did provide a first look at completion-cost data at ISU and the chapters that follow detail those findings (Chapter 4) and suggest implications for data collection and reporting at ISU, as well as for future research (Chapter 5). 


\section{CHAPTER IV: FINDINGS}

This study proceeded in two stages. The first was quantitative and produced estimates of cost to deliver six bachelor's degrees, one from each of the six colleges on the campus of Illinois State University. Those degrees were Art, Business Administration, Criminal Justice, Middle Level Teacher Education, Nursing, and Psychology. The cost estimates in those areas answered the following questions:

1. What is the estimated catalog cost of delivering each of the six degrees included in the analysis?

2. Using the transcript methodology to calculate the cost of delivering each of the six degrees to native students, what is the range across students of costs incurred by the institution, what is the mean and median cost incurred, and what is the standard deviation and the coefficient of variation for each degree?

3. Using the transcript methodology to calculate the cost of delivering final coursework for each of the six degrees to transfer students, what is the range across students of costs incurred by the institution, what is the mean and median cost incurred, and what is the standard deviation and coefficient of variation for each degree?

4. Using the transcript methodology to calculate the cost of delivering upper-division coursework in each of the six degrees to native students, what is the range across students of costs incurred by the institution, what is the mean and median cost incurred, and what is the standard deviation and coefficient of variation for each degree?

The second stage was qualitative and designed as an attempt to gain a deeper understanding of the cost estimates from the perspective of academic discipline unit 
administrators familiar with the degree programs. The research questions answered in this stage were:

1. As fiscal and academic managers, what are your thoughts about the estimated transcript and catalog costs and do the results help you to better understand the cost to your department of delivering a degree?

2. What are your thoughts regarding the data that underlie the final results in regard to the department's contribution, accuracy of the submitted FAA reports, or other information that might supplement the results?

3. How do you think these estimates might be used by yourself and others?

This chapter details the cost findings calculated in stage one of this study, summarizes the observations of the two administrators who accepted an invitation to comment on these cost data, and concludes with a summary of what the cost data suggest about varying costs across degrees and, within degree areas, across individual students themselves.

\section{Quantitative Stage: Cost Findings}

Data in Tables 15 and 16 summarize aggregate cost figures at each of the three administrative purviews (controllable, manageable, and fully allocated) for the 418 graduates, including 298 native students and 120 transfer students. The data show that the cost to deliver a bachelor's degree varies widely across programs as evidenced by catalog costs that (in the controllable purview) range from $\$ 15,412$ to $\$ 29,267$, as well across students themselves, as evidenced by the wide-ranging transcript costs. Further insights at the controllable cost level can be seen within each of the six program areas as detailed the in paragraphs that follow. Student descriptors and cost results for the individual degrees are in Appendix A. 
Table 15

Student Descriptors: Summary of the Credit Hours Across the Six Degrees

\begin{tabular}{|c|c|c|c|c|c|c|c|}
\hline \multirow[b]{2}{*}{ Student Type } & \multirow[b]{2}{*}{ Graduates } & \multicolumn{2}{|c|}{$\begin{array}{l}\text { Transferred }^{\mathrm{a}} \\
\text { Credit Hours }\end{array}$} & \multirow{2}{*}{$\begin{array}{c}\text { Awarded }^{\mathrm{b}} \\
\text { Credit Hours } \\
\text { Average } \\
\end{array}$} & \multicolumn{2}{|c|}{$\begin{array}{c}\text { ISU } \\
\text { Credit Hours }\end{array}$} & \multirow{2}{*}{$\begin{array}{c}\text { Total } \\
\text { Credit Hours } \\
\text { Hours Average }\end{array}$} \\
\hline & & Range & Average & & Range & Average & \\
\hline Native & 298 & $0-10$ & 3.42 & 1.29 & $107-188$ & 125.14 & 129.85 \\
\hline Transfer & 120 & $59-90$ & 67.16 & 0.86 & $39-90$ & 60.83 & 128.86 \\
\hline
\end{tabular}

Note: Maximum transfer hours from a community college is 70 however, some students transferred hours from completion of an associate degree at a community college in addition to hours from four-year universities and, in this case, ISU allowes a maximum of 90 total credit hours.

${ }^{a}$ Transferred Credit: Credit accepted by ISU from another institution. Does not include unaccepted credit.

${ }^{b}$ Awarded Credit: Credit hours awarded by ISU for proficiency (CLEP, department testing, advanced placement, etc.), military coursework, or military experience.

Table 16

Cost to Deliver Degrees by Administrative Purview and Student Group Aggregated Across the Six Degrees

\begin{tabular}{lcccc}
\hline Purview and Statistics & Native & $\begin{array}{c}\text { Transcript Cost } \\
\text { Native Upper Division }\end{array}$ & Transfer & $\begin{array}{c}\text { Catalog Cost } \\
\text { Native }\end{array}$ \\
\hline Controllable & & & & \\
Range & $\$ 13,391-37,348$ & $\$ 7,314-30,828$ & $\$ 5,536-29,859$ & $\$ 15,412-29,267$ \\
Mean & $\$ 22,470$ & $\$ 14,837$ & $\$ 13,557$ & $\$ 21,957$ \\
Median & $\$ 22,305$ & $\$ 14,391$ & $\$ 12,152$ & $\$ 21,480$ \\
Standard Deviation & $\$ 5,114$ & $\$ 4,858$ & $\$ 5,640$ & $\$ 4,647$ \\
Coefficient of Variation & $24 \%$ & $33 \%$ & $42 \%$ & $21 \%$ \\
& & & & \\
Manageable & & & & \\
Range & $\$ 16,404-45,802$ & $\$ 8,931-37,766$ & $\$ 6,771-36,506$ & $\$ 18,898-35,891$ \\
Mean & $\$ 26,370$ & $\$ 18,131$ & $\$ 16,573$ & $\$ 26,916$ \\
Median & $\$ 26,017$ & $\$ 17,577$ & $\$ 14,841$ & $\$ 26,301$ \\
Standard Deviation & $\$ 6,258$ & $\$ 5,942$ & $\$ 6,896$ & $\$ 5,713$ \\
Coefficient of Variation & $24 \%$ & $33 \%$ & $42 \%$ & $21 \%$ \\
& & & & \\
Fully Allocated & & & & \\
Range & $\$ 27,070-72,922$ & $\$ 14,507-59,922$ & $\$ 10,977-57,280$ & $\$ 30,488-57,038$ \\
Mean & $\$ 42,443$ & $\$ 28,794$ & $\$ 26,339$ & $\$ 42,949$ \\
Median & $\$ 41,883$ & $\$ 27,926$ & $\$ 23,467$ & $\$ 42,407$ \\
Standard Deviation & $\$ 9,622$ & $\$ 9,184$ & $\$ 10,665$ & $\$ 9,100$ \\
Coefficient of Variation & $23 \%$ & $32 \%$ & $40 \%$ & $21 \%$ \\
\hline
\end{tabular}




\section{Art Degree Costs}

The College of Fine Arts houses four academic areas: Art, Music, Theatre and Dance, and Arts Technology. The degree examined in this study is a bachelor's degree in art. Page 273 of the 2010-2012 University’s undergraduate catalog described the general path to the degree, which provides professional and academic preparation for a career in the visual arts. Students are allowed to choose from four sequences: studio arts, graphic design, art history, or art teacher education. In this study, all but two of graduates selected either studio arts or graphic design as their sequence. The catalog states that both of these two sequences require students to complete 54 hours of art coursework, including courses in art history and foundations. Further, in order to graduate, students must also complete general education requirements and enough elective courses to bring the total credit hours to at least 120 .

The PRPA office originally provided transcripts for 52 art graduates. Of these 52 graduates, 14 were identified by PRPA as native students who had transferred in 10 or fewer credit hours, thereby qualifying for inclusion in the study. Also included in the data were another 18 students identified as having transferred to the University after earning a community college associate's degree and who subsequently earned the bachelor's degree within three years of transfer.

The 14 native students graduated with an average of 130 credit hours, but only 125 were delivered by ISU. The estimates of transcript cost, at the controllable level, for the ISU hours delivered to this group ranged from $\$ 25,541$ to $\$ 37,048$ and averaged $\$ 29,919$ with a median cost of $\$ 29,500$, standard deviation of $\$ 2,902$, and a $10 \%$ coefficient of variation. The estimated catalog cost for a bachelor’s degree in art was \$29,267 which was lower than the mean transcript cost. Figure 1 presents a visual of the native student and catalog cost estimates. 
Estimated costs and statistics were also produced for the upper-division coursework of native students. The range of upper-division art costs was $\$ 15,461$ - $\$ 30,633$, with a mean of $\$ 19,979$ and median of $\$ 18,364$. The standard deviation and coefficient of variation for upper division coursework was $\$ 4,078$ and $20 \%$ respectively.

Looking specifically at the 18 transfer students who qualified for inclusion in the study, transcript costs ranged from $\$ 15,829$ to $\$ 29,859$, with a mean of $\$ 21,322$, median of $\$ 20,905$, standard deviation of $\$ 2,967$ and a coefficient of variation of $14 \%$. These descriptive statistics are visually presented in Figure 2.

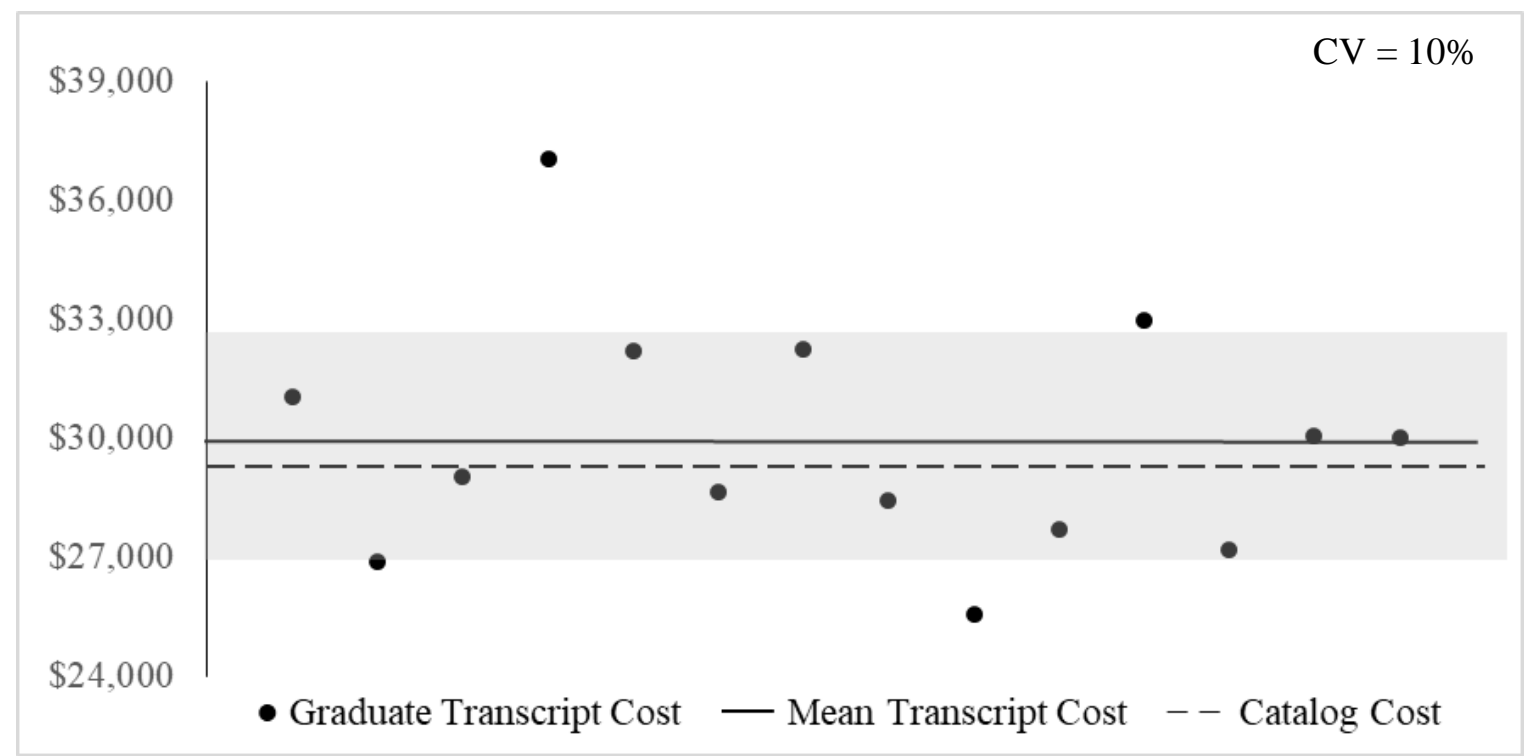

Figure 1. 2015 Native Art Graduates’ Transcript and Catalog Costs.

This figure illustrates the estimated transcript cost of the 14 native graduates in comparison to catalog cost. The standard deviation is represented by the shaded area. 


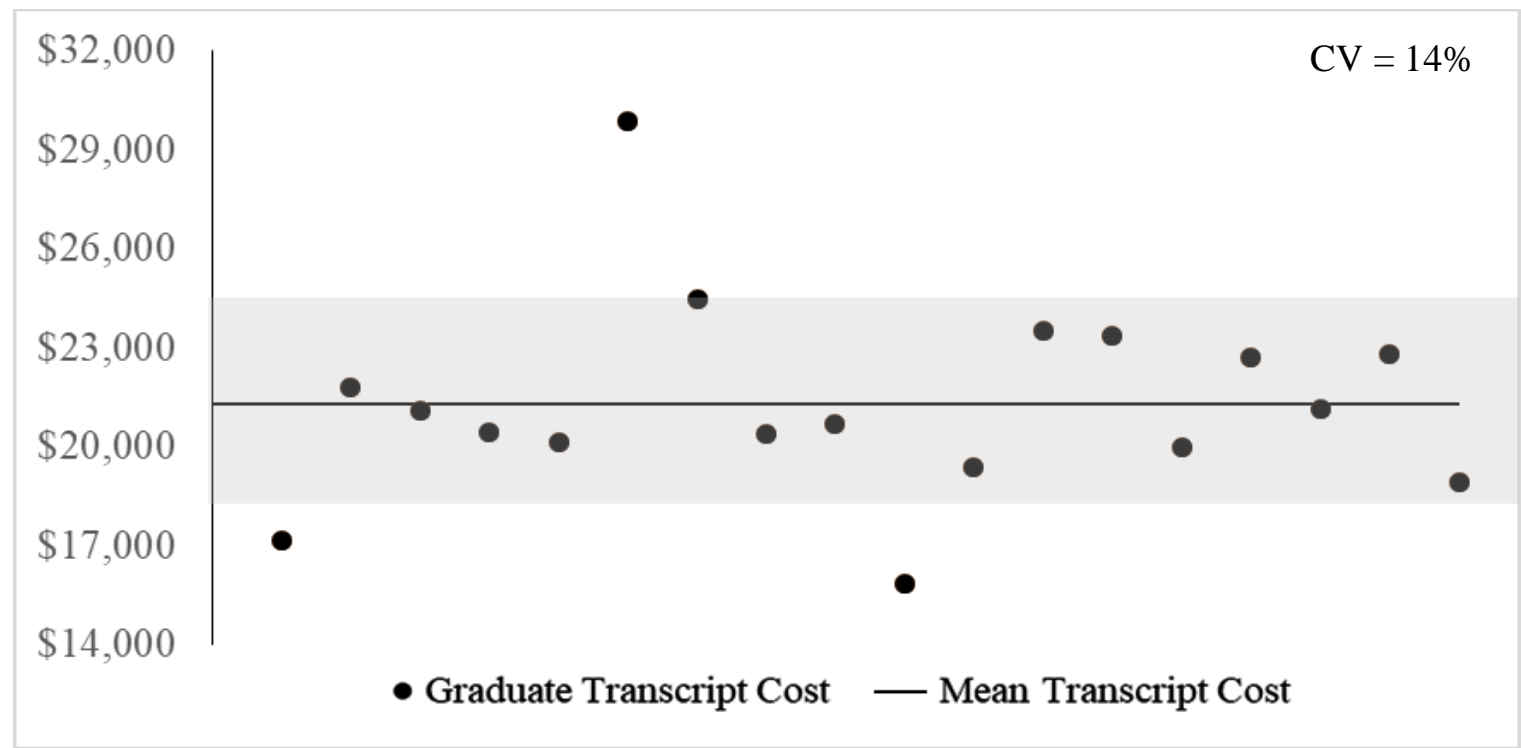

Figure 2. 2015 Transfer Art Graduates’ Transcript Costs.

This figure shows the cost to deliver an art degree to 18 transfer students. As with native graduates, the individual costs vary closely around the mean except for a few which are significantly above or below the shaded area representing the standard deviation.

\section{Business Administration Degree Costs}

The College of Business is home to four academic departments: Accounting; Finance, Insurance \& Law; Management \& Quantitative Methods; and Marketing. The degree chosen for examination in this study is delivered by the business administration program, which is administered by the Department of Management \& Quantitative Methods (MQM). The degree is intended to "prepare students for professional management careers in business, industry, and government” (Illinois State University, 2010, p.247). Unlike the other degrees examined by this study, the coursework required to obtain a bachelor's degree in business administration is delivered through the cooperation of the four departments in the College of Business, rather than the MQM department alone. The 2010-2012 catalog specifies that graduates must complete "68 required hours including 44 hours in required core and non-business courses and 24 hours of major course work” (p. 248). Of the 68 hours, only nine are delivered by departments housed outside of the College of Business (economics, English and math). 
In fiscal year 2015, the business administration program awarded bachelor's degrees to 96 students. From the original 96 graduates, 37 native and 25 transfer students met the criteria for inclusion in this study. The costs to deliver the degree to the native group ranged from $\$ 18,651$ to $\$ 26,560$, with a mean of $\$ 21,683$, median of $\$ 21,516$, standard deviation of $\$ 1,667$ and $8 \%$ coefficient of variation. In addition, the native group averaged 124 ISU credits at graduation, four more than required in the catalog description of the degree. As predicted by the excess credits, the estimated catalog cost $(\$ 20,889)$ was lower than the mean transcript cost. Figure 3 presents a visual of the native group’s degree cost results.

Turning to the upper-division costs for this native group, the range was $\$ 12,272$ to $\$ 18,569$. The mean and median costs were $\$ 14,914$ and $\$ 14,601$ respectively, standard deviation and coefficient of variation for this group (\$1,688 and 11\%) were very similar to the results for the native group as a whole, but did indicate slightly more variation in costs.

The costs to deliver the degree to the group of 25 transfer students ranged from $\$ 11,190$ to $\$ 19,497$, with a mean cost of $\$ 13,736$, median cost of $\$ 12,914$, . The transfer group’s costs varied much more than the native group costs, posting a standard deviation of \$2,145 and corresponding coefficient of variation of $16 \%$. Figure 4 provides an illustration of the transfer group results. 


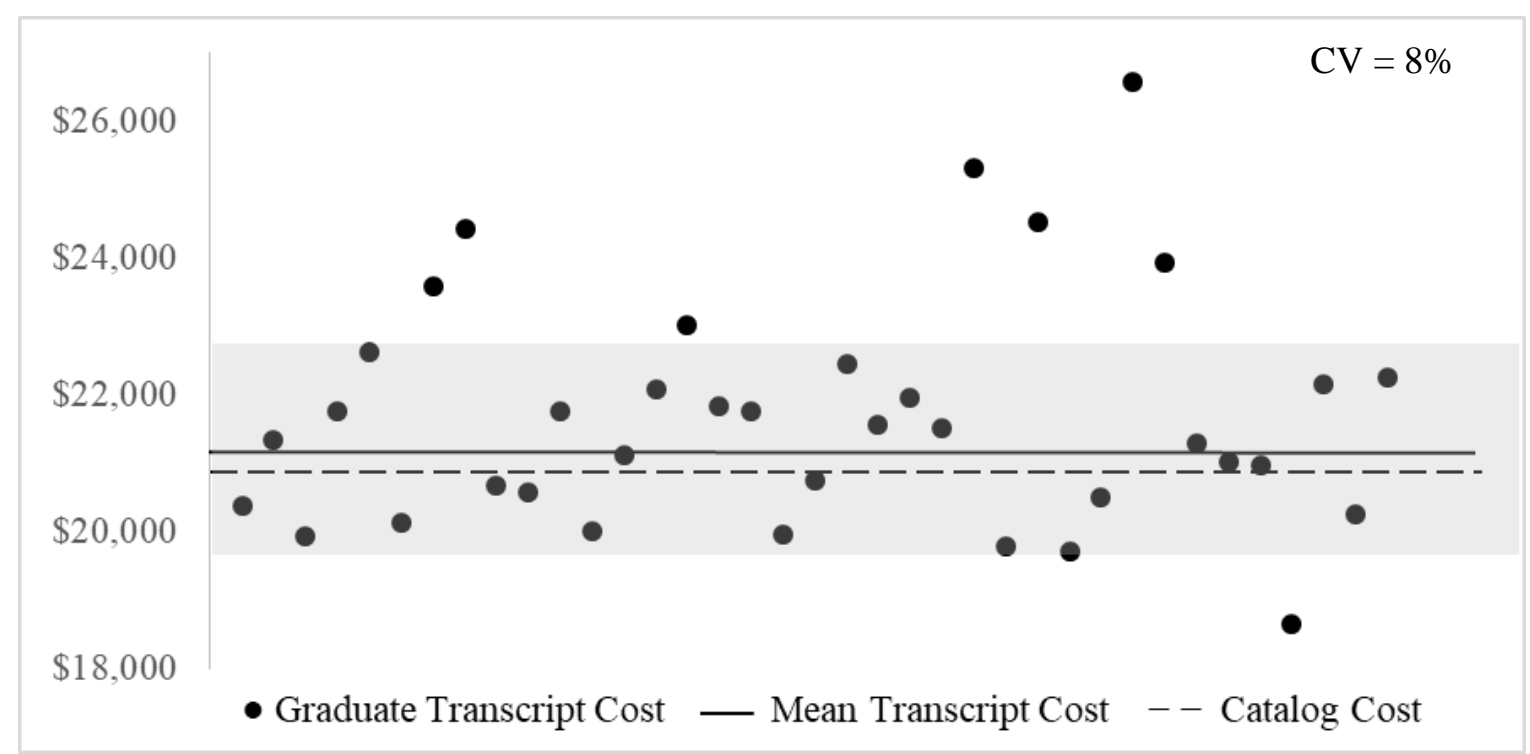

Figure 3. 2015 Native Business Administration Graduates’ Transcript and Catalog Costs. This figure illustrates that most of the 37 estimated transcript costs vary close to the mean, reflecting the $8 \% \mathrm{CV}$.

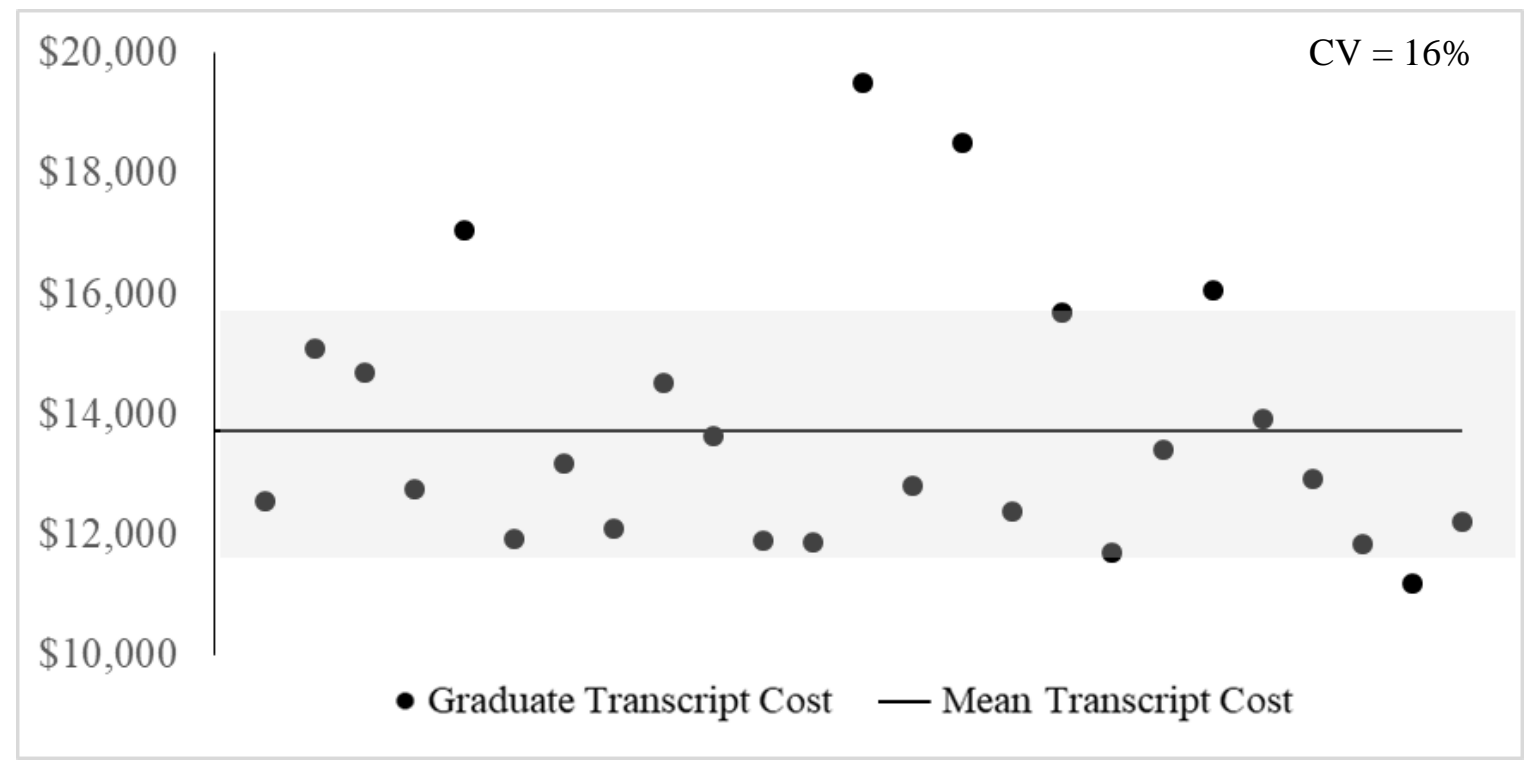

Figure 4. 2015 Transfer Business Administration Graduates’ Transcript Costs. The data points on this figure represent the estimated costs to deliver a business administration degree to 25 graduates who met the parameters of the study. 


\section{Criminal Justice Degree Costs}

The College of Applied Science and Technology houses eight academic areas including the Department of Criminal Justice Sciences, which delivers the degree selected for this study. According to the Illinois State University 2010-2012 Undergraduate Catalog:

Study in Criminal Justice involves the application of the principles of Criminal Justice and the related behavioral and social sciences to problems and issues in the field of Criminal Justice. The program focuses on the building of knowledge [and] the opportunity to gain necessary skills in the area of interviewing, program development, community organization, planning and research to function in a professional position in the field of Criminal Justice. (p. 95)

The 2010-2012 program required graduates to complete 64 major credit hours in addition to general education requirements and a sufficient number of university electives to reach a total of at least 120 hours. The major's core requirements include 34 credit hours awarded for a combination of coursework delivered by the department and credit awarded for field placement with a criminal justice related agency. In addition, students also complete 21 credit hours from a department-approved course list. From this list, students were required to select 12 hours from Group 1 (delivered by the department) and 9 hours from Group 2 (delivered by other university areas). Finally, graduates were also required to complete three specific courses in English, Sociology, and Psychology.

In fiscal 2015, 149 students were awarded a degree in Criminal Justice. From this group, 52 native students and 33 transfer students met the criteria for inclusion in the study. The cost to deliver degrees to the native students ranged from $\$ 13,391$ to $\$ 19,103$, with a mean of $\$ 15,822$ and median of $\$ 15,458$, standard deviation of $\$ 1,603$, and $10 \%$ coefficient of variation. The 
catalog cost, $\$ 15,412$, was lower than the mean transcript cost. Figure 5 illustrates the results for native students.

The average cost to deliver a bachelor's degree in criminal justice sciences to the 33 transfer students was $\$ 7,910$ and the median was $\$ 7,645$. Overall, costs ranged from $\$ 5,536$ to $\$ 14,174$, with a standard deviation of $\$ 1,578$ and $20 \%$ coefficient of variation. Figure 6 displays the results for transfer students. Finally, the study estimated costs to deliver the final years of study to upper-division native students. The costs ranged from $\$ 7,314$ to $\$ 12,632$. The mean cost for the group was $\$ 9,461$ and the median was $\$ 9,008$. The standard deviation for this group was $\$ 1,459$ and the coefficient of variation was $15 \%$.

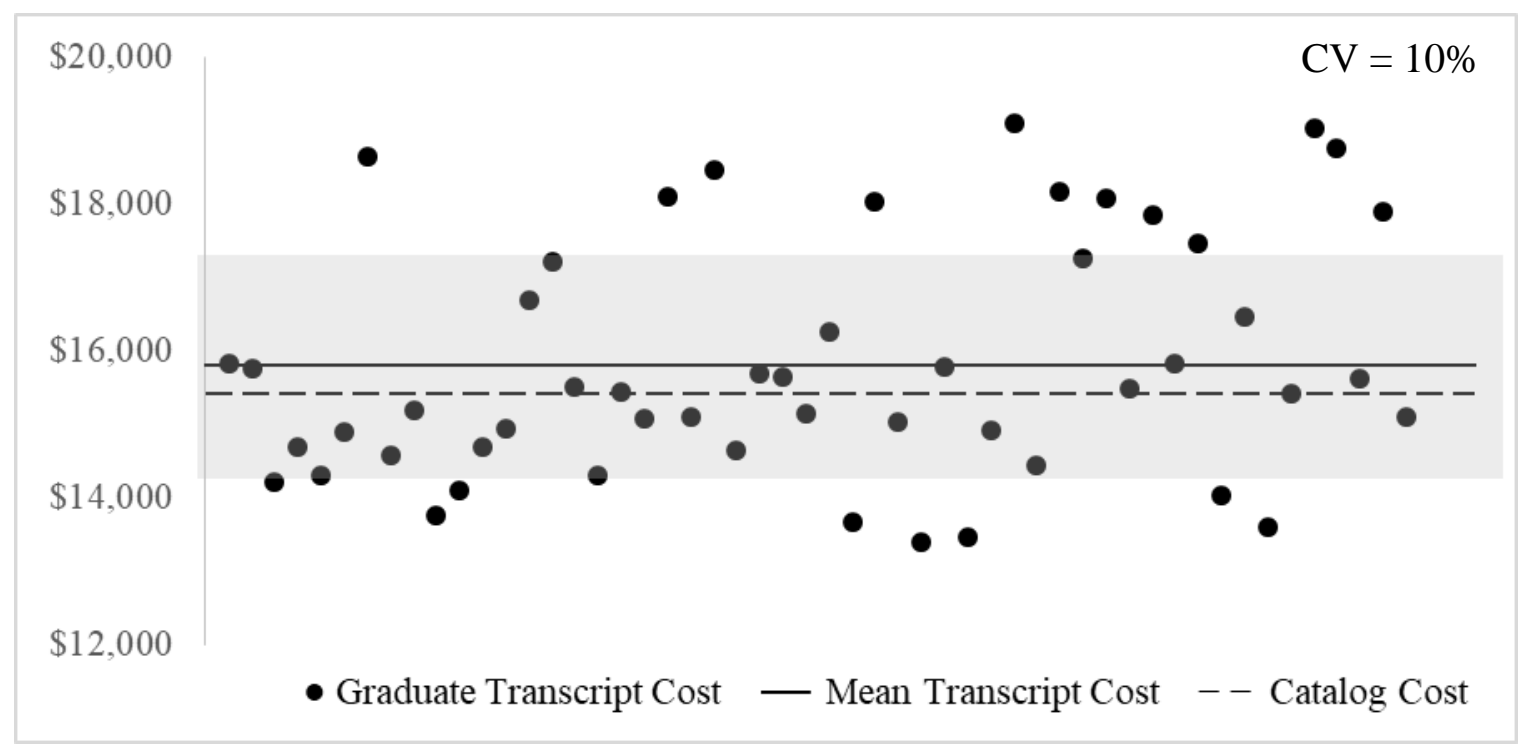

Figure 5. 2015 Native Criminal Justice Graduates’ Transcript and Catalog Costs. This figure illustrates the degree cost estimates for 52 native graduates in comparison to the catalog and mean transcript cost. The standard deviation is approximated by the shaded area. 


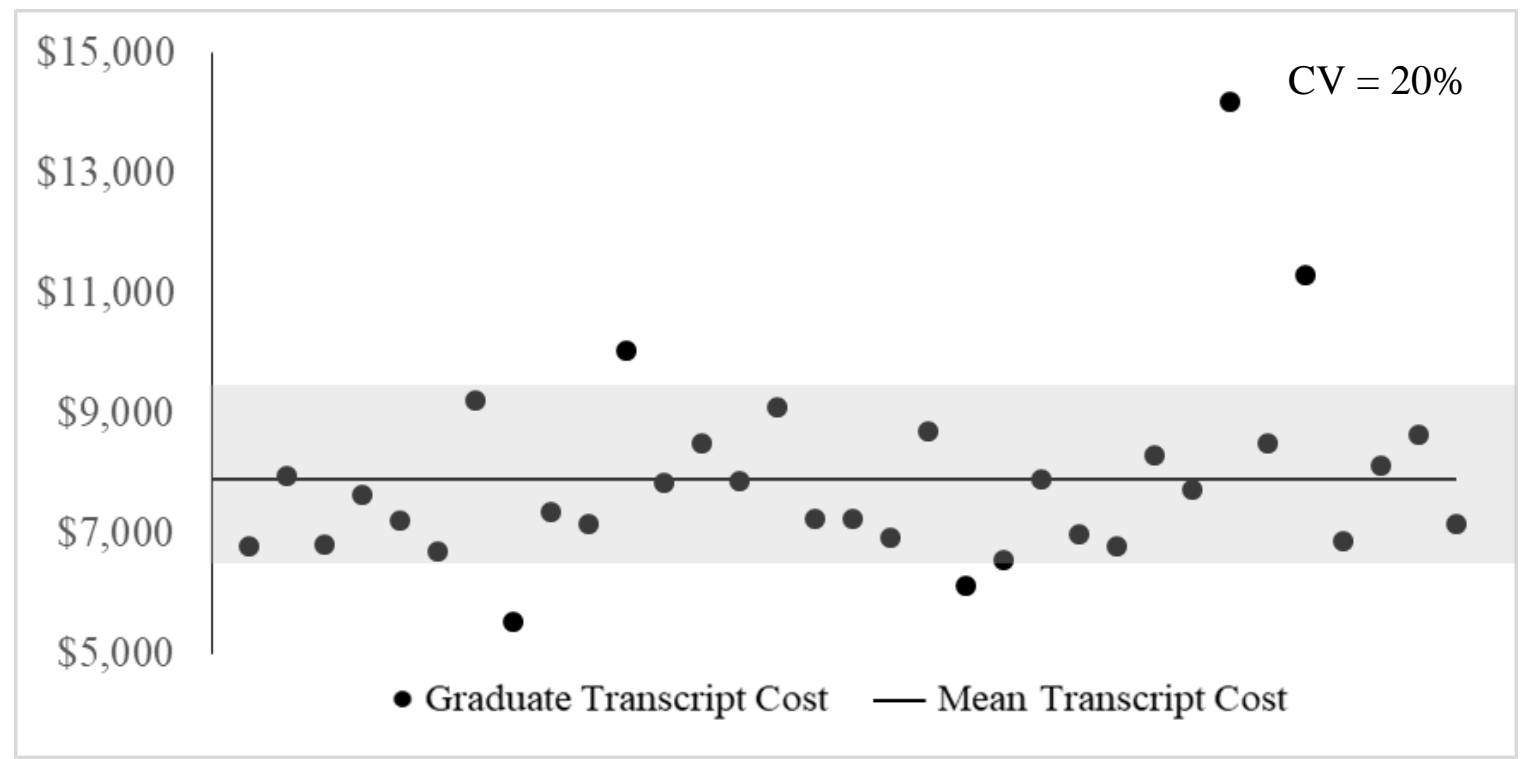

Figure 6. 2015 Transfer Criminal Justice Graduates’ Transcript Costs.

This figure displays the mean transcript cost for 33 transfer students who met study parameters. The shaded area approximates the standard deviation from the mean.

\section{Middle Level Teacher Education Degree Costs}

The College of Education houses three academic areas that deliver graduate and undergraduate instruction as well as methods coursework for secondary teacher education programs across the campus. The undergraduate degree examined in the College of Education was a bachelor's degree in education delivered by the currently named School of Teaching and Learning (TCH). This degree was awarded as a B.S. in Education that allowed graduates to teach middle school students in (a minimum of) two content areas for which the graduate received a state endorsement for proficiency. In 2015, the coursework also qualified the graduate to teach K-5 grades regardless of content area proficiency. For the sake of brevity, this manuscript refers to the degree as a Bachelor of Middle Level Teacher Education (MLE).

The 2010-12 catalog (pp. 261-262) explained that the MLE program required 40 hours of professional education delivered primarily by departments within the College of Education, plus 12 hours of student teaching. In addition to the 52 major hours, graduates were to become 
proficient in two content areas, one of which must be chosen from the core curriculum areas of mathematics, science, social sciences, or language arts. The second content area was to be selected from one of the four core curriculum areas or industrial technology, reading, physical education or health education. In total, the content areas required a minimum of forty or more hours of coursework, but some of the courses (i.e. science, math) also fulfilled general education requirements.

In fiscal year 2015, 54 students were awarded a degree in middle level education. Of those graduates, 29 native students and seven transfer students met the criteria for inclusion in the study. The mean cost to deliver the degree to the native group was $\$ 23,635$ and the median was $\$ 23,093$. The costs ranged from $\$ 19,047$ to $\$ 28,949$. The standard deviation for this group was $\$ 2,618$, and the coefficient of variation was $11 \%$. The catalog cost was estimated using the two content areas most commonly chosen by 2015 graduates, Language Arts and Math, which resulted in a cost of $\$ 22,070$. Figure 7 illustrates the native group’s cost results.

Figure 8 shows the degree costs of seven transfer students. The mean cost for this group was $\$ 16,490$ and ranged from $\$ 14,596$ to $\$ 18,174$. The median cost was $\$ 16,288$, the standard deviation was $\$ 1,266$, and the coefficient of variation was $8 \%$. The original parameters for participation in the study required a minimum of 10 students in a native or transfer group. At the time of the data request, the researcher noted that 23 of the MLE graduates were transfer students. Upon receipt of the data, it was discovered that only seven of the 23 students had completed an associate's degree prior to transferring. Due to the timing of the discovery and the workload of personnel providing the data, it was not possible to make a second request.

Finally, the study also estimated the costs to deliver the upper division credit hours to the native group. The costs for this group ranged from $\$ 11,467$ to $\$ 21,921$, with a mean of $\$ 16,603$ 
and median of $\$ 15,955$. The standard deviation of upper division costs was $\$ 2,751$ and the coefficient of variation was $17 \%$.

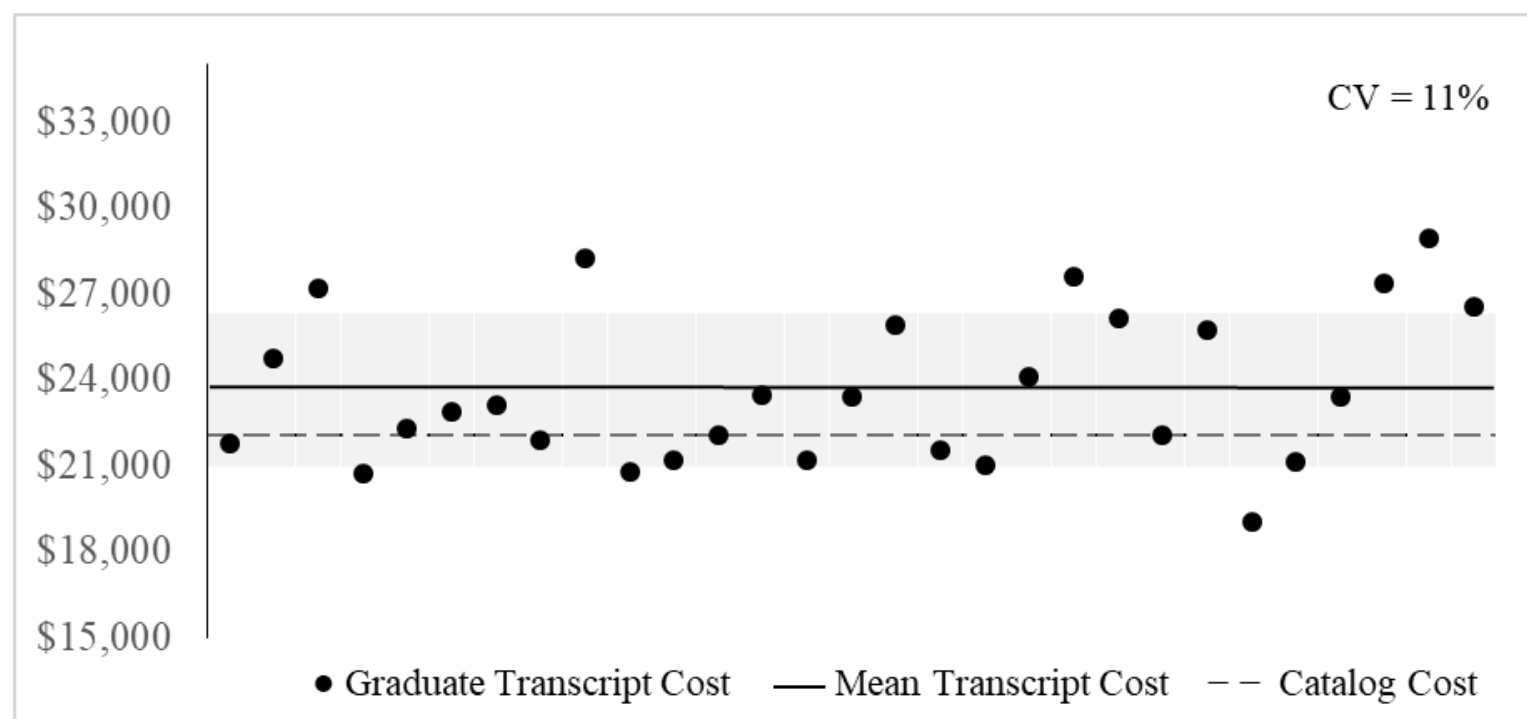

Figure 7. 2015 Native Middle Level Education Graduates’ Transcript and Catalog Costs. This figure illustrates the degree costs for 29 native graduates in comparison to the catalog and mean transcript cost. The standard deviation is approximated by the shaded area.

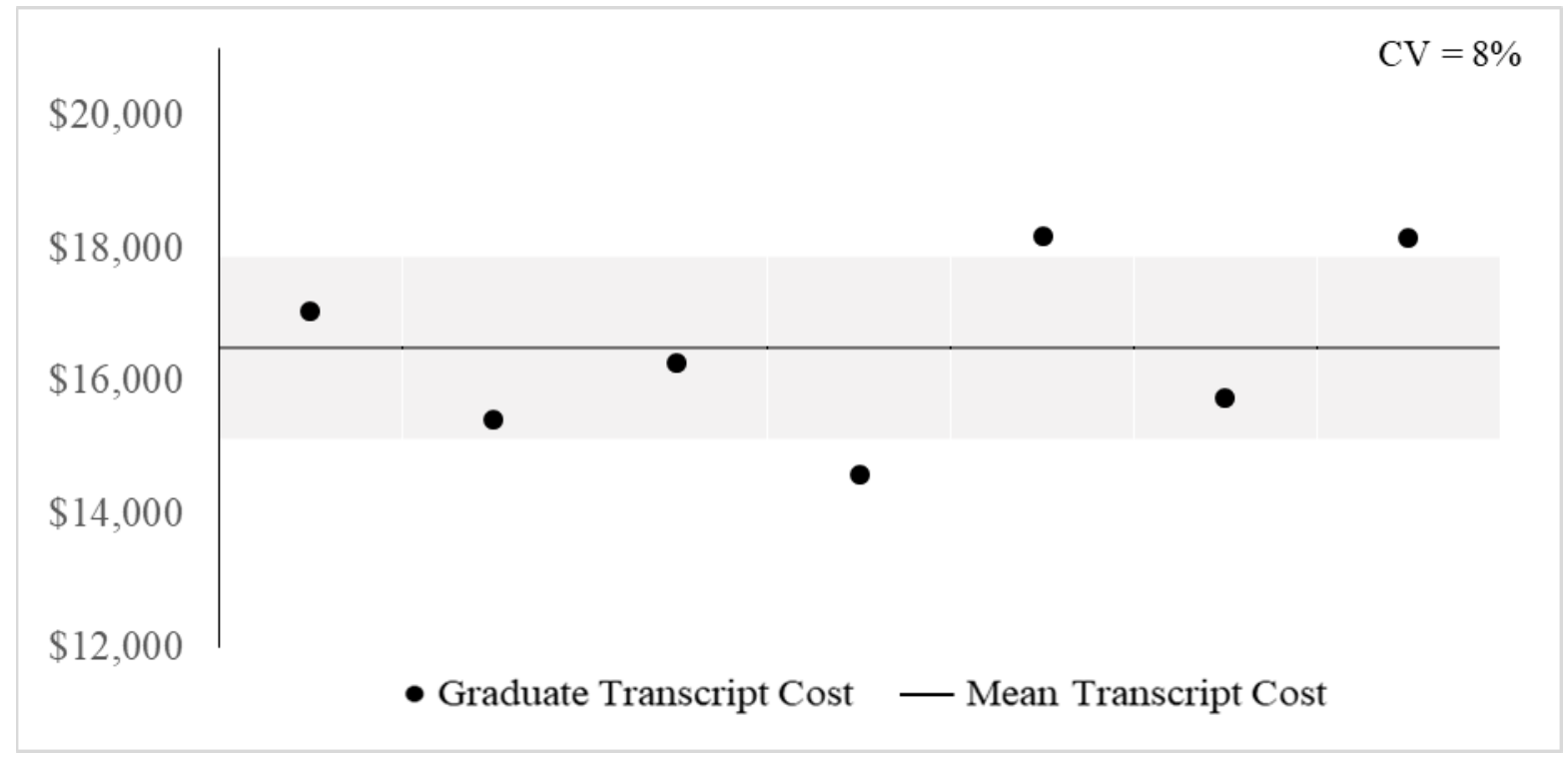

Figure 8. 2015 Transfer Middle Level Education Graduates’ Transcript Costs.

This figure displays the mean transcript cost for 7 transfer students who met study parameters. The shaded area approximates the standard deviation from the mean. 


\section{Nursing Degree Costs}

A degree in Nursing is delivered within a unique academic structure. Unlike the other five colleges, the Mennonite College of Nursing (MCN) delivers coursework only in this single academic discipline regulated by the "Illinois Nursing Act [which] serves as the legal basis for the practice of nursing in the State of Illinois” (Illinois State University, 2010-12, p. 299). The 2010-12 undergraduate catalog stated that undergraduate nursing students could follow one of two sequences leading to a bachelor’s degree in nursing (BSN).

The traditional pre-licensure BSN sequence, examined in this study, is delivered to native students and transfer students who have not previously received a registered nursing (RN) diploma through a hospital-based program or an associate's degree in nursing from a community colleges. (MCN offers two additional programs that allow registered nurses with these diplomas or associate's degrees to earn a bachelor's degree. However, students in those degree completion programs were not considered in this study.) The traditional pre-licensure BSN program requires 65 credit hours awarded for completing 15 nursing courses and one three-hour, non-nursing elective chosen from a list of current options.

In fiscal 2015, the College of Nursing awarded 187 BSN degrees. Of the group, 89 native students and 16 transfer students met the criteria for inclusion in the study. The cost to deliver the degree to native students ranged from $\$ 24,142$ to $\$ 37,348$, and averaged $\$ 26,496$, with a median cost of $\$ 25,808$. The standard deviation for the native group was $\$ 2,409$ and the coefficient of variation was $9 \%$. The catalog cost was estimated at $\$ 26,062$. A visual representation of the results is in Figure 9.

The cost to deliver a BSN to the transfer students fell within a tight range, $\$ 19,520$ to $\$ 23,544$, and averaged $\$ 20,626$, with a median cost of $\$ 19,758$. The standard deviation in costs 
was $\$ 1,488$ and the coefficient of variation was $7 \%$. Figure 10 illustrates these results. Upperdivision costs for the native students ranged from $\$ 15,336$ to $\$ 30,828$, with a mean cost of $\$ 19,957$ and median of $\$ 19,328$. The standard deviation was $\$ 2,594$ and coefficient of variation was $13 \%$.

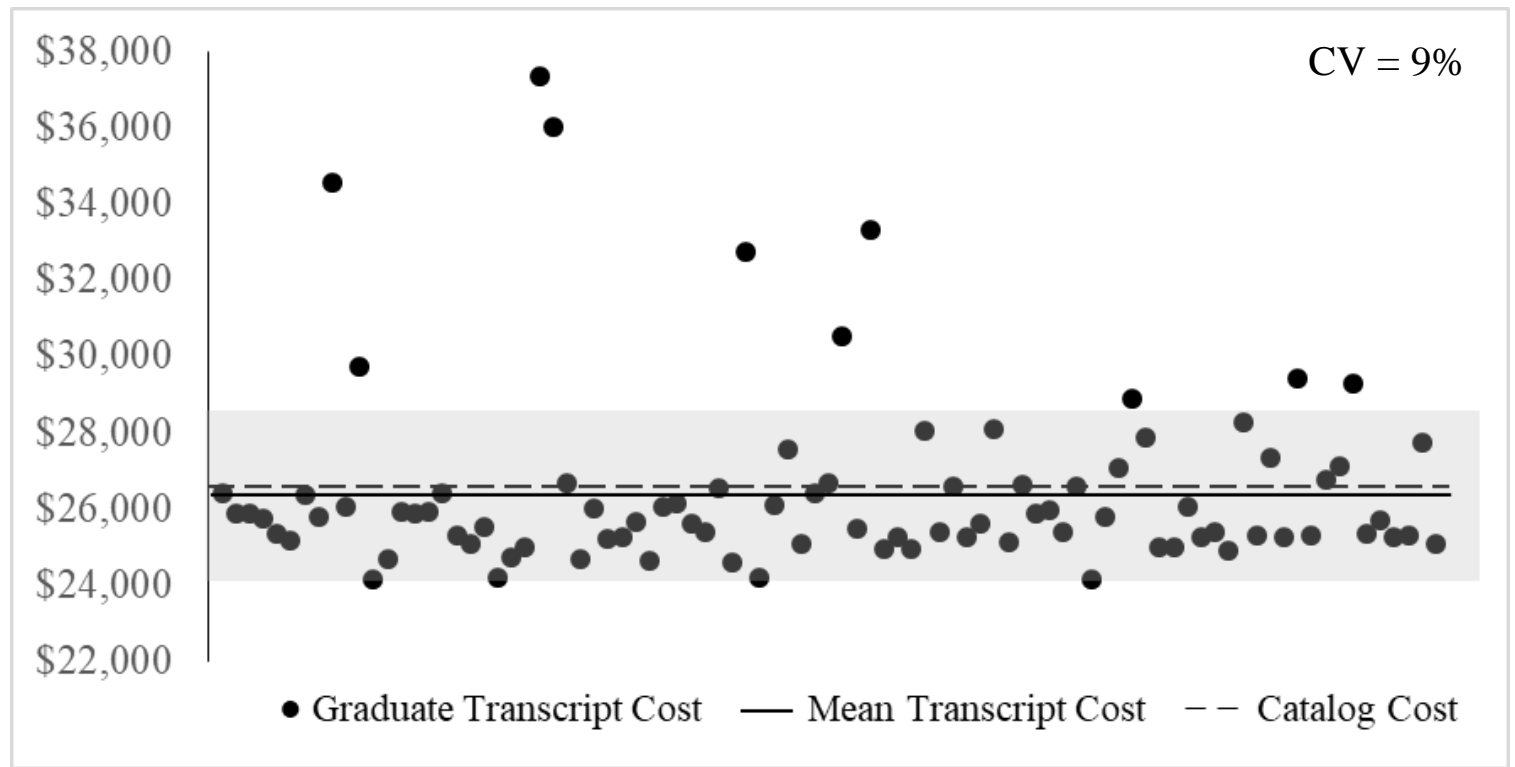

Figure 9. 2015 Native Nursing Graduates’ Transcript and Catalog Costs.

This figure illustrates the degree cost estimates for 89 native graduates in comparison to the catalog and mean transcript cost. The standard deviation is approximated by the shaded area. 


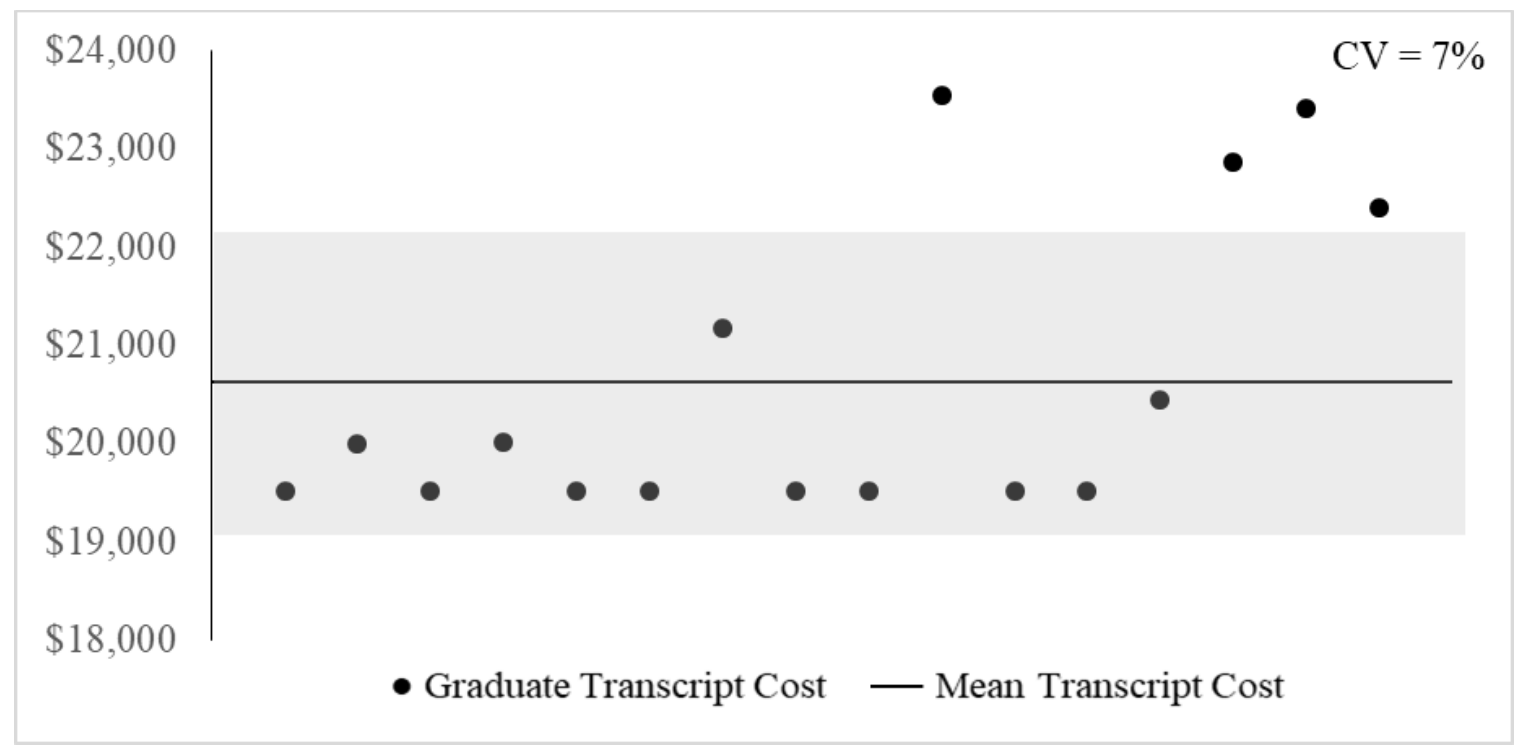

Figure 10. 2015 Transfer Nursing Graduates’ Transcript Costs.

This figure displays the mean transcript cost for 16 transfer students who met study parameters. The shaded area approximates the standard deviation from the mean.

\section{Psychology Degree Costs}

The College of Arts and Sciences is the largest college on the ISU campus, delivering degrees from 18 academic areas and includes the School of Psychology, which administers the degree selected for this study. A bachelor's degree in psychology prepares students for careers in the field in addition to providing a foundation for advanced study through courses focusing on research methods, statistical applications, and foundations of psychology. The 2010-12 Undergraduate catalog stated that the degree required students to complete a total of 58 major hours which included 41 hours within the School of Psychology. Students also completed a capstone course, apprenticeship, internship, or advanced research project in the final year (Illinois State University, 2010-12, p. 222).

Psychology’s undergraduate program is fairly large and awarded 144 bachelor's degrees in fiscal 2015. Seventy-seven native students met the criteria for inclusion in the study in addition to 21 transfer students. The transcript costs of the native student group ranged from 
$\$ 13,667$ to $\$ 27,813$, with a mean of $\$ 17,265$, median of $\$ 16,926$, and standard deviation and coefficient of variation of $\$ 2,048$ and $12 \%$ respectively. In comparison, the catalog cost to deliver the degree was estimated at $\$ 18,043$, higher than the mean transcript cost. The results are illustrated by Figure 11 .

The range of costs to deliver the same degree to transfer students was from $\$ 7,392$ to $\$ 11,029$, with a mean of $\$ 9,201$, median cost of $\$ 9,284$, which produced a standard deviation of $\$ 959$ and 10\% coefficient of variation. The cost results for this transfer student group are shown in Figure 12. When the native group moved into upper division study, the range of costs were from $\$ 7,978$ to $\$ 21,216$, the mean cost of completion was $\$ 10,911$, with a median cost of $\$ 10,618$, standard deviation of $\$ 1,932$, and coefficient of variation of $18 \%$.

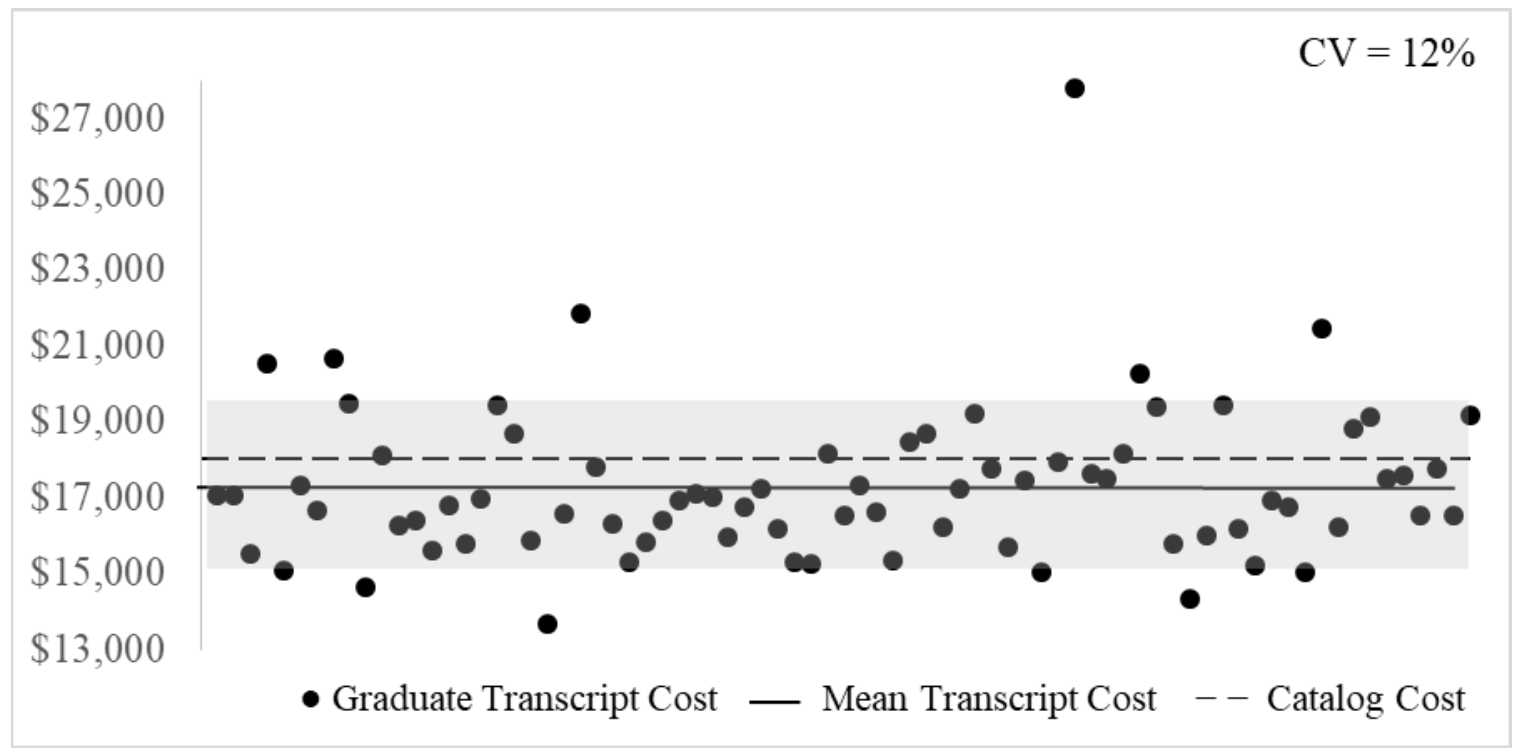

Figure 11. 2015 Native Psychology Graduates’ Transcript and Catalog Costs. This figure illustrates the degree cost estimates for 77 native graduates in comparison to the catalog and mean transcript cost. The standard deviation is approximated by the shaded area. 


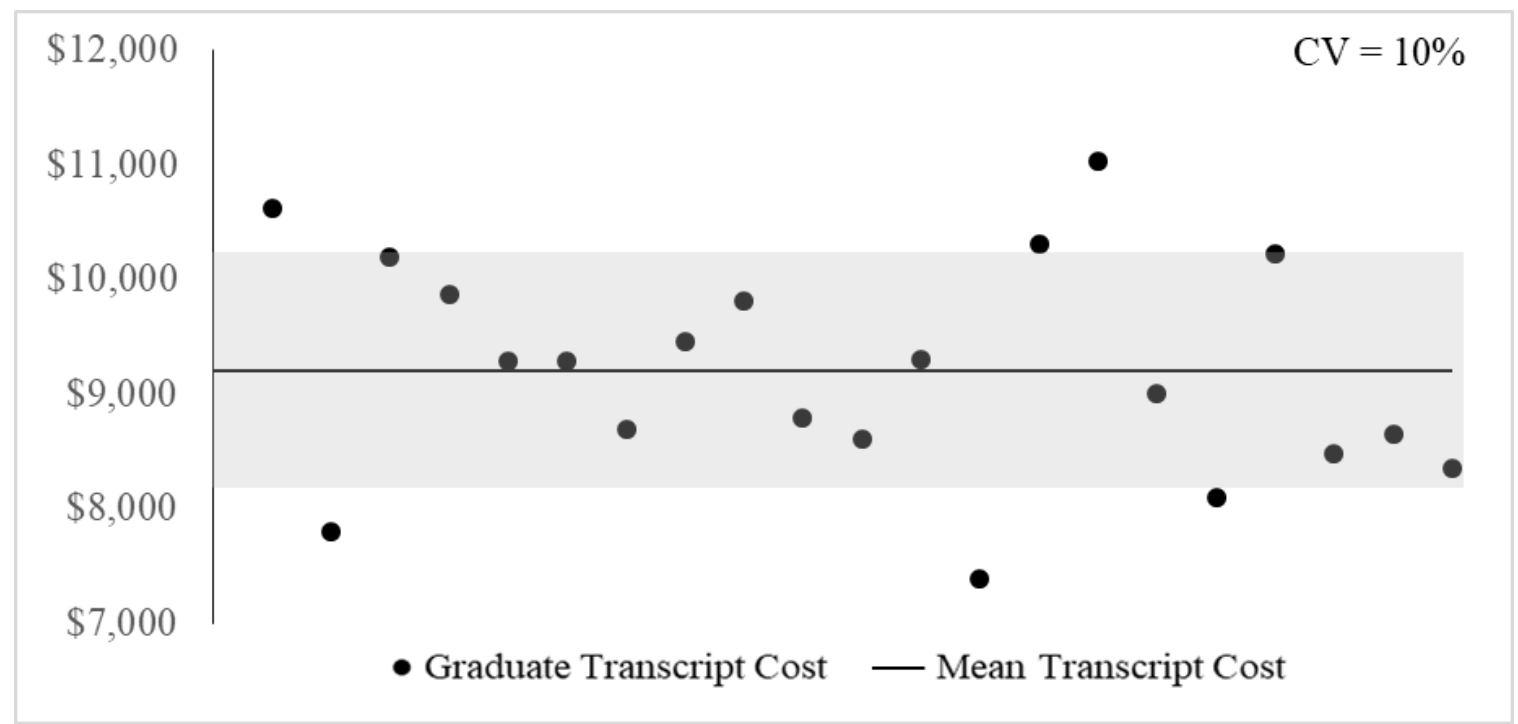

Figure 12. 2015 Transfer Psychology Graduates’ Transcript Costs.

This figure displays the mean transcript cost for 21 transfer students who met study parameters. The shaded area approximates the standard deviation from the mean.

\section{Qualitative Stage: Administrator Perceptions}

Original plans for the qualitative stage of this study called for a focus group meeting that would allow administrators from the departments or schools overseeing the six degrees to share perceptions of the cost results. However, only two of the six administrators were available and, as a result, the discussions were held via individual phone interviews. Prior to the discussions, each administrator received the costs results of all six degrees under study, in addition to the fiscal year 2015 ADUCS costs per credit hour for each of the six academic areas and a description of the expense categories provided by the IBHE. This information is provided in Appendices A and B.

In addition to the controllable purview cost results discussed in the previous section (range, mean, median, standard variation and CV for native, transfer and upper-division native groups), the administrators also were given cost results for the manageable and fully allocated purviews. However, as the conversations proceeded, the participants focused mainly on the estimated cost to deliver a degree to native students. In addition, neither participant was 
particularly interested in the comparing the results from differing cost purviews (controllable, manageable, and fully allocated). Instead, they focused on the controllable purview, the level at which they had more control over expenditures.

The first interview question asked for the administrators' initial thoughts on the cost estimates and descriptive data. In response, the administrators asked questions of their own in order to better understand the data and expressed the need for benchmarks and comparison data. A walk-through of the data helped to make them comfortable with the results, but both interviewees expressed the need for context to be included with the figures. They framed this by saying, "I can see this pulled out at a provost retreat. They will not have the report, just the tables. ... Anything to add enough to the definitions or something to make it so somebody can pick it up and understand is a benefit.... Without the definitions they have to rely on someone to tell them about it and we wouldn't want any of the data misconstrued.” As an example, one participant remarked that seeing the data for all six degrees on the same page made it "hard to not compare results to other departments.” Noting the relatively low average cost for the degree offered by the administrator's department, this administrator went on to say that, presented this way, the data implies we are "using those tuition dollars wisely [however] I think there needs to be some benchmark for reasonable costs per credit hours across units.”

The two administrators also expressed concern that the cost estimates, based only on department expenditures, did not reflect the true value of the instruction and guidance provided to the students. For example, the participants remarked that they have staff who "regularly meet with students" to check their progress toward the degree and who try to ensure that "classes are full and available when needed.” In fact, both administrators supported a fairly “lock-step program" that allows little time for "meandering" through the curriculum on the way to degree 
completion. They felt that these 'value-added' components were worth more than the dollar amount of salaries paid to the faculty and staff who provide them.

A second interview question asked for administrators' perceptions of the accuracy of the data and of what other data might need to be collected in order to obtain more accurate results. Both administrators seemed to be comfortable with the costs per credit hour reported by the university to the IBHE and with the researcher's approach to estimating the cost to deliver a Bachelor’s degree. However, both expressed concern about the Faculty Activity Analysis (FAA), a report that underlies faculty salary distribution (as discussed in Chapter Three). Both felt that the person who completes the report for their own area does their best. They questioned though, whether some departments take the report more seriously than others, whether it is "made a priority" or "just another thing on people’s plates." They also stated that the departments have little understanding of and receive no feedback on the report, commenting that "people need to see the utility in things.”

In addition, the participants expressed concern about the value that is not reported in the FAA. These concerns were reflected in the following comments:

- 'It doesn’t count the service work that faculty do. Those service burdens might be tremendously variable across time. This is important work to increase the reputation of the department and university....”

- "On the FAA, all we tell you is how much time faculty are given to do research. We don't tell you the product of that work. We frequently involve students in that work which is a tremendous value....”

- "You also don't see in the FAA how we use our advising model to keep our students on track. The FAA doesn't show the value the advisors provide....” 
Finally, in regard to data that might supplement the study’s results, one participant talked about another cost approach, noting that “students don’t come here to generate credit hours, and they don't come here for general education courses, they come here to have a major... It seems like using dollars per credit hour is not unreasonable. But another way is to look at it is dollars spent per major." Suggesting a cohort perspective, this administrator was interested in the cost to deliver the program's coursework to non-majors who either took the classes to satisfy general education requirements or later chose a different major, suggesting that those costs might be subtracted from or presented as a comparison to the cost to deliver the degree to those who major in the field.

A third question asked the administrators how they thought the cost estimates might be used. On this topic, the administrators were united. Both felt that situating the numbers in context would drive the direction of usage. For example, one administrator remarked that higher costs per credit hour might erroneously be credited to higher faculty salaries; "We would have to be careful of how it's interpreted, because if you look at the cost in UD [upper division], you might think our faculty might not need a raise if you don’t understand how [the program] works...." In this case, the administrator's program includes smaller classes in the last two years of study (due to the difficulty of the subject matter), which drives up the cost per credit hour, faculty salary notwithstanding. "Our job is that they truly understand that [the program’s curriculum]; we have to make it a priority of ours so they can make informed decisions when doing the finances.”

They also both felt that higher cost programs would receive greater scrutiny. As one of the administrators put it, "the obvious and easy answer is that people will look at higher cost areas.... There probably is a good reason for higher costs - mentoring painters isn’t done 30 students at a time. Of course the areas with lower costs are subsidizing those higher cost areas.... 
I want the world to have art and I want to have good art [but] without context and having that conversation, people will say lower-cost areas are a much better value”.

As to how university-level administration might use the figures, the participants expressed confidence in their administrator's ability to understand and convey the appropriate message. As one of the interviewees (not an art administrator) observed, "Our dean would have a fairly nuanced vision of the different training models you have to have to make things work. For example, art costs more because we want to have great artists in the world and you can't mass produce that. It has to be small group and one on one.” However, one participant thought the university should put these data in the context of public funding: "State funding is declining and it's declining everywhere so the question is, as we become more like privates ... how do we do business? If you look at the cost per student, in spite of those dwindling state funds, and this university in particular, they give us so little money, it's practically private and, in spite of that, tuition here is dramatically less than any private university really. I think there is tremendous value in a place like this.”

The interviews provided validation to this researcher that estimating the cost to deliver a degree is a useful tool. However, to make the data clear to readers, they suggested that the results should be accompanied by supplemental data or benchmarks and a narrative explaining each program and the results; the numbers alone are insufficient for decision makers. For example, programs with intense clinical hours might be more expensive to supervise. In this case, the narrative would explain the purpose of clinical instruction and the need for a small number of students supervised by each faculty member (to ensure better outcomes). In addition to this primary finding (the need for comparative data and clarifying narration), the participants pointed out two additional opportunities for improvement. First, the cost estimates, by nature, do not 
show value of activities such as research and administrative work. Second, the FAA, as a major component of PRPA's cost per credit hour calculations, may not be well understood by the departments. An explanation of its utility and feedback on the submitted FAA reports might help mitigate this concern and help academic units to better categorize the work and related expenses.

\section{Summary of Findings}

The quantitative and qualitative stages of this study resulted in five major findings. First, the cost to deliver a degree varied widely across program areas (as indicated in Tables 15 and 16) and, as the figures show in Table 17, the costs also vary across students completing the same degree. Second, in five of six degrees, the estimated catalog cost was lower than the mean transcript cost. Third, in four of the six degrees, the cost to deliver the final years of study to transfer students is less than the cost to deliver similar instruction to native upper division students. The final takeaway is that the cost estimates alone do not tell the whole story of the cost to deliver a bachelor's degree. The next chapter speculates on the underlying causes and implications of these findings, and concludes with suggestions for further research.

Table 17

Cost Results: Controllable Purview Across Majors

\begin{tabular}{lccccc}
\hline & $\begin{array}{c}\text { Native Student } \\
\text { Transcript Cost } \\
\text { Range }\end{array}$ & $\begin{array}{c}\text { Native Student } \\
\text { Transcript Cost } \\
\text { Mean }\end{array}$ & $\begin{array}{c}\text { Transfer } \\
\text { Catalog Cost }\end{array}$ & $\begin{array}{c}\text { Native Student } \\
\text { Trandent } \\
\text { Cost Mean }\end{array}$ & $\begin{array}{c}\text { Upper Division } \\
\text { Transcript Cost } \\
\text { Mean }\end{array}$ \\
\hline Art & $\$ 25,541-37,048$ & $\$ 29,919$ & $\$ 29,267$ & $\$ 21,322$ & $\$ 19,979$ \\
Business Administration & $\$ 18,651-26,560$ & $\$ 21,683$ & $\$ 20,889$ & $\$ 13,736$ & $\$ 14,914$ \\
Criminal Justice & $\$ 13,391-19,103$ & $\$ 15,822$ & $\$ 15,412$ & $\$ 7,910$ & $\$ 9,461$ \\
$\begin{array}{l}\text { Middle Level Teacher } \\
\text { Education }\end{array}$ & $\$ 19,046-28,949$ & $\$ 23,635$ & $\$ 22,070$ & $\$ 16,490$ & $\$ 16,603$ \\
Nursing & $\$ 24,142-37,348$ & $\$ 26,496$ & $\$ 26,062$ & $\$ 20,626$ & $\$ 19,957$ \\
Psychology & $\$ 13,667-27,813$ & $\$ 17,265$ & $\$ 18,043$ & $\$ 9,201$ & $\$ 10,911$ \\
\hline
\end{tabular}




\section{CHAPTER V: IMPLICATIONS, RECOMMENDATIONS, AND FUTURE RESEARCH}

This manuscript began in Chapter One with an overview of higher education's evolution in regard to funding and oversight. Emerging from the overview are four long-term trends that continue today and inform this final chapter. One trend is that higher education, once largely the purview of the wealthy, has become increasingly available to the masses. Another is that the states’ investment in higher education, once flush with funding during the "golden era," has decreased and, in many states, has not fully recovered from the recent great recession of 2008. A third trend is that states, whose legislators previously acted in a hands-off manner, are now much more interested in how their funds are being used by higher education institutions and whether they (and students) are getting a good return for their investment. Last, although higher education still provides a path for social mobility, students are expected to pay for a substantial portion of their education. Tuition is an important revenue source for higher education, one that grows each year and, in fact, now outpaces the states' investment (SHEF, 2018).

The four trends have combined to create an environment conducive to the "more and cheaper” goal of the completion agenda that seeks less expensive education options for more students. Many states have implemented programs and incentives in support of the completion agenda. Illinois, the home state of this study, launched its own version in 2008: The Illinois Public Agenda for College and Career Success. The vision of the Illinois program is to "provide effective and quality education for all people... where all residents have affordable access to high quality educational opportunities that prepare them for the jobs of the present and the future" (Illinois Public Agenda for Career and College Success, 2009, p. 3), and its top two stated goals are to increase educational attainment and ensure college affordability (p. 1).

The Illinois program was bold, but it was announced in the middle of the great recession 
from which the state has still not completely recovered. The program's five-year report shows that some progress has been made (Illinois Board of Higher Education, 2014), but its success has been impeded by the state's fiscal troubles. Those troubles began much earlier than the recent recession and are led by the challenge of unfunded pension liabilities. In fact, "public pensions in Illinois have suffered funding problems virtually from the start” (Brown \& Dye, 2018, p. 6).

Over time, pension liabilities and other fiscal challenges have created deep structural deficits that contributed to Illinois’ history of diverting appropriation money from higher education operations to other state programs in attempts to fill the gap between revenue and expenses. In fact, the Illinois Board of Higher Education recently reported that total funding for higher education operations, when adjusted for inflation, is still below 2002 levels (Robinson, 2019) despite a fiscal year 2020 budget that provides a “4.8 percent funding bump (\$53 million) for state universities” (IBHE, 2019). As is typical, when state investment falls, tuition rises and Illinois is no exception. In 2017, tuition charged by Illinois institutions accounted for $62 \%$ of combined tuition and state appropriation revenue (Román, 2019). However, that source is in peril because enrollment has been declining. "Between 2009 and 2018, total enrollment in [Illinois] public institutions declined by over 20 percent ... [and is] "still 13 percent below FY1999 levels" (Román, 2019).

\section{Causes and Implications}

Falling state investment and decreased enrollment (resulting in lower overall tuition revenue) have combined to create a difficult situation for Illinois universities and neither issue shows promise of resolving anytime soon. History shows that universities often take drastic measures when under financial duress. For example, during the 2015-2017 budget impasse Illinois universities dipped into reserves, implemented hiring freezes, and made deep cuts to 
operating costs (Woodhouse, 2016); one university was forced to declare financial exigency. However, there are other approaches that take a longer view. One option, as Kirshstein and Wellman (2012) suggested, is for universities to worry less about how much revenue is available and look more closely at how that money is spent. A potential way to do this is by examining the cost to deliver degrees, the topic of this study. Five approaches to estimating undergraduate degree costs were defined by Johnson (2009), who provided examples using discipline-level data that was centrally generated by the Florida Board of Governors. Two of those approaches, catalog and transcript methods, were used by Romano et al. (2011) to estimate completion costs at a SUNY community college with data generated within the college itself. Other pioneers in this field suggested additional perspectives of degree costs (Bailey et al., 2015; Manning \& Crosta, 2014; Belfield et al., 2014) at the community college level, but no one had further explored university-level degree costs. Attempting to move the field forward, this study estimates catalog and transcript costs at the degree level (more granular that discipline level) using data prepared within Illinois State University. The results show that the approach is viable (for Illinois universities), as illustrated by the findings in Chapter Four. The next section illustrates the causes and implications of this study's five major findings.

\section{Cost Variations Between and Within Degree Areas}

A primary finding of this study was that costs vary across and within degrees. This study did not delve deeply into the reasons for the variation across degrees, as this was not the primary purpose of the study. However, the variation in cost across degrees was also a finding of Johnson (2009), who posited that course-taking patterns of students was a primary factor. A National Bureau of Economic Research (NBER) working paper entitled, "Why is Math Cheaper than English? Understanding Cost Differences in Higher Education” (Hemelt, Stange, Furquim, 
Simon, \& Sawyer, 2018) delved further into the possible reasons for cost variation across campus. The working paper's analysis was based on data from the Delaware Cost Study and compares the costs per student-credit-hour (SCH) of several disciplines. Figure 13 is sourced from the NBER paper and compares the instructional costs per credit hour of different disciplines commonly offered by a university. In comparison, Figure 14 represents the mean costs per credit hour of academic disciplines on the Illinois State campus. The data for Figure 14 was compiled from the PRPA cost data originally provided for this study. Although the two tables are not exact comparisons, the academic disciplines do appear to be ordered in a very similar manner from highest cost to lowest. What this seems to indicate is that variations in cost of academic disciplines offered by the Illinois State campus are similar to cost variations nationwide.

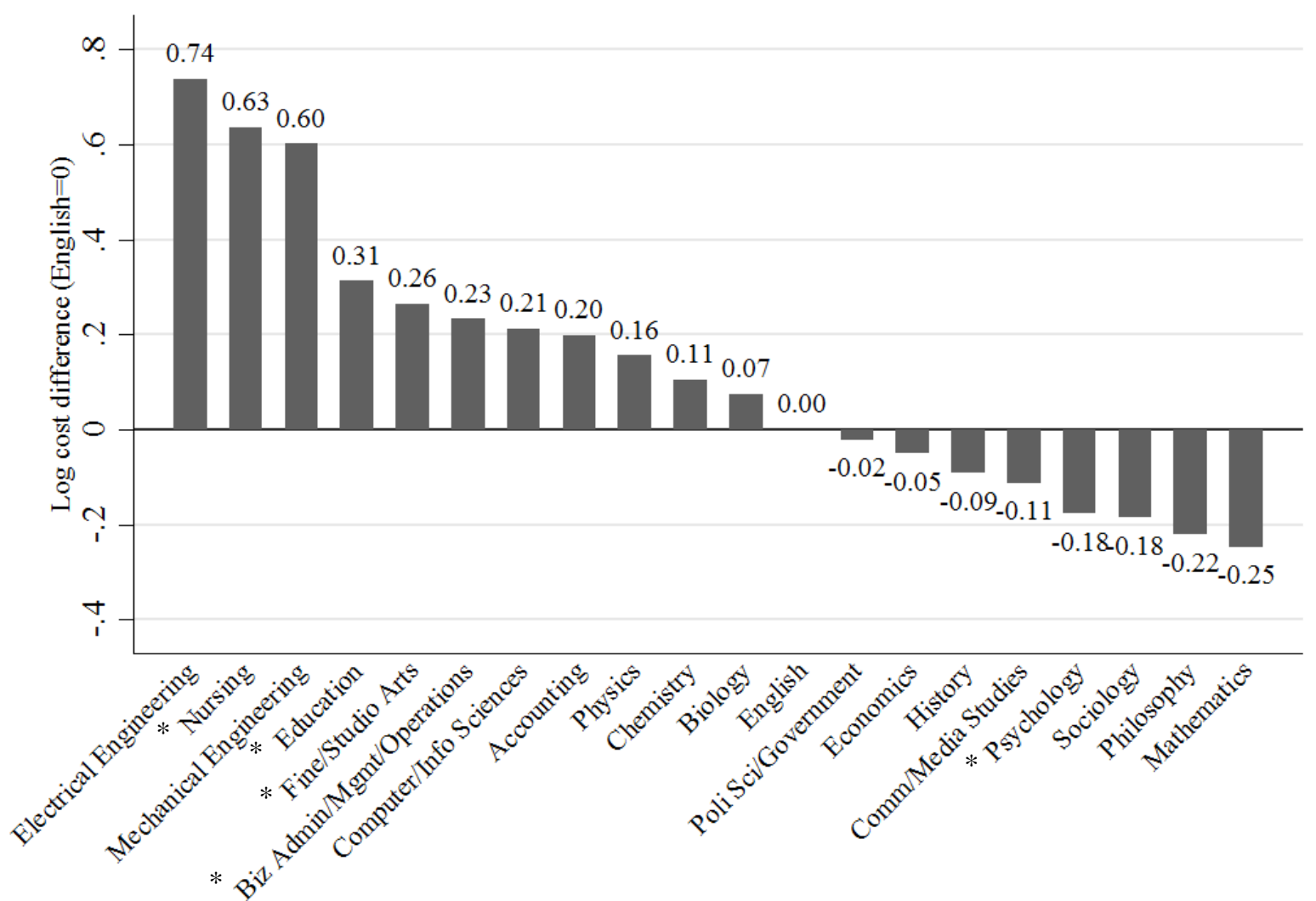

Figure 13. NBER Analysis: Baseline Cross-Field Log Cost Differences, Relative to English. * Indicates five of the six degrees examined; the NBER analysis did not include criminal justice. Source: NBER Working Paper 25314, Page 40, Figure 4 (Hemelt et al., November 2018) 


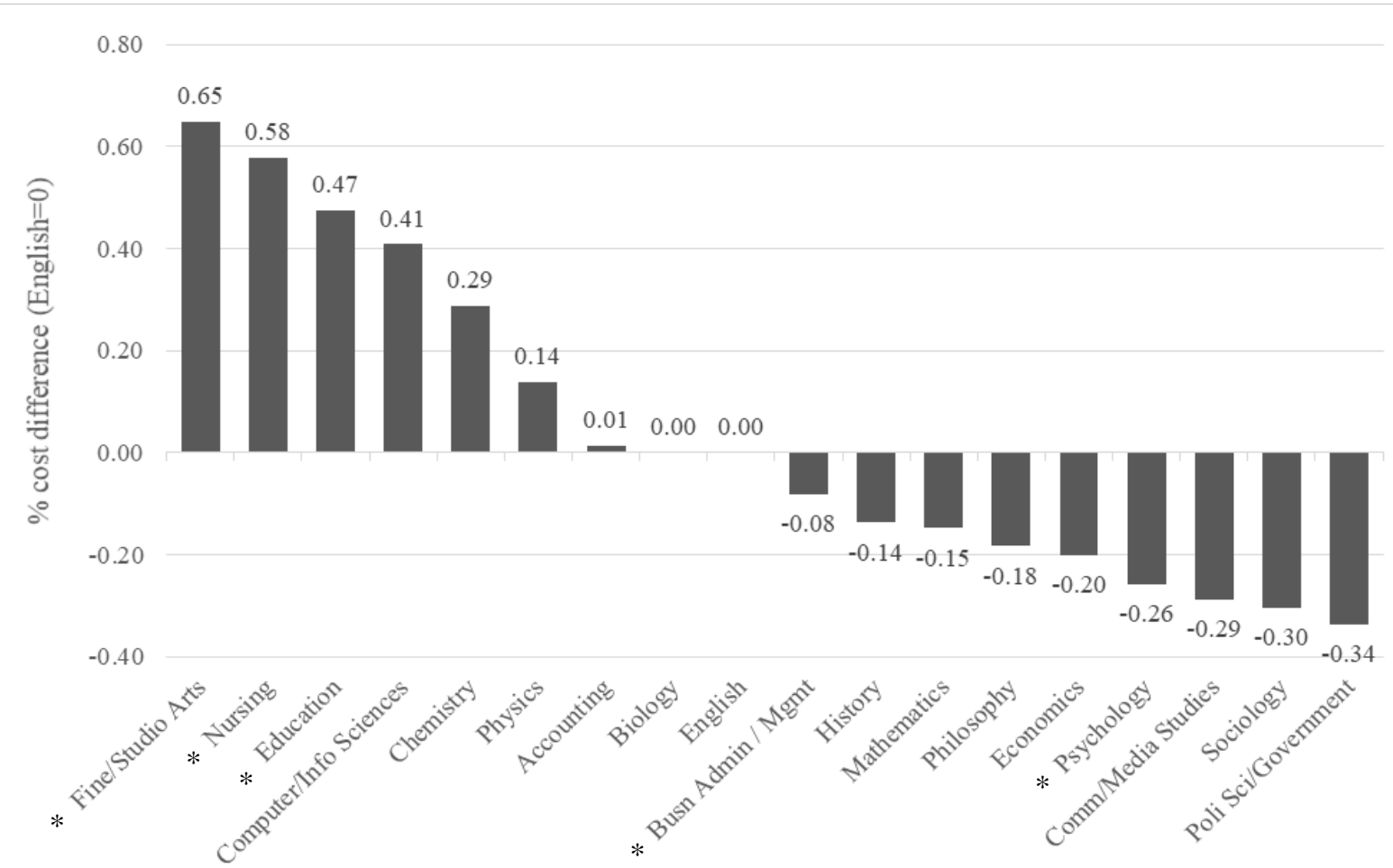

Figure 14. ADUCS Analysis: Cross-Field Percentage Cost Differences, Relative to English.

* Indicates five of the six degrees examined; the NBER analysis did not include criminal justice. Source: Mean costs per credit hour of each discipline as calculated from the quantitative data.

The NBER paper's authors found five reasons why costs might vary across academic disciplines. Two reasons relate to the costs associated with online instruction and with disciplines in science, technology, engineering, and mathematics (STEM); neither is examined in this study. However, the other three reasons are relevant here. First, the authors suggested that costs per credit hour are generally higher in programs “where graduates earn more and in pre-professional programs” (p.2). They also noted two other reasons: “differences in class size and ... faculty pay" as well as the "shift in faculty composition toward contingent faculty” (p. 2). The authors' findings help to explain, for example, why this study’s estimate of mean transcript costs to deliver degrees in Nursing and Art are higher than the other four disciplines. Nursing is a preprofessional program delivering instruction in a highly regulated environment. The art program’s 
cost to deliver instruction might be higher due to using a studio approach where only a handful of students are in each upper-division class. The NBER paper's finding may also help to explain why the psychology and criminal justice degrees have lower costs. Both disciplines offer general education courses which, by increasing the number of students, help to bring down the program's overall costs per credit hour.

As to cost variance within degrees, the results in Chapter Four revealed three primary drivers: the number of credit hours completed, the timing of coursework completion, and the concept of student choice. Of the 298 native students included in this study, the average native student completed 125 ISU credit hours, five hours more than the number required by the 20102012 catalog (Illinois State University, 2010, p. 49). Although the average number of completed credit hours was only slightly above the university graduation requirement, this figure masks considerable variation within degree areas. The native student group in business administration (BA) provides examples of the variation.

The BA group was typical of the study’s overall 298 native students. Averaging 124 completed ISU credit hours, the 37 native BA students fell naturally into three groups. Twelve students finished with 120 or fewer ISU hours (mean cost of \$20,196), another 12 completed between 120 and 125 hours (mean \$21,413), and the final 13 students completed 125 or more ISU hours (mean \$23,304). The mean cost to deliver a degree to the group with more than 125 ISU hours is $14 \%$ higher than the BA degree’s overall mean $(\$ 21,683)$ and supports the finding that ISU credit hours in excess of those required for graduation generally results in a higher degree cost within the same degree.

The group of 13 BA students with more than 125 hours appeared to include graduates who completed a minor or second major, repeated courses, and explored different disciplines. 
Although the transcripts did not indicate whether minors or second majors had been earned, a manual review of the transcripts showed that one student in the group earned the number of credits required for a minor in accounting, eight earned the number of credits required for a minor in organizational leadership, and two students completed enough hours to possibly be awarded second majors in economics and finance. In addition, 20 of the 37 native students in BA repeated a total of 48 courses, equivalent to 155 credit hours, primarily in accounting (65\%), and math and finance (16\% each). The data provided by the university did not include reasons for the repetition, but it is possible that the students failed or earned low grades in courses serving as prerequisites to major courses.

On the other side of the spectrum, 12 native BA students were very efficient and completed exactly or fewer than the 120 credit hours necessary to receive the degree. Again, typical of the study's larger native group, the graduates in this 12-student group partially fulfilled degree requirements with credit awarded for work outside of the university such as military experience or coursework, proficiency exams, or community college and other (than Illinois State) university courses. Of course, outside credits, if accepted by the university, lower the number of ISU credits required and the subsequent degree costs. However, the study's data revealed that the average native BA student was awarded 4.14 hours of outside credit, while the "efficient” group was awarded 4.67 credit hours. This is a very small difference and seemed to indicate that another factor was at work. However, nothing else of significance was found in the data. It simply appeared that the "efficient" students did not waver far from the plan of study and, even though three of these students repeated a course, outside credit was utilized to reach the 120-hour graduation requirement.

The second driver of cost variations within degrees is the timing of coursework 
completion. As mentioned in Chapter Three, costs per credit hour are divided into lower- and upper-division costs. An examination of the ADUCS data shows that upper-division courses always cost more than lower-division courses within the same academic area. This also means that delivering the final years of study is more expensive than the first few years. In addition, if a student continues to take courses past the 120 credit hours required for a degree, the total degree cost will increase at a faster rate because of the higher cost of upper-division coursework.

This result (that upper-division credit hours cost more to deliver than lower-division) is consistent regardless of the method used to divide upper-division from lower-division courses. However, it is worth noting that the method is not consistent across all cost studies. For example, the IBHE method of division (used in this study and in Johnson's Florida Study) is based upon the student's total cumulative hours at the time of course completion. Coursework completed by a student with less than 60 hours is associated with lower-division costs for the coursework. If the student has completed more than 60 hours, the coursework is associated with upper-division costs. This means that a 100-level general education course taken by a junior or senior is delivered at the upper-division cost, which is always higher than for a freshmen taking the same course and section. It also means that a 200-level course taken by a sophomore with less than 60 hours is delivered at lower-division cost, rather than the upper-division cost to deliver the same course to the juniors in the class. Dividing costs by accumulated credit hours can therefore be a little muddled. However, this is not the only method of division that can become muddy.

Other studies (i.e. The Delaware Cost Study) divide lower- and upper-division costs by course level. In fact, the ISU catalog (Illinois State University, 2010, p. 308) lists 100-level courses as primarily for freshmen and sophomores, 200 level for juniors and seniors having completed at least 45 credit hours, and 300 level as advanced undergraduate courses for students 
having completed at least 75 credit hours. In summary, 100-level courses would be considered lower division and 200- and 300-level courses would be considered upper division. This method muddies the waters twice. Assuming that full-time students complete 15 credit hours per semester, it seems to guarantee confusion about a student's class rank and which courses they are allowed to take (i.e. some, but not all sophomores, usually considered underclassmen, are allowed to take 200-level courses associated with upper-division costs). In addition, there is no guarantee that departments follow the course numbering listed in the catalog. The 200-level courses (delivered at upper-division cost) might either be intended for sophomores or for juniors and seniors. This means that a 200-level course comprised solely of sophomores would be associated with upper-division costs although many of the students may not have completed 45 credit hours.

Either method, division by cumulative hours earned by students at the time of course completion or by assigned course number, will result in a crossover of costs. Unfortunately, the data available for this study at Illinois State University did not provide enough detail to conduct a comparison or conversion; the costs per credit hour were already assigned on the basis of credit hours accumulated by students as prescribed by the IBHE. However, the provided data was sufficiently detailed to conclude that the timing of course completion does indeed effect overall degree costs.

For example, the transcript data used in this study revealed that general education courses were primarily delivered to native students during lower-division study. Based on credit hours alone (as per the University catalog), general education accounts for 42 (35\%) of the total credits (120) required for a bachelor's degree at Illinois State and, if taken during the first two years of study before students have accumulated 60 hours of course work, would lower the cost to deliver 
degrees. However, a significant number of the 298 native graduates completed more than the required 42 hours after they had reached the 60-hour mark, resulting in delivery at the upperdivision cost levels and mitigating the capacity of general education coursework to hold down the cost to deliver their degrees. For example, 19 of the 77 native psychology graduates completed Theatre 152, which satisfies the Outer Core-Fine Arts general education requirement. The cost per credit hour for five of those 19 students who took the course after accumulating 60 hours was \$445 higher (83\%) than the cost assigned to the 14 students who had completed the course prior to accumulating 60 hours.

However, timing did not always increase completion costs; in some cases costs decreased. For example, the data revealed that native art students appear to have often begun major coursework in their sophomore year and that a significant number of general education and university elective hours were taken during upper-division study by those same students. Because major coursework in art is more expensive than general education and many university electives, this approach (in the plan of study for those majoring in art) resulted in lower degree costs for the art students overall. Similarly, native MLE students often completed the first of two required content-areas in the sophomore year. (In teacher education, a content area is one in which students have completed a sufficient number of courses to demonstrate proficiency in the subject and is a required part of a MLE degree.) Courses fulfilling content areas such as math, science, and social studies are generally lower cost than other MLE major hours, but completing content areas during lower-division study rather than after the student has accumulated 60 credit hours further decreased the overall cost of those students' degrees.

The final driver of cost variations within degrees is student choice. This in an ideal expressed in the ISU undergraduate catalog (Illinois State University, 2010, p. 64) and is 
generally thought to be an important part of a student's university experience. This concept means, for example, that students can choose their major, customize or change their major (assuming department approval), or select from hundreds of available courses to satisfy general education and elective requirements. Of course, each academic area requires specific major coursework that prepares the graduate for the field, but a degree of latitude is provided when it comes to choosing the remaining courses. This latitude is shown in the plans of study that specify major coursework and timing, but fill remaining semester selections with generic “university elective” coursework, “senior college” coursework, or any “general education” class. The data shows that variation of cost within degrees increases as the number of specified major courses decrease.

Table 18 is based on the listed catalog requirements for each of the six degrees included in this study. The variation in cost for programs that allowed less latitude for student choice, such as Nursing and Business Administration, was relatively low. However, in degree areas where students were given more latitude to choose which courses to take and when, completion costs varied more widely. 
Table 18

Native Students: Percent of Required Major Hours and Related Costs and Costs Variation

$\%$ of Major Hours

to 120 Hour

\begin{tabular}{lcccc} 
Discipline & $\begin{array}{c}\text { Required } \\
\text { Major Hours }^{\mathrm{a}}\end{array}$ & $\begin{array}{c}\text { Graduation } \\
\text { Requirement }\end{array}$ & $\begin{array}{c}\text { Range of Native } \\
\text { Student Degree Costs }\end{array}$ & $\begin{array}{c}\text { Coefficient of } \\
\text { Variation }\end{array}$ \\
\hline MLE $^{\mathrm{b}}$ & 40 & $33 \%$ & $\$ 19,046-28,949$ & $11 \%$ \\
Psychology & 41 & $34 \%$ & $\$ 13,667-27,813$ & $12 \%$ \\
Art & 54 & $45 \%$ & $\$ 25,541-37,048$ & $10 \%$ \\
Criminal Justice & 64 & $53 \%$ & $\$ 13,391-19,103$ & $10 \%$ \\
Nursing & 65 & $54 \%$ & $\$ 24,142-37,348$ & $9 \%$ \\
Business Administration & 68 & $57 \%$ & $\$ 18,651-26,560$ & $8 \%$ \\
\hline
\end{tabular}

${ }^{\text {a }}$ As listed in 2010-2012 ISU Undergraduate Catalog

${ }^{\mathrm{D}}$ MLE hours listed as "Professional Education" which does not include hours required for "adequate preparation" in two content areas.

Student choices, combined with the academic mix (the variety of topics covered in a graduate's coursework) and the timing of course completion, compound the variation in degree delivery costs. The cost effects of student choice and academic mix can be seen in how the 298 native students examined in this study completed general education requirements. Following the concept of student choice, students could choose from a list of more than 100 courses in the 2010-2012 catalog, which were grouped into cores and categories (Illinois State University, 2010, p. 64) to guide the selection. For example, students were to choose two classes from the inner-core category of natural sciences (IC-NS), which included three-credit-hour courses in geology, biology, physics, and chemistry. The four disciplines make up the academic mix of the IC-NS requirement. As mentioned at the beginning of this section, per-credit-hour costs vary across academic disciplines for a variety of reasons. In this inner-core example, for fiscal year 2012 the lowest-cost course in IC-NS was geology and cost \$258 to deliver. Biology and physics courses cost successively more (\$292 and \$422, respectively), and the highest cost was for chemistry at $\$ 482$. This means that if the student chose geology and biology versus physics and 
chemistry, the cost for this IC-NS requirement could have ranged from $\$ 460$ to $\$ 904$. Timing of course completion also plays into student choice. If the student chose geology as one of the ICNS courses but waited to complete the course during the junior year (after they have accumulated 60 credit hours), the delivery cost almost doubles to $\$ 506$.

Student choice and the timing of course completion also effects the cost to deliver major coursework. A review of transcripts for native art and psychology students, for example, revealed that most finished their major hours before beginning their senior year, leaving senior college or university elective options for much of the final 30 hours. In this case, timing compounds the cost effects of student choice. With a wide variety of courses to choose from at a time when courses cost the most, the transcripts revealed that no two students took the same path. As a result, the choices in that final year drove significant variation into art and psychology degree costs.

Finally, the degree for middle level teacher education provides an example of how academic mix and course timing work together. As discussed earlier, an MLE graduate must choose two academic topics as content areas (i.e. reading, language arts, math, social studies, or science). Science provides the best example of how what and when affects cost. In general, science coursework (delivered by biology, chemistry, geography/geology, and physics) is more costly to deliver than math or social studies. However, the majority (64\%) of MLE students choosing science tended to complete the coursework during lower division study. As a result the cost to deliver science was only $\$ 2,351$, much less than the average content area cost of $\$ 2,762$.

\section{Differences Between Native and Transfer Student Cost Variation}

The examples above are based on native student findings and, as noted earlier, the qualitative data also revealed a strong focus on native students. Indeed, higher education 
statistics in general are focused on this group (i.e. graduation and persistence rates apply only to first-time, full-time students). However, transfer students make up almost one third of the graduates in this study and account for $20 \%$ of the total cost to deliver degrees. These large numbers mean that transfer students are an important group on campus and much can be learned from the group’s degree cost analysis.

As discussed earlier, the overall group of 298 native students could be divided into three groups in regard to the number of completed credit hours. This division guided the discovery of the three drivers that contributed to variation of cost within degrees (number of hours, timing of course completion, and student choice). However, the results were different for the 120 transfer graduates. Like the native students, the transfer group included similar proportions of graduates with outside credit (i.e., beyond the credit transferred in from their community colleges), repeated classes, minors, and second majors. From a top-level view, almost $40 \%$ of transfer students completed their ISU coursework in 60 hours or less (equivalent to four, 15-hour semesters). Only 13\% required 65 or more ISU credit hours to graduate, which initially seemed to indicate a strong focus on completing the bachelor's degree efficiently and which, in turn, should have produced less variation in course selection and cost. However, the premise became less promising as the data was examined further. Transcripts showed that transfer students, on average, brought 67 credit hours from their community colleges. This technically left only 53 hours to complete a bachelor's degree, but the group completed an average of 63 ISU credit hours, 10 more than should have been required. It quickly became apparent that while some transfer students were very efficient during university study, requiring only 60 or fewer credits to complete their degrees, others may have struggled, perhaps even may have suffered "transfer shock,” the concept that suggests transfer students are somewhat disoriented and academic 
performance drops during their first semester at a university (Cohen, Brawer \& Kisker, 2014).

Overall results are shown in Table 19, revealing that total ISU hours earned by transfer students varied greatly across degrees, as did the coefficients of variation. However, while Table 18 shows an inverse relationship between the number of required major hours and the coefficient of variation for each of the six degrees as completed by native students, no such correlation existed for the transfer students, shown in Table 19. This meant that the first driver of cost variation discovered during analysis of native degree costs, the number of completed ISU hours, was less applicable to the transfer students. Of course, the second driver, timing of course completion, was also a negligible factor for transfer students because all of their ISU courses were completed at upper-division cost.

Table 19

Transfer Students: Percent of Required Major Hours and Related Costs and Costs Variation

\begin{tabular}{lccccc}
\hline Dequired & $\begin{array}{c}\text { Ree } \\
\text { Major Hours }\end{array}$ & $\begin{array}{c}\text { Completed } \\
\text { ISU Hours }\end{array}$ & $\begin{array}{c}\text { Transfer } \\
\text { Range of Degree } \\
\text { Costs (ISU Hours) }\end{array}$ & $\begin{array}{c}\text { Native } \\
\text { Coefficient of } \\
\text { Variation }\end{array}$ & $\begin{array}{c}\text { Coefficient of } \\
\text { Variation }\end{array}$ \\
\hline Criminal Justice & 64 & 56 & $\$ 5,536-14,174$ & $20 \%$ & $10 \%$ \\
Busn Admin & 68 & 60 & $\$ 11,190-19,497$ & $16 \%$ & $8 \%$ \\
Art & 54 & 62 & $\$ 15,829-29,859$ & $14 \%$ & $10 \%$ \\
Psychology & 41 & 59 & $\$ 7,392-11,029$ & $10 \%$ & $12 \%$ \\
MLE $^{\text {b }}$ & 40 & 70 & $\$ 14,596-18,174$ & $8 \%$ & $11 \%$ \\
Nursing & 65 & 68 & $\$ 19,520-23,544$ & $7 \%$ & $9 \%$ \\
\hline
\end{tabular}

${ }^{a}$ As listed in 2010-2012 ISU Undergraduate Catalog

${ }^{\mathrm{b}}$ MLE hours listed as "Professional Education" which does not include hours required for "adequate preparation" in two content areas.

Although the number of credit hours and the timing of coursework completion did not appear to be driving variation in the costs of transfer student degrees awarded for the same area, student choice did appear to play a role. Comparing the variation coefficients between native and transfer students completing the same degree in Table 19, three disciplines (art, business 
administration, criminal justice) show that transfer degree costs vary less than native costs, but the reverse is true for the three remaining three areas (psychology, MLE, and nursing). A review of transcripts and an examination of ISU's list of articulation agreements (Illinois State University, 2019) revealed more information. Associate’s degrees are offered in art, business, criminal justice, and psychology. However, middle level teacher education is not offered at the community college level and students with an AA in Nursing enter a different program. Only nursing students with an AA in an area other than nursing enter the pre-licensure program examined in this study. What this means is that MLE and nursing students had much less discretion as to their course choices, concentrated as they were into three years or less. On the other hand, transfer students completing the first four degrees listed in Table 19 had greater opportunity to choose their ISU courses due to the number of major courses completed during their associate studies. It appears probable that student choice, at the community college and university level, is the driver most highly correlated to the variation of cost within degrees delivered to transfer students at Illinois State University.

\section{Catalog versus Transcript Costs}

A third major finding of the study was that, in five of the six degrees, the catalog cost was less than mean transcript cost for native graduates. (The one exception was psychology, an anomaly addressed later in this chapter.) Overall, the average native student completed 125 credit hours, five more than the 120 hours reflected in the plans of study. The average mean transcript cost was \$513 (2\%) more than the average catalog cost. This small difference was expected if we assume that most students tend to follow the plan of study, which is presumably the more efficient and effective path to a degree.

Still, students are under no obligation to follow the plan without exception. As Figures 1 - 
12 in Chapter Three illustrated, some students completing the same degree finished with a transcript cost above the catalog cost while others finished at a cost that was lower than the catalog cost. Although this finding (that catalog costs are lower than mean transcript costs) is shown in the data, it is limited. Catalog cost estimates were assumed to be the straighter paths to a degree, but the catalog descriptions of degree requirements are not written to reduce the cost to deliver the degree. In addition, these descriptions and the accompanying plans of study are not as straightforward as one might think. The major course selections and recommended order of completion allow relatively little latitude to the students. But the plans allow more freedom of choice in regard to fulfilling general education and elective requirements. As mentioned above, student choice, especially when compounded by the effects of academic mix and timing, can drive a great deal of variation into the final degree costs. This discovery limited the accuracy of the catalog cost estimates. For example, as described in Chapter Three, the portion of catalog cost representing general education was developed through the controlled chaos method, a meanof-the-means approach to account for the various disciplines offered within each category of the general education “cores” (inner, middle, and outer). A similar approach was used when plans of study called for university or senior college elective hours. Of course, other approaches might exist that better account for the cost of general education coursework, but the study's final approach (i.e., means-of-the-means) is considered by the researcher to be adequate enough to provide an initial benchmark of comparison to transcript costs, despite its limitations.

\section{Upper-Division Costs}

The fourth major finding of the study is that, in four of the six degrees, the mean cost to deliver the final years of study to transfer students was less than the mean cost to deliver similar instruction to native upper-division students. As with the previous findings, results varied within 
the same degree; not all transfer student degree costs were lower than upper-division native costs. However, in the absence of separate plans of study, the students should have been completing similar coursework during that time regardless of transfer or native status. Table 20 illustrates the results.

Table 20

Comparison of Costs: Transfer Students vs Upper-Division Native Students

\begin{tabular}{|c|c|c|c|c|c|c|c|}
\hline Degree & $\begin{array}{l}\text { Number } \\
\text { Native } \\
\text { Students }\end{array}$ & $\begin{array}{c}\text { Degree Cost Range } \\
\text { Upper-Division } \\
\text { Native } \\
\end{array}$ & $\begin{array}{c}\text { Mean Cost } \\
\text { Upper-Division } \\
\text { Native } \\
\end{array}$ & $\begin{array}{l}\text { Number } \\
\text { Transfer } \\
\text { Students }\end{array}$ & $\begin{array}{c}\text { Cost Range } \\
\text { Transfer Student } \\
\text { ISU Coursework }\end{array}$ & $\begin{array}{c}\text { Mean Cost } \\
\text { Transfer } \\
\text { Student ISU } \\
\text { Coursework }\end{array}$ & $\begin{array}{c}\text { Difference } \\
\text { (Transfer } \\
\text { Mean Cost - } \\
\text { Native) } \\
\end{array}$ \\
\hline Art & 14 & $\$ 15,461-30,633$ & $\$ 19,979$ & 18 & $\$ 15,829-29,859$ & $\$ 21,322$ & $\$ 1,342$ \\
\hline Busn Admin & 37 & $\$ 12,272-18,569$ & $\$ 14,895$ & 25 & $\$ 11,190$ - 19,497 & $\$ 13,736$ & $(\$ 1,159)$ \\
\hline Criminal Justice & 52 & $\$ 7,314$ - 12,632 & $\$ 9,461$ & 33 & $\$ 5,536-14,174$ & $\$ 7,910$ & $(\$ 1,551)$ \\
\hline Nursing & 89 & $\$ 15,336-30,828$ & $\$ 19,957$ & 16 & $\$ 19,520-23,544$ & $\$ 20,626$ & $\$ 669$ \\
\hline MLE & 29 & $\$ 11,467-21,921$ & $\$ 16,603$ & 7 & $\$ 14,596-18,174$ & $\$ 16,490$ & (\$113) \\
\hline Psychology & 77 & $\$ 7,978-21,216$ & $\$ 10,911$ & 21 & $\$ 7,392-11,029$ & $\$ 9,201$ & $(\$ 1,710)$ \\
\hline
\end{tabular}

The interpretation of this finding was confounded by the IBHE cutoff between lower- and upper-division costs for native students at the completion of 60 credit hours. Although the average transfer student brought 67 credit hours from their community college, they were allowed to bring up to 70 hours. None of these credits (beyond 60 hours) count toward the cost for ISU to deliver the final coursework, but they could lower the cost of the transfer students' ISU coursework if the transferred credits were determined to be equivalent to major or upperdivision coursework. Unfortunately, it was impossible to quantify the nature of the final 7-10 hours completed at the community college (beyond 60 credit hours) with the data provided. Although the IBHE cutoff lends a level of obscurity, the transfer students completed, on average, fewer ISU hours than what one might expect ISU native students to complete in the final two years of study. The data shows that native students completed, on average, 129.9 total hours (125.4 delivered by ISU) and transfer students completed, on average, 130.5 hours. In 
upper-division study, the native students completed an average of 65.4 hours (125.4 minus 60 lower-division hours), and transfer students completed an average of 63 ISU hours. The 2.4 hour difference (65.4 - 63) between the two groups may be one reason that transfer student costs were, on average, lower than upper-division native student costs.

Another possibility might be that transfer students have a higher level of focus on completing the degree. Indeed, the data showed that some transfer students focused on completing requirements and little else, which allowed them to graduate with 50 or fewer hours from ISU. Table 21 provides a quantitative look at these students, only one of whom used credit awarded outside of ISU or the community colleges from which they earned an associate's degree to meet graduation requirements.

Table 21

Comparison of Costs Across Degree Areas: Transfer Students with 50 or Fewer Hours to Degree

\begin{tabular}{lcccc}
\hline & $\begin{array}{c}\text { Transfer Students } \\
\text { with 50 or Fewer } \\
\text { ISU Hours }\end{array}$ & $\begin{array}{c}\text { Mean Transfer } \\
\text { Hours Completed } \\
\text { by all Transfer } \\
\text { Students }\end{array}$ & $\begin{array}{c}\text { Mean Cost to Deliver } \\
\text { Final Degree to } \\
\text { Students with 50 or } \\
\text { Fewer ISU Hours }\end{array}$ & $\begin{array}{c}\text { Mean Cost to } \\
\text { Deliver Final Degree } \\
\text { to All Transfer } \\
\text { Students }\end{array}$ \\
\hline Art & 2 & 70 & $\$ 17,616$ & $\$ 21,322$ \\
Business Administation & 2 & 69 & $\$ 11,550$ & $\$ 13,736$ \\
Criminal Justice & 5 & 70 & $\$ 6,882$ & $\$ 7,910$ \\
Psychology & 1 & 70 & $\$ 7,798$ & $\$ 9,201$ \\
\hline
\end{tabular}

Cost to the students (tuition and fees) may be another reason. From the student perspective, cost is based on two factors: the number of credit hours and the tuition charged by the institution. Academic mix, timing, and student choice do not affect tuition. Certainly the students represented in Table 21 might be cost conscious, having completed at the community college far more than the 60 hours generally required for an associate’s degree. Conversely, native students may have something the transfer students do not: the financial capacity to explore or complete additional coursework before finishing the degree. Table 22 shows this to be a 
possibility. Excluding Nursing and MLE, programs without two-year degrees, transfer students complete an average of six fewer ISU hours than the native students during upper-division study. Table 22

ISU Hours Completed

\begin{tabular}{lcc}
\hline & $\begin{array}{c}\text { Upper-Division } \\
\text { Native Student } \\
\text { ISU Hours }\end{array}$ & $\begin{array}{c}\text { Transfer } \\
\text { Student ISU } \\
\text { Hogree }\end{array}$ \\
\hline Art & 66 & 62 \\
Busn Admin & 65 & 60 \\
Criminal Justice & 64 & 56 \\
Nursing & 67 & 68 \\
MLE & 70 & 70 \\
Psychology & 66 & 59 \\
\hline
\end{tabular}

Of course, further qualitative research is required to verify these speculations. However, regardless of reasons and despite the 7-10 hour overlap created by the IBHE's 60 hour cutoff for lower-division coursework mentioned above, it was clear that the cost to deliver a degree to the transfer student group is not dissimilar from the upper division native group. The cost results show that, in general, the degree programs examined in this study appear to be managing "transfer shock" and gaps in pre-requisites for the majority of transfer students well enough for them to keep pace or perhaps perform better than the native students.

\section{Dollar Amounts Do Not Tell the Whole Story}

The last of five major findings is that dollar amounts and descriptive statistics do not tell the whole story of the cost to deliver a degree. As a life-long accountant, this researcher's observation is that many readers, when presented with numeric-based reports, especially those with dollar signs, try to make sense of the report by looking for what stands out, scanning for negative numbers, or comparing the data to their own personal knowledge to decide if it seems valid. It is a kind of mental paralysis that prevents the reader from looking beyond the numbers 
on the page and critically thinking about what those dollars really say.

The two administrators who shared their perceptions of the completion cost results confirmed that they were at first a little uncertain about how to approach the data. However, having been given time to review the reports prior the interviews, they were able to respond with comments about what the data does and does not tell a reader. As to what the administrators felt that data does show, their observations were similar to this researcher's conclusions (discussed earlier in this section). They noticed, for example, that costs vary across degrees much more than they would have guessed. They noticed that catalog cost was, in most cases, lower than transcript cost (which they felt represented efficiency) and that transfer students tend to finish at lower costs than upper-division native students (which they found surprising). They also noticed that half of the cost to deliver a degree was due to expenditures in support of administrative and university wide activities (more clearly shown in the manageable and fully allocated purviews where, as tables in Appendix A show, per-credit-hour costs are nearly double), but they did not find that surprising.

It is interesting data, they said, but it does not tell the whole story. The two administrators clearly articulated their perceptions of what the reports did not show. The data does not clearly show the concept of value; the value of disseminating research or involving students in practical applications of their knowledge is hard to quantify in dollars. The data also does not provide comparative results from similar programs in other institutions nor does it provide ISU-based benchmarks against which the cost results might be compared. Although narratives can be developed that explain how a program works, what features might be unique, and what driving factors might be behind cost variations across degree programs, only department faculty and staff, according to the interviewees, have the in-depth knowledge needed 
to act upon the data.

These observations caused this researcher to consider how the data might be negatively perceived or misused by readers without adequate supplemental information describing the degree programs and cost results. Not only do readers compare data to their personal knowledge, they scan it for data that supports or refutes their own perspectives. For example, one administrator expressed fear that the "public" might misinterpret the data or "other university programs” might use the data in their recruiting to persuade potential students that the ISU program is somehow lesser than their own.

Another fear is that readers might simply compare the costs to tuition (admittedly, tuition is higher than the average fully allocated native cost), without understanding that expenditures for research and community service are not included. After all, degrees are not the only product of a university. In fact, the estimated degree costs only relate to the costs of delivering instruction (plus required overhead) to graduates, without adjustments for the costs related to students who leave the university without a degree (which Bailey et al. [2015] factor into their cost analysis) or who do not complete within six years (three for transfer students). The costs also do not include expenditures related to many services provided or paid by the university such as institutional student aid or scholarships, Medicare, unemployment, university press, campus ROTC program, or capital expenditures for larger equipment and new buildings.

These fears leave the researcher with questions about how the data might best be reported and used in ways that genuinely help college administrators meet the doing-more-with-less challenge. Estimating the cost to deliver a degree is a relatively new perspective on university finance; in order to truly understand the driving factors behind variations in cost and to verify the study's other findings, more quantitative and qualitative data will be required. In addition to what 
the data does and does not show, the study's estimates and conclusions were also limited by the underlying data. Originally prepared for another purpose and defined by an external agency without input from the campus, the readily available data simply provides a starting point from which a campus can begin to understand its cost to deliver a degree, what improvements might be necessary to provide better data, and what actions might be taken based on the results.

\section{Recommendations to Improve Results}

The primary goal of this exploratory study was to estimate the cost to deliver a degree using readily available data provided by the University. This was done, but with some difficulty. Indeed, as the analysis proceeded, inherent limitations (as discussed in Chapter Three) of the ISU data and the larger study became apparent. Although the data received from the University was complete and well organized, it was not originally intended to be used as it was by this study. More accurate figures will be needed should ISU commit to calculating cost-per-completion data on a regular basis. This section describes recommended changes to data gathering and reporting, as well as approaches that could be taken to mitigate the data's limitations when possible.

\section{Recommendations to Mitigate Data Limitations}

Future analysis of completion costs would benefit from five recommendations as to the collection and retention of the data. The first recommendation is to address historical changes. As the data was being cleaned for import into the cost database, the researcher noted that changes to organizational structure or unit titles are not indicated historically in the data. This is a common approach in database administration, but it created difficulty for this study. For example, during the period covered by this study (FY 2010 - FY2015), two academic areas reorganized into "Schools” and department or program titles were changed. However, both old and new titles were included in the data with no easy way to associate one to the other. The 
researcher also noted that the data contains no indicators of changes in degree requirements that may have occurred between fiscal 2010 and 2015. If a specific unit or degree has undergone substantial changes, researchers must be able to determine if the cost of completion has also changed and in which direction. Further, if major degree changes are in transition, the change must be properly accounted for as a factor to be watched over time, rather than mistaken as a trend in the degree's cost.

A recommendation that mitigates the issues associated with historical changes is to create event indicator tables. It is unreasonable for PRPA to track the details of historical changes, but it might be helpful to maintain tables that indicate a change event and the implementation date. For organizational changes, a crosswalk table could match old names and structures with the new. For changes in degree requirements, a separate table could provide a trigger to researchers who would subsequently determine if additional analysis of the transition is warranted. The same table might also include changes to course numbers and an indication as to whether the course was simply renumbered or represents new content.

The second recommendation is to better align cost data and transcript data. One issue with data alignment is that the academic discipline cost data, prepared for the IBHE, is not wellaligned with the student record (transcript data). For example, the Department of Geology and Geography submits two FAA reports, one for each of its two disciplines: geology and geography. However, all coursework is identified in the transcript data with the course identifier GEO, regardless of the discipline. A second issue is that not all academic programs prepare the FAA. The Department of Military Science, for example, does not award a degree and does not prepare an FAA. The result is that no costs are available to associate with the courses on student transcripts. Other academic areas offer multiple degrees, but prepare a single FAA. For example, 
the School of Teaching and Learning offers four undergraduate degrees related to varying levels of K-12 education, but submits a single FAA. In this case, the cost and transcript data is aligned, but the University's research office does not have sufficient information to prepare separate percredit-hour costs for each program.

A recommendation that provides a possible solution to data alignment issues is to create additional fields in the existing data. In the student records, a field could be added that helps the researcher associate coursework to its awarding program, regardless of the course identifier. A similar field can also be added to the FAA, which already associates funding and reporting (awarding) departments to each course. Using this approach, only one FAA is prepared, but the report provides a method of associating courses to a specific program. When preparing the IBHE data for the annual ADUCS report, the field could simply be ignored if separate costs are not required.

The third recommendation, if catalog cost is to become a qualified benchmark against which to compare transcript costs, is to determine an acceptable method of costing general education and university electives when specific courses are not recommended by the catalog or plans of study. For example, this study utilized the controlled chaos approach to apply costs to non-specific general education courses. However, better approaches might be identified by individual departments. For example, verbally communicated de facto plans of study might be used by department advisors that provide more specific course recommendations than the generalized plans posted to the University’s websites.

The fourth recommendation is to determine which student groups are important to track (native, upper-division native, and transfer) and at what purview of cost (controllable, manageable, and fully allocated). The study's interview participants were provided with the cost 
results for all student groups and cost purviews, but they focused on native students and controllable costs. However, the focus might have been different if more departments had participated or if the participants represented differing levels of administration. The University should determine if the time and effort required to gather and report the degree costs for three student groups at three purview levels is outweighed by the benefit provided to either the individual departments or university administration in their analysis of completion costs.

The fifth recommendation deals with the FAA, the basis of faculty salary allocations: Review and possibly modify the instructions, increase communication between PRPA and departments, and add fields to the spreadsheet to provide quality indicators. For example, the researcher noted that inconsistencies in department reporting (of the FAA) are a limitation inherent in the data. This limitation was confirmed during the qualitative stage; the interview participants expressed concern about the consistency with which the instructions were interpreted across departments and how big of a priority each department placed on accuracy. In addition, the participants wondered how the University used the report and noted that they received very little feedback after submission. Of course, this is a familiar refrain in regard to university reporting, but more communication might stimulate critical thought, especially in aligning degree coursework with costs, as described earlier.

The FAA can also be used to address a limitation of the larger study, the lack of quality indicators. For example, the NRC panel (National Research Council, 2012), suggested that faculty rank is an indicator of instructional quality. The current FAA aligns each faculty member with courses taught during the term. It would be relatively easy to add a column indicating faculty rank (in addition to the field for program or degree in recommendation two). Another field could ask for changes to department titles, organizational structure, or degree requirements 
that also might be perceived to be improvements in quality. This field, possibly combined with additional communication between PRPA and the department, would also help maintain the event indicator tables suggested in recommendation one.

\section{Recommendations to Improve Reporting of Degree Costs}

The previous section proposed five recommendation to improve the data and mitigate its limitations. However, no change to the data will be of use if it is not reported in a manner that helps readers understand the results and what actions they might take to improve those results. This became very clear during the interviews. Although the administrators were very familiar with their own programs, they had some difficulty interpreting the results and felt strongly that more information must be provided along with the numbers. Two primary recommendations are provided in the following discussion.

The first recommendation is to provide data to compare or benchmark completion costs and to understand if action might be required. The two administrator participants were provided with the same data for each of the six degrees: catalog and transcript costs for native, upperdivision native and transfer students estimated at three administrative levels. Each component provides a different perspective. Catalog cost, for example, helps the academic area to determine how closely the students are following the plan of study’s recommended path. Upper-division native student costs are a rough comparison to transfer student completion costs. However, to complete a full analysis of a program's completion costs, more comparative data is needed. If it were available, a comparison to another Illinois university's cost for the same degree area might illuminate differences in curriculum, which might also be associated with a program's quality. The same comparison could be made against an out-of-state program, if the data were prepared in a consistent manner across institutions. Another basis of comparison is to examine changes 
over time for the same degree. This would help readers better understand the cost implications of changes to degree requirements, faculty composition, class sizes, enrollment, etc. These examples are only a handful of comparative bases; the university community may be able to think of others that help programs better understand their cost to deliver a degree.

The second recommendation, gathered during the interviews, is to prepare a narrative that fully explains the unique requirements of each degree. For example, a reader from outside of the nursing or middle level education programs might not understand the value of clinical hours or, without more information, a reader might not understand why the business administration degree includes more major hours (generally at a higher cost) than, for example, the psychology degree. Also, because the cost results currently lack indicators of quality, the narratives can be used to fill the gap. For example, some academic areas practice close or intrusive advising designed to keep students on track. This practice might indicate quality, especially if it can be connected to higher graduation and persistence rates or less variation in degree costs. When quality indicators are eventually added to the results, narratives should explain changes in cost, as it relates to quality, over time. For example, a decrease in cost might come at the expense of a decreased proportion of tenure-track faculty. Conversely, an increased proportion of tenure-track faculty might help justify an increase to completion costs or, on a more positive note, show that the addition increased quality without increasing costs.

\section{Remaining Considerations}

Two data limitations are not addressed by the recommendations described above. The first of the remaining limitations in the data was that ISU had converted the student records from a legacy mainframe to a new system just prior to when the data was gathered for the study: late 2016 and early 2017. Although the researcher did not discover inconsistencies in the data due 
solely to the conversion, one must assume that the university systems and research staff have now completed data validation and that this limitation is not relevant for continuing research.

The second data limitation was that the basis of allocating non-instruction expenditures results in increasingly higher costs the further they are incurred from the academic department. Using the allocation of college overhead as an example, the reporting department with the highest annual expense receives a proportionally higher overhead allocation than other departments under the college's purview. The college overhead allocation adds to the department's accumulated expenses and, as a result, the allocation of costs from the next category of expense is also larger. When the final costs are calculated for the program, the figures are significantly higher, not because it costs more to deliver instruction in that discipline, but simply because the department's total expenditures, in comparison to other departments in the same college, were higher.

This limitation is not easily addressed because the allocation formula is required by the IBHE and must be followed by every Illinois university as it prepares the annual submission of costs per credit hour. One option is that the University continue to gather data through the FAA reports, but allocate the expenses of subsequent cost categories in a different manner for university completion cost purposes. However, this means that the University must determine its own allocation bases. Choosing this option also means that it would be more difficult to compare completion costs to other universities in Illinois that offer the same degree. A second option is to simply recognize, in the narrative, that cost categories beyond the controllable purview (i.e., at the department or college level) might skew the results in a manner not directly connected to instruction. Pursuing this option means that cost estimated at the manageable and fully allocated purviews might be perceived to be of lesser value. 
Because both options have a negative side, a better recommendation (to address overhead allocation bases) is that the University work with the IBHE to determine if completion costs are a metric the Board would like to pursue. If so, the Board could work with all Illinois universities to determine more appropriate or agreeable bases of allocation (to ensure consistency across the state) in addition to reaching out to other state boards that might be interested in completion costs (to provide additional comparative data).

\section{Recommendations for Future Research}

This study calculated completion costs of six degrees awarded by Illinois State University. However, this study was exploratory, and research into completion costs on this campus should be expanded if the University decides to commit to an annual analysis. Future researchers might consider three factors that informed the study's conclusions. First, the conclusions are based on the estimated completion costs of six degrees and the perceptions of two administrators. Expanding the approach to the remaining 59 degrees (and many more programs within each degree area) and subsequent conversations with additional departmentlevel administrators might lead to quite different conclusions.

Second, the results of this study were not reviewed by university level administrators during the qualitative stage. In future research, this level of review will be critical to understanding how the variety of degrees offered by ISU complement each other and enhance the university's larger financial setting. For example, the data examined in this study indicates that some degrees subsidize other programs by offering (and absorbing the cost of) one or more courses that satisfy general education requirements. As a result, completion costs for those degrees might be higher than if the cost of general education coursework was allocated as an administrative cost to all departments. 
The third factor deals with the parameters and analysis utilized for estimating degree costs of transfer students. In this study, 120 of the original 286 transfer students were selected on the bases of having completed an associate's degree at a community college and finishing a bachelor's degree at ISU in three years or less. However, an additional 110 transfer students began at a community college and finished at ISU within three years, but did not complete the two-year degree. Future research should consider whether the cost to deliver degrees to this group of 110 transfer students should also be examined. A comparison of the cost results from the two groups of transfer students might help the University to better understand the choices of transfer students and, as a result, the analysis could lead to improved communication with community colleges (in regard to academic programs) and a better understanding of how an associate's degree affects the costs incurred by ISU to deliver the final years of study.

Expanding the study is important to future research, but the biggest take-away from this study's findings is that student choice was the primary factor in the variation of costs within degrees regardless of whether the students were native or transfer. This finding poses a difficult question for future researchers: As a university calculates completion costs in response to demands for higher graduation rates as well as greater efforts to keep costs in check for both students and the state, how does it find the balance between student choice and institutional direction? The ability to choose coursework, change majors, complete minors and second majors, or switch from full-time to part-time attendance is part of the university culture. However, some would say that choice is a tyranny that adds unnecessary anxiety and sends students running to counseling and health services (Schwartz, 2004), adding increased costs for student services. Indeed, some scholars (Bailey et al., 2015) believe that providing too much choice is counter-productive, leading to confusing degree paths and, this researcher would add, 
increased completion times and costs.

In fact, re-thinking student choice may provide more questions than answers. During this process, the University will have to determine what tools might be used to reduce completion costs without a corresponding decrease in quality. Perhaps improved communication on websites could help to reduce poor information and excess credits. Maybe increasing the clarity of degree requirements in the catalog would also help. Providing more intrusive advising and tighter connections with community colleges might also contribute. Plans of study with stricter recommendations could keep cohorts of students together throughout their study, contributing to increased persistence and graduation. The University might also explore the approaches of other campuses that attempted to reduce student choice and consider how well those approaches are working. Ultimately, the ability of whether student choice should be limited is a decision for university administration. The decision of how to limit student choice rests with the departments and its success will depend upon each department's culture and its willingness to change.

\section{Closing}

The push for more completions at cheaper cost is a national phenomenon that shows no sign of waning. This is a tremendous challenge for universities in Illinois because appropriations from the state are limited by structural deficits. If tuition is raised to cover attenuated appropriations, a university education for the decreasing number of Illinois' potential students will be more difficult to afford. On the national scene, some states are beginning to increase higher education funding, but tuition continues to rise and now accounts for a higher proportion of total revenue at public institutions than state appropriations. This trend is highlighted by recent events in Alaska. Facing a 40\% decrease in state funding, Alaska had no choice but to raise tuition and/or cut expenses in the most draconian way (Elias, 2019). What would Illinois 
universities do if faced with the same dilemma? What would any university do? Certainly, increasing revenue (through tuition) will not be a long-term solution and across the board cuts and mass layoffs may not be the best option for universities or students.

Illinois universities must begin to develop other perspectives on financing that look more to containing costs than increasing revenue. Determining the cost to deliver degrees is one approach to cost containment, but the calculation of completion costs will not of itself contain costs. Once trends in completion costs are estimated and analyzed, universities will have one more tool to add to a holistic review that examines the links between productivity, costs, and quality. The results of this holistic review can provide data-driven answers to the proponents of the completion agenda who question why a university education costs so much to deliver quality instruction in addition to explaining what steps are being taken to contain those costs and how student choice effects the number and cost of degrees that can be produced. 


\section{REFERENCES}

Ambrosio, M., \& Merisotis, J. (2000). Higher education cost measurement: Public policy issues, options, and strategies. A compilation of background papers prepared for a seminar on cost measurement and management. Washington DC: The New Millennium Project on Higher Education Costs, Pricing, and Productivity. Retrieved from http://www.ihep.org/sites/default/files/uploads/docs/pubs/higheredcostmeasurement.pdf

Bailey, T. (2012). Can community colleges achieve ambitious graduation goals? In A. P. Kelly, \& M. Schneider (Eds.), Getting to graduation (pp. 73-101). Baltimore: Johns Hopkins University Press.

Bailey, T., Smith Jaggars, S., \& Jenkins, D. (2015). Redesigning America's community colleges: A clearer path to student success / Thomas R. Bailey, Shanna Smith Jaggars, Davis Jenkins. Cambridge, Massachusetts: Harvard University Press.

Bauman, D. (2018, February 2). Why students are leaving Illinois in droves - And why it matters. The Chronicle of Higher Education. Retrieved from https://www-chroniclecom.libproxy.lib.ilstu.edu/article/Why-Students-Are-Leaving/242436

Becker, G. S. (1964). Human capital; a theoretical and empirical analysis, with special reference to education, by Gary S. Becker New York: Columbia University Press.

Belfield, C., Crosta, P., \& Jenkins, D. (2014). Can community colleges afford to improve completion? Measuring the cost and efficiency consequences of reform. Educational Evaluation and Policy Analysis, 36(3), 327-345. doi:10.3102/0162373713517293

Brown, J. R. \& Dye, R. F. (2015, June). Illinois pensions in a fiscal context: A (basket) case study. (National Bureau of Economic Research Working Paper No. 21293) Retrieved from: https://www.nber.org/papers/w21293 
Burke, J. C. (2005). Achieving accountability in higher education: Balancing public, academic, and market demands / Joseph C. Burke and Associates. San Francisco: Jossey-Bass.

Carey, K. (2007). Truth without action: The myth of higher-education accountability. Change, 39(5), 24-29.

Carnegie Commission on Higher Education. (1973). Higher education: Who pays? Who benefits? Who should pay? A report and recommendations. New York: McGraw-Hill.

Clark, B.R. (1983). The higher education system: Academic organization in cross-national perspective. Berkeley: University of California Press.

Cohen, A. M., Brawer, F. B., \& Kisker, C. B. (2014). The American community college (6th ed.). San Francisco: Jossey-Bass.

Conger, S.B., Bell, A. \& Stanley, J. (2010). State Higher Education Executive Officers Fourstate cost study. Retrieved from http://www.sheeo.org/sites/default/files/publications/SHEEO_Cost\%20Study\%20Report_ 2010.pdf

Delaney, J. A., \& Doyle, W. R. (2011). State spending on higher education: Testing the balance wheel over time. Journal of Education Finance, 36(4), 343-368.

Desrochers, D. M., \& Hurlburt, S. (2016, January). Trends in College Spending: 2003-2013 Where Does the Money Come From? Where Does It Go? What Does It Buy? Retrieved from https://deltacostproject.org/sites/default/files/products/15-4626 Final01 Delta Cost Project College Spending 11131.406.P0.02.001 ....pdf 
Divounguy, O. \& Hill, B. (2018, September 13). What goes up must come down: why Illinois is ill-prepared for the next recession. Illinois Policy. Retrieved from: https://www.illinoispolicy.org/what-goes-up-must-come-down-why-illinois-is-illprepared-for-the-next-recession/

Elias, J. (2019, July 9). Alaska’s Data Tell a Familiar National Story. The Chronicle of Higher Education. Retrieved from: https://www.chronicle.com/article/Alaska-s-Data-Tell$\mathrm{a} / 246632$

Halstead, D. K. (1991). Higher education revenues \& expenditures: A study of institutional costs / [by Kent Halstead] Washington, D.C.: Research Associates of Washington.

Harris, D. N., \& Goldrick-Rab, S. (2010). The (un)productivity of American higher education: From "cost disease" to cost-effectiveness [WISCAPE working paper]. Wisconsin Center for the Advancement of Postsecondary Education. Retrieved from http://files.eric.ed.gov/fulltext/ED515051.pdf

Hemelt, S. W., Stange, K. M, Furquim, F., Simon, A. \& Sawyer, J. E. (2018, November). Why is math cheaper than English? Understanding cost differences in higher education. . (National Bureau of Economic Research Working Paper No. 25314) Retrieved from: https://www.nber.org/papers/w25314

Higher Education Consortia. (2019). The Delaware cost study: The national study of instructional costs \& productivity. University of Delaware, Office of Institutional Research and Effectiveness. Retrieved from: https://ire.udel.edu/descriptive-summary/ Hovey, H. A. (1999). State spending for higher education in the next decade: The battle to sustain current support. San Jose, CA: National Center for Public Policy and Higher Education. 
Humphreys, D. (2012). What's wrong with the completion agenda--and what we can do about it. Liberal Education, 98(1), 8-17.

IBHE, ICCB, \& ISAC. (2019, June 18). Increase to Illinois higher education is a move in the right direction [News release]. Retrieved from: https://www.ibhe.org/pdf/2019.06.18_Higher_Ed_Increase_Release.pdf

Illinois Board of Higher Education. (2014, April). The Public Agenda 5 Years Later: Assessing Illinois’ Education Progress. [Press release] Retrieved from: https://www.ibhe.org/assets/files/NCHEMSReport_KeyFindings.pdf

Illinois Board of Higher Education. (2014). Academic discipline unit cost study. (No. 2012-13). Springfield, IL: Illinois Board of Higher Education. Retrieved from http://www.ibhe.org/Data\%20Bank/costStudies/2013/DisciplineUnitCost.pdf

Illinois Comptroller. (2016). Munger: Illinois on pace to dig \$6.2 billion deeper in debt this year. Retrieved from https://illinoiscomptroller.gov/news-portal/munger-illinois-on-pace-todig-6-2-billion-deeper-in-debt-this-year/\#.VwP7vqQrIz4

Illinois Public Agenda for College and Career Success. (2009). [Powerpoint]. Retrieved from https://www.ibhe.org/assets/files/070109_PublicAgenda.pdf

Illinois State University. (2010). Undergraduate Catalog 2010-2012. Retrieved from: https://illinoisstate.edu/downloads/catalog/archive/undergrad1012.pdf

Illinois State University. (2015). Undergraduate Catalog 2014-2016: 2015 Supplement. Retrieved from: https://illinoisstate.edu/downloads/catalog/archive/2015supplement.pdf Illinois State University. (2019) Articulation Agreements. Retrieved from: http://registrar.illinoisstate.edu/transfer/agreements.shtml 
Johnson, N. (2009). What does a college degree cost? Comparing approaches to measuring "cost per degree". Washington, DC: Delta Cost Project. Retrieved from http://www.deltacostproject.org/sites/default/files/products/johnson3-09_WP.pdf

Johnstone, D. B., \& Marcucci, P. N. (2010). Financing higher education worldwide: Who pays? Who should pay? / D. Bruce Johnstone and Pamela N. Marcucci Baltimore: Johns Hopkins University Press.

Kelly, A. P., \& Schneider, M. (2012). Getting to graduation: The completion agenda in higher education. Baltimore: Johns Hopkins University Press.

Kilgore, S., \& Elliott, E. (1987). Foreword. In D. To (Ed.) Estimating the cost of a bachelor's degree: An institutional cost analysis (pp. iii-v). Office of Educational Research and Improvement. Retrieved from http://www.eric.ed.gov/contentdelivery/servlet/ERICServlet?accno=ED283499;

Kirshstein, R., \& Wellman, J. (2012). Technology and the broken higher education cost model. Educause Review, 7(5), 12-24. Retrieved from www.deltacostproject.org/sites/default/files/products/ERM1251.pdf

Manning, T. M., \& Crosta, P. M. (2014). Program costs and student completion. New Directions for Community Colleges, 2014(168), 41-51. doi:10.1002/cc.20119

Massy, W. F. (2008). Cost and pricing in higher education. In H. F. Ladd, \& E. B. Fiske (Eds.), Handbook of research in education finance and policy (pp. 671-687). New York, NY: Routledge.

Massy, W. F., Sullivan, T. A., \& Mackie, C. (2013). Improving measurement of productivity in higher education. Change: The Magazine of Higher Learning, 45(1), 15-23. 
McKeown-Moak, M. (2000). A view from the states: A survey of the collection and use of cost data by states. In J. Wellman, \& C. O'Brien (Eds.), Higher education cost measurement: Public policy issues, options, and strategies. (pp. 10-27). Washington DC: The New Millennium Project on Higher Education Costs, Pricing, and Productivity. Retrieved from http://www.ihep.org/sites/default/files/uploads/docs/pubs/higheredcostmeasurement.pdf

McKeown-Moak, M. (2013). The "new" performance funding in higher education. Educational Considerations, 40(2), 3-12.

Merriman, D. F. (2014). Overview of the economic and fiscal situation in Illinois. Champaign, IL: Institute of Government and Public Affairs. Retrieved from http://igpa.uillinois.edu/sites/igpa.uillinois.edu/files/toolbox-budget/files/MerrimanEconomic-Overview-web.pdf

Middaugh, M. F. (2000). The Delaware study of instructional costs and productivity: A consortial approach to assessing instructional expenditures. Washington DC: The Institute for Higher Education Policy.

Middaugh, M. F., Graham, R., \& Shahid, A. (2003). A study of higher education instructional expenditures: The Delaware study of instructional costs and productivity. (No. NCES2003-161). Washington DC: National Center for Education Statistics. Retrieved from http://nces.ed.gov/pubs2003/2003161.pdf

Mitchell, M., Palacios, V., \& Leachman, M. (2014). States are still funding higher education below pre-recession levels. Washington DC: Center on Budget and Policy Priorities. Retrieved from http://www.cbpp.org/sites/default/files/atoms/files/5-1-14sfp.pdf 
National Conference of State Legislatures. (2019, January 1). Interactive database: State Postsecondary governance and finance policies. Retrieved from http://www.ncsl.org/research/education/interactive-guide-to-state-post-secondarygovernance-and-finance-policies.aspx\#/

National Research Council. (2012). Improving measurement of productivity in higher education. Panel on measuring higher education productivity: Conceptual framework and data needs. Washington, D.C.: The National Academies Press.

Office of Planning, Research, and Policy Analysis. (2015). Degrees conferred by college, level, department and major: Fiscal years 2011 through 2015. Normal, IL: Illinois State University. Retrieved from http://prpa.illinoisstate.edu/data_center/student/FY11FY15\%20Degrees\%20Report\%20by\%20Major.xlsx

Prescott, B. T., \& Bransberger, P. (2012). Knocking at the college door: Projections of high school graduates. Western Interstate Commission for Higher Education. Retrieved from http://www.wiche.edu/info/publications/knocking-8th/knocking-8th.pdf

Robinson, N. (2019). Setting a context for fiscal Year 2020 budget development [Powerpoint]. Illinois Board of Higher Education. Retrieved from: https://www.ibhe.org/board/2018/ september/Preliminary_Context_and_Planning_for_FY2020_Budget.pdf

Román, G. (2019, January 22). It’s time to reverse Illinois’ two-decade retreat from higher education. Center for Tax and Budget Accountability. Retrieved from: https://budgetblog.ctbaonline.org/its-time-to-reverse-illinois-two-decade-retreat-fromhigher-education-8bb5de1e66f 
Romano, R. M., Losinger, R., \& Millard, T. (2011). Measuring the cost of a college degree: A case study of a SUNY community college Sage Publications Inc. doi: $10.1177 / 0091552111416226$

Romano, R. M., \& Palmer, J. C. (2015). Financing Community Colleges: Where We Are, Where We're Going. Lanham, Maryland: Rowman \& Littlefield.

Seybert, J. A., \& Rossol, P. M. (2010). What drives instructional costs in two-year colleges: Data from the Kansas study of community college instructional costs and productivity. Planning for Higher Education, 38(3), 38-44.

Snyder, T. D. (1993). 120 years of American education: A statistical portrait. Washington, DC: U.S. Dept. of Education, Office of Educational Research and Improvement, National Center for Education Statistics.

Sprague, S. (2014). What can labor productivity tell us about the U.S. economy? Beyond the Numbers, 3(12) Retrieved from http://www.bls.gov/opub/btn/volume-3/what-can-laborproductivity-tell-us-about-the-us-economy.htm

State Higher Education Executive Officers. (2014). State higher education finance FY 2013. Retrieved from http://www.sheeo.org/sites/default/files/publications/SHEF_FY13_04292014.pdf

State Higher Education Executive Officers. (2015). State higher education finance FY2014 Retrieved from http://www.sheeo.org/sites/default/files/projectfiles/SHEF\%20FY\%202014-20150410.pdf

State Higher Education Executive Officers. (2018). State higher education finance FY2017 Retrieved from http://www.sheeo.org/sites/default/files/ SHEF_FY2017.pdf 
State Higher Education Executive Officers. (2019). SHEF 2018: SHEF methodological and technical information Retrieved from https://sheeo.org/wpcontent/uploads/2019/04/SHEEO_SHEF_FY18_TechPaper.pdf

The White House, Office of the Press Secretary. (2009). Remarks of President Barack Obama: Address to joint session of congress. [Press release]. Retrieved from https://obamawhitehouse.archives.gov/the-press-office/remarks-president-barack-obamaaddress-joint-session-congress

To, D. (1987). Estimating the cost of a bachelor's degree: An institutional cost analysis. Office of Educational Research, and Improvement. Retrieved from http://www.eric.ed.gov/contentdelivery/servlet/ERICServlet?accno=ED283499

Toner, M. (2015). The highly endangered higher education business model (and how to fix it). Presidency, 18(3), 15-18.

U.S. Department of Education. Institute of Education Sciences, National Center for Education Statistics. (2015). Integrated postsecondary education data system (IPEDS): Classification of instructional programs (CIP). Retrieved from https://nces.ed.gov/ipeds/cipcode/Default.aspx?y=55

U.S. Department of Education. Institute of Education Sciences, National Center for Education Statistics. (2018). Digest of Education Statistics. Retrieved from: https://nces.ed.gov/programs/digest/d17/tables/dt17_326.10.asp

U.S. Department of Labor. (2008). Multifactor productivity: Frequently asked questions. Washington, DC: Bureau of Labor Statistics. Retrieved from http://www.bls.gov/mfp/mprfaq.htm\#1 
U.S. Department of Labor. (2014). Overview of BLS productivity statistics. Washington, DC: Bureau of Labor Statistics. Retrieved from http://www.bls.gov/bls/productivity.htm Wellman, J., \& O'Brien, C. (2000). Higher education cost measurement: Public policy issues, options, and strategies. A compilation of background papers prepared for a seminar on cost measurement and management. Washington DC: The New Millennium Project on Higher Education Costs, Pricing, and Productivity. Retrieved from http://www.ihep.org/sites/default/files/uploads/docs/pubs/higheredcostmeasurement.pdf

Woodhouse, K. (2016, January). Burdened by a Budget Impasse: Universities in Illinois are covering millions in state costs as politicians continue to debate a 2015-16 budget halfway into the fiscal year. Inside Higher Ed. Retrieved from: https://www.insidehighered.com/news/2016/01/07/universities-left-footing-bill-budgetcrisis-looms-illinois

Zumeta, W. (2004). State higher education financing: Demand imperatives meet structural, cyclical, and political constraints. In E. P. St. John, \& M. D. Parsons (Eds.), Public funding of higher education: Changing contexts and new rationales (pp. 79-107). Baltimore, MD: The Johns Hopkins University Press.

Zumeta, W. (2012). States and higher education: On their own in a stagnant economy. The 2012 NEA almanac of higher education (pp. 27-37). Washington DC: National Education Association. Retrieved from http://www.nea.org/assets/docs/2012_Almanac_StatesandHE.pdf

Zumeta, W., Breneman, D. W., Callan, P. M., \& Finney, J. E. (2012). Financing American higher education in the era of globalization / William Zumeta ... [et al.] Cambridge, MA: Harvard Education Press. 


\section{APPENDIX A: QUANTITATIVE STAGE COST FINDINGS}

Table A-1

Student Descriptors: 2015 Art Graduates

\begin{tabular}{|c|c|c|c|c|c|c|c|}
\hline \multirow[b]{2}{*}{ Student Type } & \multirow[b]{2}{*}{ Graduates } & \multicolumn{2}{|c|}{$\begin{array}{l}\text { Transferred }^{\mathrm{a}} \\
\text { Credit Hours }\end{array}$} & \multirow{2}{*}{$\begin{array}{c}\text { Awarded }^{\mathrm{b}} \\
\text { Credit Hours } \\
\text { Average }\end{array}$} & \multicolumn{2}{|c|}{$\begin{array}{c}\text { ISU } \\
\text { Credit Hours }\end{array}$} & \multirow{2}{*}{$\begin{array}{c}\text { Total } \\
\text { Credit Hours } \\
\text { Hours Average }\end{array}$} \\
\hline & & Range & Average & & Range & Average & \\
\hline Native & 14 & $0-7$ & 3.43 & 1.64 & $111-163$ & 125.21 & 130.29 \\
\hline Transfer & 18 & $60-84$ & 67.51 & 0.33 & $45-84$ & 61.78 & 129.62 \\
\hline
\end{tabular}

${ }^{a}$ Transferred Credit: Credit accepted by ISU from another institution. Does not include unaccepted credit.

${ }^{b}$ Awarded Credit: Credit hours awarded by ISU for proficiency (CLEP, department testing, advanced placement, etc.), military coursework, or military experience.

Table A-2

Cost to Deliver Degrees: 2015 Art Graduates

\begin{tabular}{|c|c|c|c|c|}
\hline Purview and Statistic & Native & $\begin{array}{l}\text { Transcript Cost } \\
\text { Native UD }\end{array}$ & Transfer & $\begin{array}{c}\text { Catalog Cost } \\
\text { Native }\end{array}$ \\
\hline \multicolumn{5}{|l|}{ Controllable } \\
\hline Range & $\$ 25,541$ - 37,048 & $\$ 15,461-30,633$ & $\$ 15,829$ - 29,859 & $\$ 29,267$ \\
\hline Mean & $\$ 29,919$ & $\$ 19,979$ & $\$ 21,322$ & \\
\hline Median & $\$ 29,500$ & $\$ 18,364$ & $\$ 20,905$ & \\
\hline Standard Deviation & $\$ 2,902$ & $\$ 4,078$ & $\$ 2,967$ & \\
\hline Coefficient of Variation & $10 \%$ & $20 \%$ & $14 \%$ & \\
\hline \multicolumn{5}{|l|}{ Manageable } \\
\hline Range & $\$ 31,278-45,423$ & $\$ 18,875$ - 37,515 & $\$ 19,349-36,506$ & $\$ 35,891$ \\
\hline Mean & $\$ 36,660$ & $\$ 24,426$ & $\$ 26,063$ & \\
\hline Median & $\$ 36,151$ & $\$ 22,425$ & $\$ 25,545$ & \\
\hline Standard Deviation & $\$ 3,569$ & $\$ 5,007$ & $\$ 3,634$ & \\
\hline Coefficient of Variation & $10 \%$ & $20 \%$ & $14 \%$ & \\
\hline \multicolumn{5}{|l|}{ Fully Allocated } \\
\hline Range & $\$ 49,841-72,123$ & $\$ 29,658$ - 59,279 & $\$ 30,240-57,280$ & $\$ 57,038$ \\
\hline Mean & $\$ 58,196$ & $\$ 38,469$ & $\$ 40,877$ & \\
\hline Median & $\$ 57,345$ & $\$ 35,166$ & $\$ 39,967$ & \\
\hline Standard Deviation & $\$ 5,588$ & $\$ 7,923$ & $\$ 5,730$ & \\
\hline Coefficient of Variation & $10 \%$ & $21 \%$ & $14 \%$ & \\
\hline
\end{tabular}

${ }^{a}$ UD is Upper Division which represents all credit hours earned subsequent to the first 59 hours. 
Table A-3

Student Descriptors: 2015 Business Administration Graduates

\begin{tabular}{|c|c|c|c|c|c|c|c|}
\hline \multirow[b]{2}{*}{ Student Type } & \multirow[b]{2}{*}{ Graduates } & \multicolumn{2}{|c|}{$\begin{array}{l}\text { Transferred }^{\mathrm{a}} \\
\text { Credit Hours }\end{array}$} & \multirow{2}{*}{$\begin{array}{c}\text { Awarded } \\
\text { Credit Hours } \\
\text { Average }\end{array}$} & \multicolumn{2}{|c|}{$\begin{array}{c}\text { ISU } \\
\text { Credit Hours }\end{array}$} & \multirow{2}{*}{$\begin{array}{c}\text { Total } \\
\text { Credit Hours } \\
\text { Hours Average }\end{array}$} \\
\hline & & Range & Average & & Range & Average & \\
\hline Native & 37 & $0-10$ & 3.57 & 0.57 & $113-142$ & 124.19 & 128.32 \\
\hline Transfer & 25 & $59-70$ & 66.88 & 0.72 & $48-90$ & 60.36 & 127.96 \\
\hline
\end{tabular}

${ }^{a}$ Transferred Credit: Credit accepted by ISU from another institution. Does not include unaccepted credit.

${ }^{b}$ Awarded Credit: Credit hours awarded by ISU for proficiency (CLEP, department testing, advanced placement, etc.), military coursework, or military experience.

Table A-4

Cost to Deliver Degrees: 2015 Business Administration Graduates

\begin{tabular}{lcccc}
\hline & & \multicolumn{2}{c}{ Transcript Cost } & Catalog Cost \\
Purview and Statistic & Native & Native UD & Transfer & Native \\
\hline Controllable & & & & \\
Range & $\$ 18,651-26,560$ & $\$ 12,272-18,569$ & $\$ 11,190-19,497$ & $\$ 20,889$ \\
Mean & $\$ 21,683$ & $\$ 14,914$ & $\$ 13,736$ & \\
Median & $\$ 21,516$ & $\$ 14,601$ & $\$ 12,914$ & \\
Standard Deviation & $\$ 1,667$ & $\$ 1,688$ & $\$ 2,145$ & \\
Coefficient of Variation & $8 \%$ & $11 \%$ & $16 \%$ & \\
& & & & \\
Manageable & & & & \\
Range & $\$ 22,831-32,544$ & $\$ 14,919-23,045$ & $\$ 13,670-23,851$ & \\
Mean & $\$ 26,558$ & $\$ 18,230$ & $\$ 16,789$ & \\
Median & $\$ 26,336$ & $\$ 17,852$ & $\$ 15,782$ & \\
Standard Deviation & $\$ 2,053$ & $\$ 2,076$ & $16 \%$ & \\
Coefficient of Variation & $8 \%$ & $11 \%$ & & \\
& & & & \\
Fully Allocated & & & $\$ 2,632$ & \\
Range & $\$ 36,856-52,090$ & $\$ 23,630-36,655$ & $\$ 21,619-38,012$ & \\
Mean & $\$ 42,725$ & $\$ 28,963$ & $\$ 26,661$ & \\
Median & $\$ 42,337$ & $\$ 28,573$ & $\$ 2,101$ & \\
Standard Deviation & $\$ 3,236$ & $\$ 3,356$ & $12 \%$ & \\
Coefficient of Variation & $8 \%$ & & & \\
\hline
\end{tabular}

${ }^{a} \mathrm{UD}$ is Upper Division which represents all credit hours earned subsequent to the first 59 hours. 
Table A-5

Student Descriptors: 2015 Criminal Justice Graduates

\begin{tabular}{lccccccc}
\hline & & \multicolumn{2}{c}{ Transferred $^{\mathrm{a}}$} & Awarded $^{\mathrm{b}}$ & \multicolumn{2}{c}{ ISU } & Total \\
& & \multicolumn{2}{c}{$\begin{array}{c}\text { Credit Hours } \\
\text { Student Type }\end{array}$} & Gredit Hours & Credit Hours & Credit Hours \\
Gative & 52 & $0-10$ & 3.10 & 0.62 & $107-144$ & 123.37 & 127.08 \\
Transfer & 33 & $59-90$ & 67.18 & 2.33 & $39-86$ & 56.26 & 125.76 \\
\hline
\end{tabular}

${ }^{a}$ Transferred Credit: Credit accepted by ISU from another institution. Does not include unaccepted credit.

${ }^{b}$ Awarded Credit: Credit hours awarded by ISU for proficiency (CLEP, department testing, advanced placement, etc.), military coursework, or military experience.

Table A-6

Cost to Deliver Degrees: 2015 Criminal Justice Graduates

\begin{tabular}{lcccc}
\hline Purview and Statistic & Native & $\begin{array}{c}\text { Transcript Cost } \\
\text { Native UD }\end{array}$ & Transfer & Catalog Cost \\
\hline Controllable & & & & \\
Range & $\$ 13,391-19,103$ & $\$ 7,314-12,632$ & $\$ 5,536-14,174$ & $\$ 15,412$ \\
Mean & $\$ 15,822$ & $\$ 9,461$ & $\$ 7,910$ & \\
Median & $\$ 15,458$ & $\$ 9,008$ & $\$ 7,645$ & \\
Standard Deviation & $\$ 1,603$ & $\$ 1,459$ & $\$ 1,578$ & \\
Coefficient of Variation & $10 \%$ & $15 \%$ & $20 \%$ & \\
& & & & \\
Manageable & & & & \\
Range & $\$ 16,404-23,419$ & $\$ 8,931-15,477$ & $\$ 6,771-17,358$ & $\$ 18,898$ \\
Mean & $\$ 19,388$ & $\$ 11,560$ & $\$ 9,676$ & \\
Median & $\$ 18,936$ & $\$ 11,000$ & $\$ 9,342$ & \\
Standard Deviation & $\$ 1,969$ & $\$ 1,790$ & $\$ 1,940$ & \\
Coefficient of Variation & $10 \%$ & $15 \%$ & $20 \%$ & \\
& & & & \\
Fully Allocated & & & $\$ 10 \%, 977-28,014$ & $\$ 30,488$ \\
Range & $\$ 27,070-38,159$ & $\$ 14,507-25,214$ & $\$ 15,712$ & \\
Mean & $\$ 31,764$ & $\$ 18,737$ & $\$ 15,116$ & \\
Median & $\$ 31,043$ & $\$ 17,816$ & $20 \%$ & \\
Standard Deviation & $\$ 3,110$ & $\$ 2,901$ & $15 \%$ & \\
Coefficient of Variation & $10 \%$ & & & \\
\hline
\end{tabular}

${ }^{a} \mathrm{UD}$ is Upper Division which represents all credit hours earned subsequent to the first 59 hours. 
Table A-7

Student Descriptors: 2015 Middle Level Education Graduates

\begin{tabular}{|c|c|c|c|c|c|c|c|}
\hline \multirow[b]{2}{*}{ Student Type } & \multirow[b]{2}{*}{ Graduates } & \multicolumn{2}{|c|}{ Transferred $^{\mathrm{a}}$} & \multirow{2}{*}{$\begin{array}{l}\text { Awarded }^{\mathrm{b}} \\
\text { Average }\end{array}$} & \multicolumn{2}{|c|}{ ISU } & \multirow{2}{*}{$\begin{array}{l}\text { Credit Hours } \\
\text { Hours Average }\end{array}$} \\
\hline & & Range & Average & & Range & Average & \\
\hline Native & 29 & $0-10$ & 2.24 & 1.59 & $108-157$ & 129.02 & 132.84 \\
\hline Transfer & 7 & $62-73$ & 67.57 & 0.00 & $63-79$ & 70.00 & 137.57 \\
\hline
\end{tabular}

${ }^{a}$ Transferred Credit: Credit accepted by ISU from another institution. Does not include unaccepted credit. ${ }^{b}$ Awarded Credit: Credit hours awarded by ISU for proficiency (CLEP, department testing, advanced placement, etc.), military coursework, or military experience.

Table A-8

Cost to Deliver Degrees: 2015 Middle Level Education Graduates

\begin{tabular}{|c|c|c|c|c|}
\hline \multirow[b]{2}{*}{ Purview and Statistic } & \multicolumn{3}{|c|}{ Transcript Cost } & \multirow{2}{*}{$\begin{array}{c}\text { Catalog Cost } \\
\text { Native }\end{array}$} \\
\hline & Native & Native UD ${ }^{\mathrm{a}}$ & Transfer & \\
\hline \multicolumn{5}{|l|}{ Controllable } \\
\hline Range & 19,046 - 28,949 & $11,467-21,921$ & $14,596-18,174$ & $\$ 22,070$ \\
\hline Mean & $\$ 23,635$ & $\$ 16,603$ & $\$ 16,490$ & \\
\hline Median & $\$ 23,093$ & $\$ 15,955$ & $\$ 16,288$ & \\
\hline Standard Deviation & $\$ 2,618$ & $\$ 2,751$ & $\$ 1,266$ & \\
\hline Coefficient of Variation & $11 \%$ & $17 \%$ & $8 \%$ & \\
\hline \multicolumn{5}{|l|}{ Manageable } \\
\hline Range & $23,329-35,458$ & $14,005-26,810$ & $17,843-22,216$ & $\$ 27,023$ \\
\hline Mean & $\$ 28,949$ & $\$ 20,296$ & $\$ 20,156$ & \\
\hline Median & $\$ 28,266$ & $\$ 19,488$ & $\$ 19,895$ & \\
\hline Standard Deviation & $\$ 3,222$ & $\$ 3,381$ & $\$ 1,552$ & \\
\hline Coefficient of Variation & $11 \%$ & $17 \%$ & $8 \%$ & \\
\hline \multicolumn{5}{|l|}{ Fully Allocated } \\
\hline Range & $37,626-56,834$ & 22,194 - 42,694 & 28,389 - 35,326 & $\$ 43,423$ \\
\hline Mean & $\$ 46,467$ & $\$ 32,192$ & $\$ 31,985$ & \\
\hline Median & $\$ 45,295$ & $\$ 30,839$ & $\$ 31,357$ & \\
\hline Standard Deviation & $\$ 5,086$ & $\$ 5,449$ & $\$ 2,478$ & \\
\hline Coefficient of Variation & $11 \%$ & $17 \%$ & $8 \%$ & \\
\hline
\end{tabular}

${ }^{a} \mathrm{UD}$ is Upper Division which represents all credit hours earned subsequent to the first 59 hours. 
Table A-9

Student Descriptors: 2015 Nursing Graduates

\begin{tabular}{|c|c|c|c|c|c|c|c|}
\hline \multirow[b]{2}{*}{ Student Type } & \multirow[b]{2}{*}{ Graduates } & \multicolumn{2}{|c|}{ Transferred $^{\mathrm{a}}$} & \multirow{2}{*}{$\begin{array}{l}\text { Awarded }^{\mathrm{b}} \\
\text { Average }\end{array}$} & \multicolumn{2}{|c|}{ ISU } & \multirow{2}{*}{$\begin{array}{l}\text { Credit Hours } \\
\text { Hours Average }\end{array}$} \\
\hline & & Range & Average & & Range & Average & \\
\hline Native & 89 & $0-10$ & 4.33 & 1.03 & $109-175$ & 125.62 & 130.98 \\
\hline Transfer & 16 & $62-84$ & 68.50 & 0.38 & $62-90$ & 68.44 & 137.31 \\
\hline
\end{tabular}

${ }^{a}$ Transferred Credit: Credit accepted by ISU from another institution. Does not include unaccepted credit.

${ }^{b}$ Awarded Credit: Credit hours awarded by ISU for proficiency (CLEP, department testing, advanced placement, etc.), military coursework, or military experience.

Table A-10

Cost to Deliver Degrees: 2015 Nursing Graduates

\begin{tabular}{|c|c|c|c|c|}
\hline \multirow[b]{2}{*}{ Purview and Statistic } & \multicolumn{3}{|c|}{ Transcript Cost } & \multirow{2}{*}{$\begin{array}{c}\text { Catalog Cost } \\
\text { Native }\end{array}$} \\
\hline & Native & Native UD ${ }^{\mathrm{a}}$ & Transfer & \\
\hline \multicolumn{5}{|l|}{ Controllable } \\
\hline Range & $\$ 24,142$ - 37,348 & $\$ 15,336$ - 30,828 & $\$ 19,520-23,544$ & $\$ 26,062$ \\
\hline Mean & $\$ 26,496$ & $\$ 19,957$ & $\$ 20,626$ & \\
\hline Median & $\$ 25,808$ & $\$ 19,328$ & $\$ 19,758$ & \\
\hline Standard Deviation & $\$ 2,409$ & $\$ 2,594$ & $\$ 1,488$ & \\
\hline Coefficient of Variation & $9 \%$ & $13 \%$ & $7 \%$ & \\
\hline \multicolumn{5}{|l|}{ Manageable } \\
\hline Range & $\$ 29,546-45,802$ & $\$ 18,716$ - 37,766 & $\$ 23,856-28,781$ & $\$ 32,009$ \\
\hline Mean & $\$ 32,425$ & $\$ 24,380$ & $\$ 25,213$ & \\
\hline Median & $\$ 31,575$ & $\$ 23,597$ & $\$ 24,146$ & \\
\hline Standard Deviation & $\$ 2,967$ & $\$ 3,189$ & $\$ 1,826$ & \\
\hline Coefficient of Variation & $9 \%$ & $13 \%$ & $7 \%$ & \\
\hline \multicolumn{5}{|l|}{ Fully Allocated } \\
\hline Range & $\$ 47,092$ - 72,922 & $\$ 29,318$ - 59,922 & $\$ 37,501-45,476$ & $\$ 51,050$ \\
\hline Mean & $\$ 51,664$ & $\$ 38,301$ & $\$ 39,693$ & \\
\hline Median & $\$ 50,286$ & $\$ 36,987$ & $\$ 37,967$ & \\
\hline Standard Deviation & $\$ 4,718$ & $\$ 5,153$ & $\$ 2,948$ & \\
\hline Coefficient of Variation & $9 \%$ & $13 \%$ & $7 \%$ & \\
\hline
\end{tabular}

${ }^{a} \mathrm{UD}$ is Upper Division which represents all credit hours earned subsequent to the first 59 hours. 
Table A-11

Student Descriptors: 2015 Psychology Graduates

\begin{tabular}{|c|c|c|c|c|c|c|c|}
\hline \multirow[b]{2}{*}{ Student Type } & \multirow[b]{2}{*}{ Graduates } & \multicolumn{2}{|c|}{ Transferred $^{\mathrm{a}}$} & \multirow{2}{*}{$\begin{array}{l}\text { Awarded }^{\mathrm{b}} \\
\text { Average }\end{array}$} & \multicolumn{2}{|c|}{ ISU } & \multirow{2}{*}{$\begin{array}{c}\text { Credit Hours } \\
\text { Hours Average }\end{array}$} \\
\hline & & Range & Average & & Range & Average & \\
\hline Native & 77 & $0-10$ & 2.95 & 2.19 & $109-188$ & 124.79 & 129.93 \\
\hline Transfer & 21 & $60-71.5$ & 65.98 & 0.14 & $50-73$ & 58.76 & 124.88 \\
\hline
\end{tabular}

${ }^{a}$ Transferred Credit: Credit accepted by ISU from another institution. Does not include unaccepted credit. ${ }^{b}$ Awarded Credit: Credit hours awarded by ISU for proficiency (CLEP, department testing, advanced placement, etc.), military coursework, or military experience.

Table A-12

Cost to Deliver Degrees: 2015 Psychology Graduates

\begin{tabular}{|c|c|c|c|c|}
\hline Purview and Statistic & Native & $\begin{array}{l}\text { Transcript Cost } \\
\text { Native UD }\end{array}$ & Transfer & $\begin{array}{c}\text { Catalog Cost } \\
\text { Native }\end{array}$ \\
\hline \multicolumn{5}{|l|}{ Controllable } \\
\hline Range & $\$ 13,667-27,813$ & $\$ 7,978-21,216$ & $\$ 7,392-11,029$ & $\$ 18,043$ \\
\hline Mean & $\$ 17,265$ & $\$ 10,911$ & $\$ 9,201$ & \\
\hline Median & $\$ 16,926$ & $\$ 10,618$ & $\$ 9,284$ & \\
\hline Standard Deviation & $\$ 2,048$ & $\$ 1,932$ & $\$ 959$ & \\
\hline Coefficient of Variation & $12 \%$ & $18 \%$ & $10 \%$ & \\
\hline \multicolumn{5}{|l|}{ Manageable } \\
\hline Range & $\$ 16,753-34,083$ & $\$ 9,753-25,962$ & $\$ 9,023-13,483$ & $\$ 22,097$ \\
\hline Mean & $\$ 21,153$ & $\$ 13,336$ & $\$ 11,242$ & \\
\hline Median & $\$ 20,735$ & $\$ 12,968$ & $\$ 11,337$ & \\
\hline Standard Deviation & $\$ 2,514$ & $\$ 2,369$ & $\$ 1,178$ & \\
\hline Coefficient of Variation & $12 \%$ & $18 \%$ & $10 \%$ & \\
\hline \multicolumn{5}{|l|}{ Fully Allocated } \\
\hline Range & $\$ 27,638-55,292$ & $\$ 15,844-41,971$ & $\$ 14,580-21,666$ & $\$ 34,301$ \\
\hline Mean & $\$ 34,481$ & $\$ 21,478$ & $\$ 18,135$ & \\
\hline Median & $\$ 33,723$ & $\$ 20,891$ & $\$ 18,179$ & \\
\hline Standard Deviation & $\$ 3,986$ & $\$ 3,821$ & $\$ 1,917$ & \\
\hline Coefficient of Variation & $12 \%$ & $18 \%$ & $11 \%$ & \\
\hline
\end{tabular}

${ }^{a} \mathrm{UD}$ is Upper Division which represents all credit hours earned subsequent to the first 59 hours. 


\section{APPENDIX B: IBHE COST CATEGORIES AND DESCRIPTIONS}

\section{Costs per Credit Hour by Academic Discipline Unit Cost Study (ADUCS) Cost Categories}

Table B-1

2015 ADUCS Costs per Credit Hour by Category for the First Three of Six Selected Degrees

\begin{tabular}{|c|c|c|c|c|c|c|}
\hline \multirow[b]{3}{*}{ Categories of Cost ${ }^{a}$} & \multicolumn{6}{|c|}{ Business } \\
\hline & \multicolumn{2}{|c|}{ Art } & \multicolumn{2}{|c|}{ Administration } & \multicolumn{2}{|c|}{ Criminal Justice } \\
\hline & $\begin{array}{l}\text { Lower }^{\mathrm{b}} \\
\text { Division }\end{array}$ & $\begin{array}{l}\text { Upper }^{\mathrm{c}} \\
\text { Division }\end{array}$ & $\begin{array}{l}\text { Lower } \\
\text { Division }\end{array}$ & $\begin{array}{c}\text { Upper } \\
\text { Division }\end{array}$ & $\begin{array}{l}\text { Lower } \\
\text { Division }\end{array}$ & $\begin{array}{l}\text { Upper } \\
\text { Division }\end{array}$ \\
\hline Direct Salary Costs & $\$ 114.70$ & $\$ 182.16$ & $\$ 38.13$ & $\$ 62.19$ & 43.95 & $\$ 63.30$ \\
\hline Indirect Salary Costs & 39.51 & 31.18 & 0.69 & 1.17 & 0 & 12.53 \\
\hline College or School Overheads & 34.18 & 48.43 & 14.58 & 19.46 & $\underline{6.5}$ & 9.78 \\
\hline $\begin{array}{l}\text { Subtotal, Departmental and College Costs } \\
\text { (Controllable Cost Purview) }\end{array}$ & $\$ 288.91$ & $\$ 374.58$ & $\$ 106.99$ & $\$ 141.65$ & 85.23 & $\$ 130.67$ \\
\hline Overhead Support Unique to Function & 18.29 & 23.72 & 6.77 & 8.97 & 5.4 & 8.27 \\
\hline Academic Support & 46.55 & 60.35 & 17.24 & 22.82 & $\underline{13.73}$ & 21.05 \\
\hline Subtotal (Manageable Cost Purview) & $\$ 353.75$ & $\$ 458.65$ & $\$ 131.00$ & $\$ 173.44$ & 104.36 & $\$ 159.99$ \\
\hline Student Services & 10.84 & 10.84 & 10.84 & 10.84 & 10.84 & 10.84 \\
\hline Institutional Support & 101.84 & 131.14 & 39.62 & 51.48 & $\underline{32.18}$ & 47.72 \\
\hline Subtotal with University Overheads & $\overline{\$ 466.44}$ & $\overline{\$ 600.64}$ & $\overline{\$ 181.47}$ & $\overline{\$ 235.77}$ & $\overline{147.38}$ & $\overline{\$ 218.56}$ \\
\hline O\&M Physical Plant & 90.68 & 116.77 & 35.28 & 45.84 & $\underline{28.65}$ & 42.49 \\
\hline Total - All Costs (Fully Allocated Cost Purview) & $\$ 557.13$ & $\$ 717.41$ & $\$ 216.75$ & $\$ 281.60$ & 176.04 & $\$ 261.06$ \\
\hline
\end{tabular}

${ }^{a}$ Categories of cost (and subtotals) are specified by the Illinois Board of Higher Education. Cost purviews (controllable, manageable, fully allocated) are determined by the researcher to represent increasing levels of administrative control over the expenditures.

${ }^{\mathrm{b}}$ Lower division represents the cost to deliver credit hours to students who have completed less than 60 total credit hours.

${ }^{\mathrm{C}}$ Upper division represents the cost to deliver credit hours to student who have completed more than 59 total credit hours. 
Table B-2

2015 ADUCS Costs per Credit Hour by Category for the Last Three of Six Selected Degrees

\begin{tabular}{|c|c|c|c|c|c|c|}
\hline \multirow[b]{2}{*}{ Categories of Cost ${ }^{a}$} & \multicolumn{2}{|c|}{ Middle Level } & \multicolumn{2}{|c|}{ Nursing } & \multicolumn{2}{|c|}{ Psychology } \\
\hline & $\begin{array}{l}\text { Lower } \\
\text { Division }\end{array}$ & $\begin{array}{l}\text { Upper } \\
\text { Division }\end{array}$ & $\begin{array}{l}\text { Lower } \\
\text { Division }\end{array}$ & $\begin{array}{l}\text { Upper } \\
\text { Division }\end{array}$ & $\begin{array}{l}\text { Lower } \\
\text { Division }\end{array}$ & $\begin{array}{l}\text { Upper } \\
\text { Division }\end{array}$ \\
\hline Direct Salary Costs & $\$ 103.60$ & $\$ 106.19$ & $\$ 168.72$ & $\$ 159.60$ & $\$ 43.12$ & $\$ 87.57$ \\
\hline Indirect Salary Costs & 1.73 & 11.01 & 2.34 & 33.40 & 3.87 & 3.80 \\
\hline College or School Overheads & 42.72 & 75.08 & 15.39 & 18.15 & 3.51 & 5.68 \\
\hline $\begin{array}{l}\text { Subtotal, Departmental and College Costs } \\
\text { (Controllable Cost Purview) }\end{array}$ & $\$ 257.23$ & $\$ 305.58$ & $\$ 274.85$ & $\$ 306.69$ & $\$ 99.22$ & $\$ 159.21$ \\
\hline Overhead Support Unique to Function & 16.29 & 19.35 & 17.40 & 19.42 & 6.28 & 10.08 \\
\hline Academic Support & 41.45 & 49.24 & 44.29 & 49.42 & 15.99 & 25.65 \\
\hline Subtotal (Manageable Cost Purview) & $\$ 314.97$ & $\$ 374.17$ & $\$ 336.54$ & $\$ 375.53$ & $\$ 121.49$ & $\$ 194.94$ \\
\hline Student Services & 10.84 & 10.84 & 10.84 & 10.84 & 10.84 & 10.84 \\
\hline Institutional Support & 91.01 & 107.55 & 97.04 & 107.92 & 36.96 & 57.48 \\
\hline Subtotal with University Overheads & $\overline{\$ 416.81}$ & $\overline{\$ 492.55}$ & $\overline{\$ 444.42}$ & $\overline{\$ 494.29}$ & $\overline{\$ 169.30}$ & $\overline{\$ 263.27}$ \\
\hline O\&M Physical Plant & 81.03 & 95.76 & 86.40 & 96.10 & 32.91 & 51.18 \\
\hline Total - All Costs (Fully Allocated Cost Purview) & $\$ 497.84$ & $\$ 588.31$ & $\$ 530.82$ & $\$ 590.39$ & $\$ 202.21$ & $\$ 314.45$ \\
\hline
\end{tabular}

${ }^{a}$ Categories of cost (and subtotals) are specified by the Illinois Board of Higher Education. Cost purviews (controllable, manageable, fully allocated) are determined by the researcher to represent increasing levels of administrative control over the expenditures.

${ }^{\mathrm{b}}$ Lower division represents the cost to deliver credit hours to students who have completed less than 60 total credit hours.

'Upper division represents the cost to deliver credit hours to student who have completed more than 59 total credit hours.

\section{Definitions of Expense Categories provided by IBHE}

Direct Salaries This category reflects the faculty assignments to the primary functions of instruction, organized research, and public service. Direct salaries for instruction include faculty assignments related to the direct instruction of students. This includes teaching students in courses, supervision of student teaching and applied studies, thesis supervision, independent study, tutorials, and preparation of class presentations. Direct salaries for organized research and public service reflect the assignment of faculty to these activities in the Faculty Activity Analysis.

Indirect Instruction This category includes those assigned activities, which encompass all duties related to instruction of students other than direct instruction. It includes supervision of teaching other than student teaching, academic advising, coordinating instruction of different sections of the same course, and duties related to instruction for which direct instruction is the responsibility of another person. 
Departmental Research This activity category includes research duties specifically assigned to a faculty member by the head of an academic department. Department heads often may choose to assign a portion of a faculty member's effort to do scholarly research in lieu of teaching. Such assigned effort, which need not be approved by a university research committee, may contribute to the professional development of a faculty member and may lead to a publication of results and findings. With the exception of a release-time instructional contribution required by the terms of an externally funded research grant, all research effort assigned at the departmental level should be included as Departmental Research.

Department Overheads This activity category includes those administrative activities, which are carried out in support of the efficient operation of the department. It includes the portion of faculty members' departmental activity, which cannot be directly assigned to direct instruction, indirect instruction, departmental research, organized research, or public service. The reported figures indicate the amount of department overhead that has been allocated to the instructional function. Department overhead may also be allocated to organized research and public service.

College or School Overheads This category includes the cost of academic administration identified with a school or college and is prorated to appropriate departments by departmental costs. Due to various organizational structures among the public universities, the costs in this category are not comparable.

Total Department and College Costs This category includes the total costs associated with direct instruction, indirect instruction, departmental research, departmental overheads, and college or school overheads.

Overhead Support Unique to a Function This category includes support costs attributable to a single function and prorated among disciplines according to their expenditures for each function. For instance, a discipline with no organized research activities would not be assigned any organized research overhead.

All Other Academic Support This category includes the usual academic support areas (excluding academic administration): Libraries, Hospitals and Patient Services, Museums and Galleries, Academic Support Not Elsewhere Classified.

Student Services This category includes the following areas: Social and Cultural Development, Counseling and Career Services, Student Health/Medical Services, Intercollegiate Athletics, Financial Assistance, Financial Aid Administration, Student Service Administration

Institutional Support This category includes the following areas: System Office Support, Executive Management, Financial Management and Operations, General Administration and Logistical Services, Faculty and Staff Auxiliary Services, Public Relations/Development.

Operation and Maintenance of Physical Plant This category includes the following Areas: Superintendence, Custodial Services, Building Maintenance, Grounds Maintenance, Utilities, Repair and Maintenance, Security, Fire Protection, Transportation, Rental of Space, Other O \& M Activities. 